OPEN ACCESS

Edited by:

Eric Cascales,

Aix-Marseille Université, France

Reviewed by:

Dhrubajyoti Nag,

Wayne State University, United States

Carlos J. Blondel,

Andres Bello University, Chile

*Correspondence:

Dirk Linke

dirk.linke@ibv.uio.no

Specialty section:

This article was submitted to

Microbial Physiology and Metabolism,

a section of the journal

Frontiers in Microbiology

Received: 24 September 2021

Accepted: 24 November 2021

Published: 15 December 2021

Citation:

Mekasha S and Linke D (2021) Secretion Systems in Gram-Negative

Bacterial Fish Pathogens.

Front. Microbiol. 12:782673.

doi: 10.3389/fmicb.2021.782673

\section{Secretion Systems in Gram-Negative Bacterial Fish Pathogens}

\author{
Sophanit Mekasha and Dirk Linke* \\ Section for Genetics and Evolutionary Biology, Department of Biosciences, University of Oslo, Oslo, Norway
}

Bacterial fish pathogens are one of the key challenges in the aquaculture industry, one of the fast-growing industries worldwide. These pathogens rely on arsenal of virulence factors such as toxins, adhesins, effectors and enzymes to promote colonization and infection. Translocation of virulence factors across the membrane to either the extracellular environment or directly into the host cells is performed by single or multiple dedicated secretion systems. These secretion systems are often key to the infection process. They can range from simple single-protein systems to complex injection needles made from dozens of subunits. Here, we review the different types of secretion systems in Gram-negative bacterial fish pathogens and describe their putative roles in pathogenicity. We find that the available information is fragmented and often descriptive, and hope that our overview will help researchers to more systematically learn from the similarities and differences between the virulence factors and secretion systems of the fish-pathogenic species described here.

Keywords: fish pathogen, Gram-negative, fish disease, secretion system, virulence factor, aquaculture

\section{INTRODUCTION}

Production of cultured fish is one of the fastest-growing sectors of the aquaculture industries. The annual report from the Food and Agriculture Organization of the United Nations indicate that the production reached 179 million tons in 2018 (FAO, 2020). Sustainable production of farmed fish and their commercialization are primarily challenged by the expansion of infectious diseases caused by pathogenic microbes. Bacterial fish pathogens can cause systemic infection where they infect different organs of the fish, or they cause external infections by ulcerating the skin, gills, fin rots and mouth (Bernoth et al., 1997; Mohanty and Sahoo, 2007; Austin and Austin, 2016; Gourzioti et al., 2016; Ina-Salwany et al., 2019). In both cases, the fish cannot be marketed even in cases where the disease is not lethal. Thus, the high global spread of fish diseases causes great economic loss to the aquaculture industry and development of systematic prevention mechanisms is key to its sustainability.

Fish pathogens can infect both edible and ornamental fish species. Some ornamental fish such as zebrafish are used as host model organisms to understand the virulence mechanisms of pathogens in fish in general (Rowe et al., 2014; Nag et al., 2020). This review mainly covers virulence mechanisms of Gram-negative pathogens that target common edible fish. We have also made an attempt to differentiate the virulence factors that are proven to be involved in fish disease from the ones where the evidence is indirect, e.g., inferred from other host examples, and that thus need further investigation.

The composition of the fish microbiota and the presence of pathogens has been evaluated by culture-dependent and/or advanced "omics" techniques for several years. The most prominent 
Gram-negative bacterial fish pathogens are distributed across the phyla Proteobacteria and Bacteroidetes (Figure 1), and a high number of identified and widely studied pathogens belong to the phylum Proteobacteria. The range of diseases found in fish reflect the diversity of virulence factors and virulence mechanisms utilized by these microbes. In general, bacterial infection is successful when the pathogen can successfully adhere to the host tissue, multiply and invade.

Information obtained from genome sequenced-bacterial strains shows that pathogenic and non-pathogenic fish-associated microbes can be very closely related [Figure 1, (Sudheesh et al., 2012)]. Thus, pathogens often acquire unique strategical adaptations specific for their infectious lifestyle that distinguishes them from their close, non-infectious relatives. Such adaptation is often associated with horizontal transfer of gene clusters of virulence genes located on either the chromosome (Naka et al., 2013; Amaro et al., 2015) or the more "flexible" gene pool of plasmids (Naka et al., 2011; Rivas et al., 2011; Amaro et al., 2015). Such blocks of virulence-associated DNA are known as "pathogenicity islands" (PAIs) that promote the pathogenicity of the strains (Hacker and Kaper, 1999; Hacker and Carniel, 2001; Osorio et al., 2015). Loss of potent virulence factors such as secretion systems either reduce or halt bacterial pathogenicity (Stanley et al., 2003; Dacanay et al., 2006; Fadl et al., 2006; Jyot et al., 2011).

Bacterial pathogens rely on the synergistic action of different virulence determinants and on specialized secretion systems to cause disease in susceptible hosts (Finlay and Falkow, 1997; Thanassi and Hultgren, 2000). Initiation of infection is often triggered by adherence of the pathogen to the skin or mucosal surface of the host tissue using attachment mechanisms such as non-fimbrial adhesins (Ostland et al., 1997; Weber et al., 2010; Guardiola et al., 2019), pili or fimbriae (Ho et al., 1990; Mattick, 2002; Gerlach and Hensel, 2007; Craig et al., 2019) which recognize specific receptors. A successful uptake of the pathogen into host cells is then mediated by specific invasion factors (e.g., invasins) which are either membrane anchored proteins of the pathogen or are secreted through specialized secretion systems. Invasins promote translocation of pathogens in host cell [(Meuskens et al., 2019), Yersinia spp.]. Once inside the host, the survival rate of pathogens is modulated by numerous structural and metabolic virulence factors such as capsules and iron acquisition systems, respectively (Lindler et al., 1998; Winkelmann et al., 2002; Hsieh et al., 2003; Møller et al., 2005; Guan et al., 2013; Balado et al., 2018). Encapsulated pathogens are resistant to phagocytosis due to the protective carbohydrate layer that blocks host immune response components from binding to immunogenic membrane proteins of the bacteria (Cress et al., 2014). In many infections, bacterial growth and metabolism is solely limited by the availability of free iron, which is typically completely sequestered in the host organisms. The competition for this limited resource forces pathogens to acquire and use high-affinity siderophore or hemedependent iron acquisition systems to scavenge iron sequestered in host iron-binding proteins, such as transferrins or hemoglobin. Last but not least, the visible symptoms of disease such as inflammation, bleeding, or lethal shock is typically induced by different toxins. An important toxin is a structural component of Gram-negative pathogens, the lipopolysaccharides, that are a key component of the cell membrane and that exert intense biological effects on the host which may be lethal (Sampath, 2018). In addition to these so-called endotoxins, extracellular toxic proteins known as exotoxins, are produced and secreted by pathogens via specific secretion machinery. Unlike the extensive systemic damage of endotoxins that is mainly based on an adverse immune reaction, exotoxins typically target local tissues and are often restricted to particular cell types or receptors (Cavaillon, 2018). For other virulence factors, their identification and in-depth characterization is fundamental to the development of specific diagnostics and treatment tools. For instance, molecular, structural and biochemical characterizations of genes and proteins involved in secretion systems are useful for discovery of novel treatments for combating pathogenicity in bacteria (Costa et al., 2015; Alteri and Mobley, 2016).

In the case of fish pathogens, the knowledge on virulence factors and disease mechanisms is lagging behind, compared to the often very detailed information available for human pathogens. In this review, we summarize the current knowledge on one class of virulence determinants of fish pathogens, the secretion systems, and on the virulence factors that they secrete. In the course of collecting this information, we noticed that information on the Gram-positive fish pathogens shockingly sparse in this regard. This is why this review focuses on Gramnegative species, that cause most of the more notorious and economically relevant bacterial fish diseases. We hope that this review will be useful for researchers in the field of fish diseases, by providing an overview, and help in the quest to develop vaccines and treatments against fish pathogens that challenge the aquaculture industry worldwide.

\section{Bacterial Secretion Systems}

Secretion systems are utilized by bacteria in processes such as growth, motility, pathogenic or symbiotic interactions with their hosts, and formation of microbial communities (Johnson et al., 2014; Costa et al., 2015; Gallique et al., 2017). In pathogenic species, many virulence factors are translocated across the membrane by dedicated secretion systems that are diverse in size, composition and architecture (Costa et al., 2015; Green and Mecsas, 2016).

Gram-negative bacteria possess two phospholipid membranes separated by a periplasmic space accommodating a thin layer of peptidoglycan chain. This creates additional challenges for protein secretion compared to the Gram-positive bacteria that contain only one lipid bilayer encircled by a peptidoglycan layer that forms a thick cell wall (Silhavy et al., 2010). In both Gram-positive and Gram-negative bacteria, two main secretion pathways employed for the secretion of proteins across the cytoplasmic membrane. These are the general secretory (Sec) pathway (Tsirigotaki et al., 2017) and the twinarginine translocation (Tat) pathway (Palmer and Berks, 2012), where the first translocates unfolded proteins and the latter transports folded proteins. Thus, the two pathways translocate proteins into the periplasm in Gram-negative bacteria and are responsible for extracellular secretion of proteins across the 


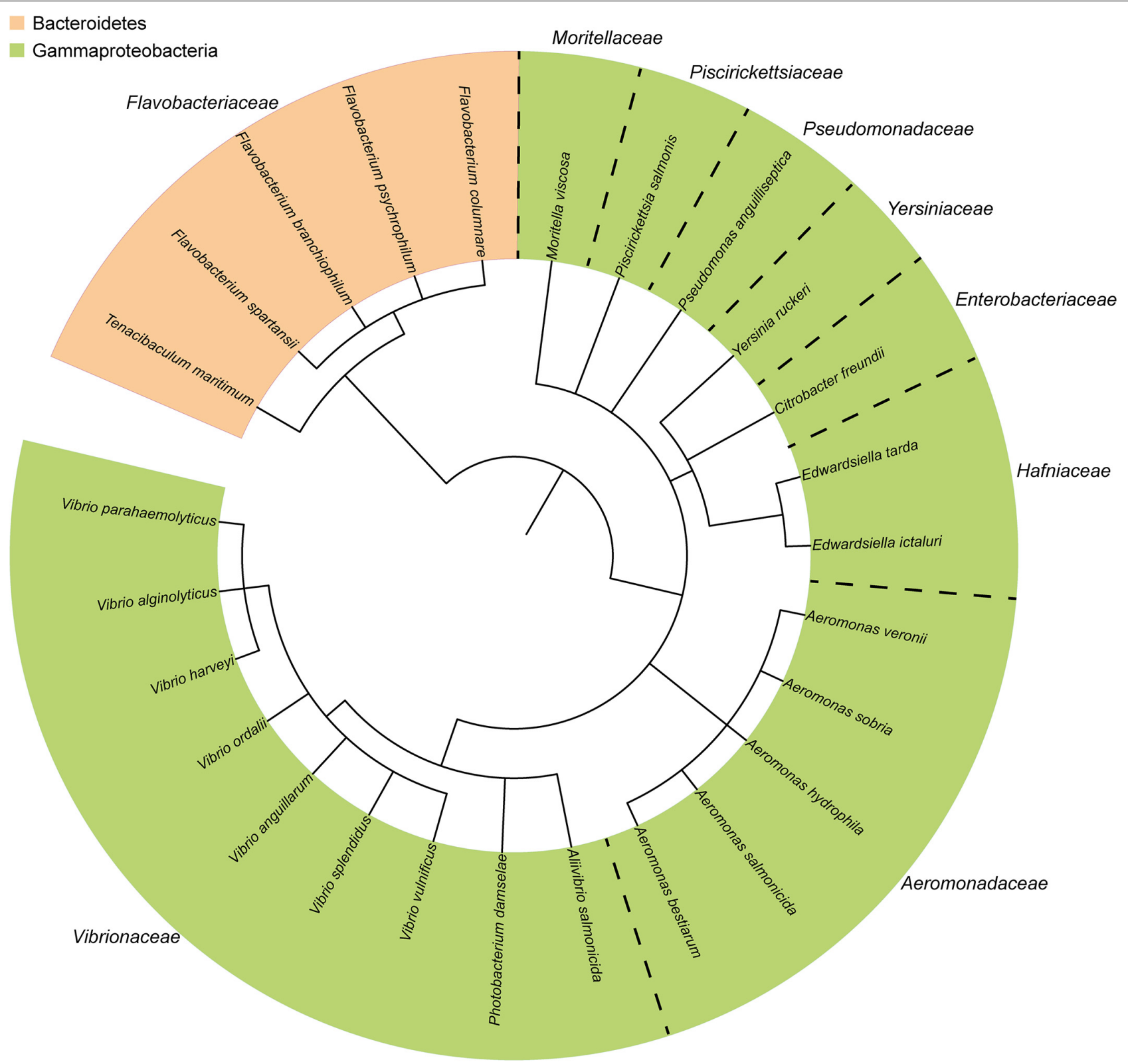

FIGURE 1 | Taxonomic distribution of the most common Gram-negative bacterial fish pathogens. The phylogenetic tree was generated using the phyloT online tool (http://phylot.biobyte.de/), based on annotations from ITOL (http://itol.embl.de/) (Letunic and Bork, 2006).

single plasma membrane in Gram-positive bacteria (Palmer and Berks, 2012; Tsirigotaki et al., 2017). Outside of these two basic secretion pathways, both Gram-positive bacteria and Gramnegative bacteria possess diverse more specialized secretion systems (Green and Mecsas, 2016). It is worth noting that some species classified traditionally as Gram-positive bacteria such as Mycobacteria possess a complex additional membrane layer called the mycomembrane (Dulberger et al., 2020). These bacteria possess a specialized secretion system called type VII secretion system (T7SS) that translocates proteins across this complex cell envelope (Rivera-Calzada et al., 2021). The secretion systems of Gram-positive bacteria is out of the scope of the current review. Below, we list individual examples of Gram-negative fishpathogenic species and their secretion systems and virulence factors, ordered by taxonomy (Table 1).

\section{Gram-Negative Bacteria}

So far, eight types of Gram-negative bacteria secretion systems (designated as Type I-VI, Type VIII and Type IX or T1SST6SS, T8SS and T9SS) have been reported that are classified based on their composition, architecture, function and specificity. There is a multitude of reviews describing the functional and structural features of secretion systems (Gerlach and Hensel, 2007; Costa et al., 2015; Lasica et al., 2017; Burdette et al., 2018; 
TABLE 1 | List of common Gram-negative fish pathogens, including taxonomy information, disease type, virulence factors and virulence-related secretion systems obtained from experimental and/or genomic data.

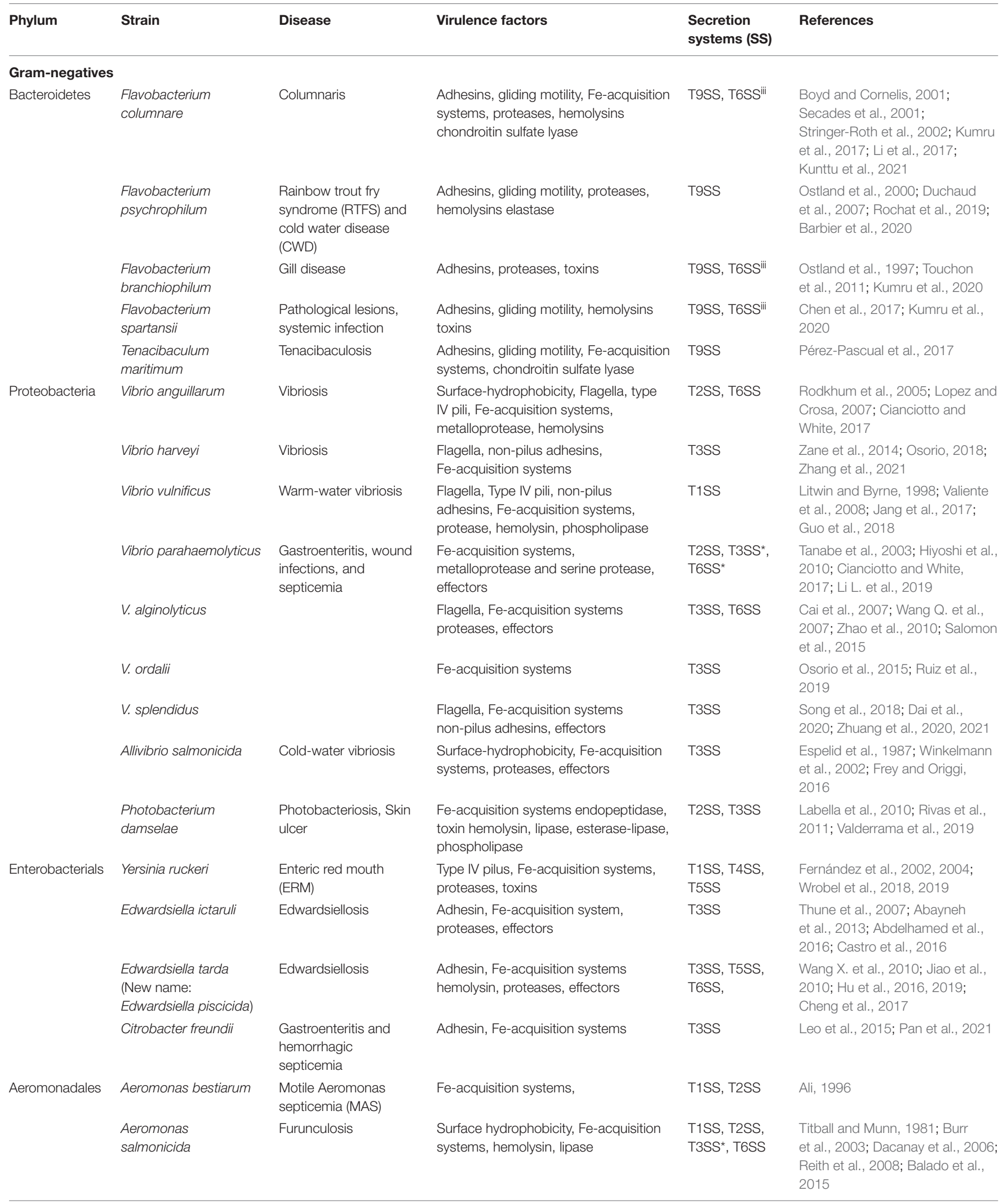


TABLE 1 | (Continued)

\begin{tabular}{|c|c|c|c|c|c|}
\hline Phylum & Strain & Disease & Virulence factors & $\begin{array}{l}\text { Secretion } \\
\text { systems (SS) }\end{array}$ & References \\
\hline & Aeromonas hydrophila & $\begin{array}{l}\text { Motile Aeromonas } \\
\text { septicemia (MAS) }\end{array}$ & $\begin{array}{l}\text { Surface hydrophobicity, adhesin, } \\
\text { Fe-acquisition systems, hemolysins, } \\
\text { proteases }\end{array}$ & $\begin{array}{l}\text { T1SS, T2SS* } \\
\text { T3SS, T6SS }\end{array}$ & $\begin{array}{l}\text { Barghouthi et al., 1989b; Chopra } \\
\text { et al., 1993; Fadl et al., 2006; } \\
\text { Barger et al., } 2020\end{array}$ \\
\hline & Aeromonas veronii & $\begin{array}{l}\text { Motile Aeromonas } \\
\text { septicemia (MAS) }\end{array}$ & Adhesin, Fe-acquisition systems & T3SS & $\begin{array}{l}\text { Namba et al., 2008; Silver and } \\
\text { Graf, 2009; Li et al., 2011; } \\
\text { Tekedar et al., 2019b }\end{array}$ \\
\hline & Aeromonas sobria & $\begin{array}{l}\text { Motile Aeromonas } \\
\text { septicemia (MAS) }\end{array}$ & Pili, hemolysin & T1SS, T2SS & Chakraborty et al., 1990 \\
\hline Thiotrichales & Piscirickettsia salmonis & Piscirickettsiosis & $\begin{array}{l}\text { Adhesin, Fe-acquisition systems, } \\
\text { chaperonin, toxins }\end{array}$ & $\begin{array}{l}\text { T3SS, T4SS, } \\
\text { T6SS }\end{array}$ & $\begin{array}{l}\text { Rojas et al., 2013; Rozas and } \\
\text { Enríquez, 2014; Ortiz-Severín } \\
\text { et al., } 2019\end{array}$ \\
\hline Alteromonadales & Moritella viscosa & Winter ulcer & $\begin{array}{l}\text { Flagella, Type IV pili, hemolysin, } \\
\text { peptidase }\end{array}$ & $\begin{array}{l}\text { T1SS, T2SS, } \\
\text { T6SS }\end{array}$ & $\begin{array}{l}\text { Løvoll et al., 2009; Björnsdóttir, } \\
\text { 2011; Bjornsdottir et al., } 2012\end{array}$ \\
\hline Pseudomonadales & $\begin{array}{l}\text { Pseudomonas } \\
\text { anguilliseptica }\end{array}$ & $\begin{array}{l}\text { "Red spot disease" also } \\
\text { known as "sekiten-byo" }\end{array}$ & Flagella, capsular antigen & NA & $\begin{array}{l}\text { Lönnström et al., 1994; Berthe } \\
\text { et al., 1995; López-Romalde } \\
\text { et al., 2003a }\end{array}$ \\
\hline
\end{tabular}

* Secretion systems where the direct involvement in fish disease still has to be established, as most data was generated with non-fish models. NA, data not available.

Meuskens et al., 2019; Gorasia et al., 2020), allowing us to skip over the detailed description of each system, and to focus only on features that are relevant to fish pathogens. Extending the list of secretion systems, a recent report proposed the existence of a type X secretion system (T10SS) (Palmer et al., 2021). In short, these specialized secretion systems in Gram-negative bacteria can generally be classified into two categories. The first category includes those spanning both the inner and outer membranes such as the T1SS (Holland et al., 2005; Kanonenberg et al., 2018), T2SS (Nivaskumar and Francetic, 2014), T3SS (Deng et al., 2017), T4SS (Christie et al., 2014), T6SS (Russell et al., 2014a) and T9SS (Lasica et al., 2017; Veith et al., 2017; Gorasia et al., 2020). The second category includes the T5SSs (Meuskens et al., 2019) and T8SS (also known as the curli biogenesis system) (Bhoite et al., 2019; Yan et al., 2020) which span only the outer membrane $(\mathrm{OM})$. This second category, and also the T2SS and T9SS rely on the Sec and Tat pathways to translocate their substrates into the periplasm, while the others are independent and secrete proteins directly from the cytosol into the medium or even into host cells in a single step.

\section{BACTEROIDETES}

The phylum Bacteroidetes, also known as Cytophaga-FlexibacterBacterioides (CFB), contains diverse anaerobe Gram-negative rods belonging to the Flavobacteriaceae family. Bacteroidetes inhabit diverse ecological niches including soil, sediments, oceans and freshwater and are the most predominant members of the animal gut microbiota. They are dominantly commensal and seldomly pathogenic to their host (Thomas et al., 2011; Fierer et al., 2012; An et al., 2013; Sunagawa, 2015; Hahnke et al., 2016).

\section{Flavobacteriaceae}

The family Flavobacteriaceae is the largest family in the phylum Bacteroidetes, which contains more than ninety genera.
This family includes important fish pathogens that belong to the genera Flavobacterium and Tenacibaculum (McBride, 2014). These pathogens cause severe diseases that impose significant economic losses in the aquaculture industry, and they are commonly isolated from diverse diseased finfish. Common fish pathogens of this family include Flavobacterium columnare, F. psychrophilum, F. branchiophilum, F. spartansii and Tenacibaculum maritimum (Wakabayashi et al., 1986; Bernardet and Bowman, 2006; Loch and Faisal, 2014; Chen et al., 2017).

Flavobacterium columnare, formerly known as Flexibacter columnaris (Bernardet et al., 1996) is an economically important fish pathogen. It is the causative agent of columnaris disease that results in skin lesions, fin erosion and gill necrosis, leading to a high degree of mortality (Declercq et al., 2013). Flavobacterium psychrophilum, also considered as an economically important bacteroidetes, causes severe mortality associated with hemorrhagic septicemia (Bernardet and Bowman, 2006). Disease terminologies such as "rainbow trout fry syndrome" (RTFS) and "cold water disease" (CWD) mostly denominate infections caused by F. psychrophilum and are based on the susceptibility of rainbow trout fry for these types of infection at temperatures below $10^{\circ} \mathrm{C}$ (Holt et al., 1989; Nematollahi et al., 2003b). Flavobacterium branchiophilum is a causative agent for gill disease, and while it is not usually isolated from internal organs, its severe mortality is associated with hemorrhagic septicemia. The known virulence factors related to this disease involve a cholera-like toxin and several adhesins [discussed below (Touchon et al., 2011)]. Flavobacterium spartansii, a recently discovered species that was initially isolated from salmon gills and kidneys causes systemic infection with symptoms such as muscle ulceration, necrotic gills, unilateral exophthalmia and friable kidneys (Loch and Faisal, 2014). Tenacibaculum maritimum, formerly known as Flexibacter maritimus, is the causative agent for tenacibaculosis, which is an ulcerative disease of marine fish that poses serious threats of economic losses in the aquaculture industry. Tenacibaculosis 
cause mostly external symptoms such as skin ulcers, mouth erosion, fin necrosis and rotted tails (Wakabayashi et al., 1986; Pérez-Pascual et al., 2017).

Despite the global challenge of the diseases and the financial losses caused by some members of Flavobacteriaceae, research into their mechanisms of pathogenicity is still in its infancy. However, recent studies revealed at least some of the virulence factors that these members of Flavobacteriaceae utilize to infect their fish host (Touchon et al., 2011; Chen et al., 2017; Li et al., 2017; Pérez-Pascual et al., 2017; Barbier et al., 2020; Kumru et al., 2020). Among these are genes and proteins responsible for gliding motility, various stress responses, adhesion, and they include secretion systems, degrading enzymes such as proteases, collagenases, polysaccharide lyases, sialidase and hemolysins that are utilized for the invasion and colonization of their host (Duchaud et al., 2007; Touchon et al., 2011; Tekedar et al., 2012; Chen et al., 2017; Pérez-Pascual et al., 2017; Kumru et al., 2020).

\section{Transmission Routes and Adherence}

Mucosal surfaces such as skin and gill are primary adhesion sites for several Flavobacteriaceae such a F. columnare, $F$. branchiophilum, F. spartansii, and T. maritimum. Several adhesin candidates have been identified, including surface lipopolysaccharides, capsules and fimbriae (Magarinos et al., 1995; Ostland et al., 1997; Klesius et al., 2008; Loch and Faisal, 2014; Pérez-Pascual et al., 2017). In addition, adherence based on hemagglutinins and lectin-like carbohydrates that are part of the capsule are responsible for attachment to gill tissue in F. columnare (Decostere et al., 1999; Bernardet and Bowman, 2006). Flavobacterium psychrophilum seem to adhere to gill tissue using several leucine-rich repeat proteins, similar to BspA and LrrA of bacteroidetes causing periodontal disease (Sharma et al., 1998; Kondo et al., 2002; Nematollahi et al., 2003a). Flavobacterium psychrophilum adheres to stomach and intestinal mucosa in rainbow trout (Nikoskelainen et al., 2001). In both F. psychrophilum and F. columnare the ability to agglutinate, adhere to, and hemolyze rainbow trout erythrocytes is associated with a sialic acid-binding lectin found in some serotypes of the pathogen (Lorenzen et al., 1997; Møller et al., 2003). The adherence of F. branchiophilum on mucosal surfaces of gills is the initial stage of infection in gill disease and this may be facilitated by several adhesin genes horizontally acquired by the pathogen (Ostland et al., 1997; Touchon et al., 2011).

Several adhesins of members of the Flavobacteriaceae family are secreted through T9SSs (Touchon et al., 2011; PérezPascual et al., 2017; Barbier et al., 2020; Kunttu et al., 2021). Flavobacterium columnare, F. psychrophilum, F. spartansii, T. maritimum, possess genes involved in gliding motility, an active process independent of pili or flagella (Perry, 1973; Alvarez et al., 2006; Touchon et al., 2011; Loch and Faisal, 2014; PérezPascual et al., 2017; Penttinen et al., 2018). Flavobacterium columnare, F. spartansii, T. maritimum and F. psychrophilum contain T9SS-associated genes such as gld and spr, that are involved in gliding motility. It has been shown that deletion of gld genes such as gldD, gldG and gldN not only leads to deficits regarding the ability of gliding motility and adhesion, but also negatively affects biofilm formation and extracellular hemolytic and proteolytic activities, indicating that T9SSs are involved in both gliding motility and secretion of proteins (Sato et al., 2010; Touchon et al., 2011; McBride and Nakane, 2015; Chen et al., 2017; Li et al., 2017; Pérez-Pascual et al., 2017; Barbier et al., 2020; Kumru et al., 2020). Despite the unique gliding motility properties of numerous bacteroidetes, some member species of the family such as F. branchiophilum, T. maritimum are reported to utilize a non-gliding motility mechanism as they contain pili, fimbriae or pili-like structures on their cell surface (Heo et al., 1990; Rahman et al., 2014).

\section{Survival Mechanisms in the Host}

Pathogens have evolved different mechanisms to overcome bacterial competition in order to secure efficient colonization of their host. Among the bacteroidetes, that are the overall most dominant phylum of animal gut microbiota, F. johnsoniae is known to possess a unique T6SS named T6SS ${ }^{i i i}$ which is directly involved in bacterial competition (Russell et al., 2014b). Similarly, genomic analysis of some strains of F. branchiophilum, F. spartansii, and F. columnare show the presence of T6SS ${ }^{i i i}$ coding genes that might be involved in host bacterial competition (Abby et al., 2016; Kumru et al., 2017, 2020).

Furthermore, bacteroidetes evolved diverse survival mechanisms to escape the hostile environments generated by host cells to hinder their colonization. These include defense mechanisms against bacterial pathogens such as the production of reactive oxygen species (ROS) by host macrophages (Secombes, 1996). Bacteroidetes harbor genes encoding superoxide dismutase, catalase-peroxidase, and thiol peroxidase to resist ROS-mediated killing (Duchaud et al., 2007; Chen et al., 2017; Levipan et al., 2018). Iron acquisition systems have been identified in F. columnare (Guan et al., 2013; Zhang et al., 2017), F. psychrophilum (Møller et al., 2005), F. spartansii (Chen et al., 2017), F. branchiophilum, and $T$. maritimum (Avendaño-Herrera et al., 2005), whose function is to compete for the limited iron stock in host cells. The uptake of iron-siderophore complexes by bacteroidetes are not fully explored, however, several TonB-dependent outer membrane receptors such as, OmpA related proteins, ferrichrome-iron receptor precursor (FhuA) and ferric uptake receptor (Fur) protein are identified in the genomes of $F$. columnare (Dumpala et al., 2010; Guan et al., 2013), F. psychrophilum (Alvarez et al., 2008) T. maritimum (Avendaño-Herrera et al., 2005) that may function as iron importer across the outer membrane as is shown for several Gram-negative bacteria (Letain and Postle, 1997; Braun et al., 1998).

Secretion of exopolysaccharides by pathogenic bacteria provides a beneficial environment for survival in the host. F. columnare secretes large quantities of exopolysaccharides during infection using polysaccharide exporters that transport polysaccharides from the cytoplasm to the periplasm (Zhang et al., 2017).

\section{Proteases and Their Secretion Systems}

Fish-pathogenic flavobacteriaceae isolated from different fish species produce several secreted proteases with elastase, gelatinase, collagenase, and caseinase activities that may 
have significant roles in virulence (Bertolini et al., 1994; Dalsgaard and Madsen, 2000; Ostland et al., 2000; Duchaud et al., 2007). The two economically important bacteroidetes F. psychrophilum and F. columnare cause severe mortality associated with hemorrhagic septicemia and columnaris, respectively, by using multi-factorial virulence factors including the metalloproteases (Griffin, 1987; Secades et al., 2001, 2003). Fpp1 and Fpp2, which are calcium dependent proteases that cleave protein-rich extracellular matrices of connective and muscular tissues during colonization (Secades et al., 2001, 2003). Fpp1 and Fpp2 contain the conserved carboxy terminal domain (CTD-domain) for protein secretion through T9SS, which suggest that the T9SS is the secretion system for these metalloproteases ( $\mathrm{Li}$ et al., 2017; Barbier et al., 2020).

Virulence-associated collagenases are among the conserved virulence factors in F. spartansii (Chen et al., 2017), F. columnare (Olivares-Fuster and Arias, 2008), F. psychrophilum (Nakayama et al., 2016), and T, maritimum (Pérez-Pascual et al., 2017). They are used by the pathogens to disrupt collagen-rich tissues of the host. The specific secretion pathways for these collagenases are yet to be explored, however, different studies show the dependency of secreted proteolytic enzymes on T9SS (Chen et al., 2017; Li et al., 2017; Pérez-Pascual et al., 2017).

Polysaccharide lyases such as Chondroitin AC lyase that degrade complex acidic polysaccharides such as hyaluronic acid and chondroitin sulfates located mainly on the extra-cellar matrix of fish tissues are potential virulence factors in F. columnare, where this has been shown in vivo using rainbow trout (StringerRoth et al., 2002; Li et al., 2017) and in T. maritimum where the activity was tested on chondroitin sulfate-supplemented agar (Pérez-Pascual et al., 2017). These enzymes are suggested to initiate and promote infection and are secreted by T9SS: mutational deactivation of a component of T9SS, gldN, in F. columnare lead to the loss of the ability to degrade chondroitin (Li et al., 2017; Pérez-Pascual et al., 2017).

Extracellular elastases produced by F. psychrophilum may have roles in the digestion of host tissues (Madsen and Dalsgaard, 1998; Nematollahi et al., 2003b; Rochat et al., 2019). Unlike for most other virulence factors of fish-pathogenic flavobacteriaceae the secretion pathway of elastase from F. psychrophilum is T9SSindependent (Rochat et al., 2019). Yet, the specific secretion system for the elastase is unidentified.

Glycoproteins are described to be involved in pathogenesis in several pathogenic Gram-negative bacteria (Guerry, 2007), taking part in processes such as cell adhesion and motility (Virji, 1997; Young et al., 2002; Grass et al., 2003; Szymanski et al., 2003). In F. psychrophilum, several glycoproteins were previously identified and predicted to promote infection (Merle et al., 2003; Dumetz et al., 2007). An outer membrane glycosyltransferase, FpgA, expressed by F. psychrophilum has been shown to promote polysaccharide-mediated gliding motility and bacteria-host cell interactions (Fernández-Gómez et al., 2013; Pérez-Pascual et al., 2015). Mutations in the $f p g A$ gene not only impair pathogenicity, but also downregulate expression of the metalloproteases Fpp2 and Fpp1 discussed earlier in this section (Pérez-Pascual et al., 2015). However, neither the secretion apparatus for the metalloproteases Fpp1 and Fpp2 nor its connection to the enzyme FpgA itself is understood.

\section{Hemolysins and Their Secretion Systems}

Hemolysins are potent virulence factors for fish pathogens such as F. psychrophilum, F. columnare, F. spartansii and T. maritimum. They are involved in the lysis of host erythrocytes and in recovering their hemoglobin-bound iron pool for growth (Avendaño-Herrera et al., 2005; Møller et al., 2005; HögforsRönnholm and Wiklund, 2010; Chen et al., 2017; Kayansamruaj et al., 2017). Hemolytic enzymes play a part in the virulence of F. psychrophilum (Högfors-Rönnholm and Wiklund, 2010). F. psychrophilum contains a putative hemolysin gene, FP0063, with $53 \%$ similarity with the hemolysin of Vibrio anguillarum VAH5 (see the Vibrio section below). The Vibrio hemolysin has been shown to degrade erythrocytes creating a devastative host cell damage (Rodkhum et al., 2005; Duchaud et al., 2007). Similarly, F. spartansii harbors virulence-related hemolysin genes that are vital in pathogenesis process such as tissue damage and sepsis (Chen et al., 2017). Flavobacterium columnare contain hemolysin genes that are prominent for pathogenesis (Kayansamruaj et al., 2017; Kumru et al., 2017). Tenacibaculum maritimum contains a gene encoding for sphingomyelinase, a toxin directly involved in hemolysis (Oda et al., 2010; PérezPascual et al., 2017). The secretion mechanisms of hemolysins of fish-pathogenic flavobacteriaceae is not yet clear. However, mutations affecting genome regions encoding T9SS responsible for gliding motility, including the examples GldJ, GldK, GldM, and GldN from F. psychrophilum led to reduced hemolytic activity, indicating that the secretion of hemolysins is at least indirectly influenced by T9SS (Castillo et al., 2015; Barbier et al., 2020).

\section{Other Protein Toxins and Their Secretion Systems}

Flavobacterium spartansii harbors genes encoding for toxin thiolactivated cytolysin (TACY) which possibly modulate or lyse the function of enterocyte membranes through formation of pore (Chen et al., 2017). Flavobacterium branchiophilum produces a cholera-like toxin protein, identified as FBFL15_0919 (Touchon et al., 2011), which has high sequence similarity with the cholera toxin (CTA) produced by $V$. cholera and the heat-labile toxin (LTA) produced by enterotoxigenic Escherichia coli. The LTA and CTA toxins stimulate adenylate cyclase and provoke the massive loss of fluid and electrolytes through the intestinal epithelium of the host (Sixma et al., 1991; de Haan and Hirst, 2000; Broeck et al., 2007). Similarly, FBFL15_0919 is speculated to disturb the osmoregulatory function of the epithelial cells of the gills. Gill cells are involved in excretion of urea and in uptake of salts, in addition to oxygen uptake (Wilkie, 2002). The exact secretion mechanism for FBFL15_0919 is not yet investigated, however, CTA is reported to be exported by T2SS (Robien et al., 2003).

Despite the availability of genome sequences of fish pathogens such as F. psychrophilum, many of the secretion systems for virulence factors that are key to the pathogenesis of other Proteobacteria are not yet described in detail in Flavobacteriaceae. Genes for key components for secretion systems from almost all classes have been found in the genomes 
of different Flavobacterium species, but have not yet been directly linked to virulence experimentally (Kumru et al., 2020). Much more is known about the components for T9SSs (Duchaud et al., 2007). Mutation of genes involved in gliding (the gld genes), which are components of the T9SS in F. johnsonia (a well-studied member of the fish-pathogenic bacteroidetes) lead not only deterioration of motility but also to significant changes in the secretion of extracellular enzymes (McBride et al., 2003; Braun et al., 2005; Braun and McBride, 2005) strongly suggesting that the T9SS may be the most crucial virulence factor of bacteroidetes. It facilitates pathogenicity through providing multiple virulence tools for successful infection ranging from colonization to host cell disruption processes (Li et al., 2017; Penttinen et al., 2018; Barbier et al., 2020).

\section{PROTEOBACTERIA (CLASS: GAMMAPROTEOBACTERIA)}

\section{Vibrionales}

The Vibrionales are a separate order within the Proteobacteria that contains only one Family, the Vibrionacae. They encompass many important facultative anaerobic fish pathogens, mainly from the genera Vibrio, Allivibrio and Photobacterium.

Vibrios are rod-shaped ubiquitous and important pathogens to varied marine and freshwater fish species (Rucker, 1959). Vibriosis, one of the common diseases in the aquaculture industry with outbreaks that lead to high mortality of farmed fish, imposes severe negative impacts on productivity, sustainability and profitability. Diverse pathogenic vibrio species have been isolated from diseased fish with vibriosis symptoms that include bruised, red spotted and ulcerated skin, mouth and fin sores, and systemic infection symptoms like tissue necrosis, hemorrhagic muscles, and other bleedings (Buller, 2004; Toranzo et al., 2005). All pathogenic vibrios, including the humanpathogenic Vibrio cholerae, are directly connected to aquatic environments. The genome of the vibrios is encompasses two chromosomes, an unusual feature compared to other bacterial genera (Okada et al., 2005). The most common pathogenic vibrio species responsible for fish vibriosis include $V$. anguillarum, $V$. harveyi, V. vulnificus, $V$. parahaemolyticus, $V$. alginolyticus, V. ordalii, V. splendidus, and in addition the species Allivibrio salmonicida and Photobacterium damselae that are part of closely related Vibrionacae genera (Austin B. et al., 2003; Austin and Austin, 2012). Vibrio cholerae is able to colonize diverse fish species indicating that fish could be a vector for $V$. cholerae. However, direct pathogenicity of $V$. cholerae to fish is debatable (Halpern and Izhaki, 2017).

\section{Transmission Routes and Adherence}

The main routes of transmission for vibriosis include direct contact (entry through skin and/or damaged mucous layers) and oral (ingestion) transmissions (Grisez et al., 1996; Svendsen and Bøgwald, 1997; Jun and Woo, 2003; Weber et al., 2010). The initial stage of infection involves colonization of the skin mucosa and biofilm formation facilitated by exopolysaccharides (Croxatto et al., 2007; Weber et al., 2010). Adherence of the bacteria to host surfaces and survival in the host are particularly determined by the surface hydrophobicity of pathogenic bacteria (Lee and Yii, 1996; Balebona et al., 1998). For instance, $V$. anguillarum and V. salmonicida utilize surface hydrophobicity to survival in hosts organism (Horne and Baxendale, 1983; Espelid et al., 1987; Hjelmeland et al., 1988).

Vibrionaceae utilize specific pili or various non-pilus adhesins that facilitate adhesion to host cells and initiate infection. Adhesion can be mediated by flagella in $V$. anguillarum, $V$. alginolyticus, $V$. harveyi, $V$. splendidus, and $V$. vulnificus indicating that motility is key for adhesion in these organisms (Milton et al., 1996; O’Toole et al., 1996; Ormonde et al., 2000; Luo et al., 2016; Dai et al., 2020; Xu et al., 2021). In addition to flagella, the outer membrane protein TolC and NADH oxidase dihydrolipoamide dehydrogenase play pivotal roles in the adhesion of $V$. harveyi and $V$. splendidus, respectively (Dai et al., 2019; Zhu et al., 2019). Experiments performed on non-fish cell lines show other factors including the adhesin VpadF, enolase, capsular polysaccharide, T6SSs, multivalent adhesion molecule 7 (MAM7) and a mannose-sensitive hemagglutinin (MSHA) pilus bind to different receptors to facilitate cell attachment by V. parahaemolyticus (Hsieh et al., 2003; Krachler et al., 2011; Yu et al., 2012; O’Boyle et al., 2013; Jiang et al., 2014; Liu and Chen, 2015). A $\beta$-pore forming toxin, phobalysin, plays a pivotal role in host cell adherence in Photobacterium damselae (Rivas et al., 2015; von Hoven et al., 2018).

Survival mechanisms in the hostOnce inside the host, survival of Vibrionaceae is achieved through distinct virulence mechanisms such as regulation of iron acquisition, neutralization of acidic environments, combating oxidative stress, induction of host immune cell death, and immune evasion. V. vulnificus neutralizes acidic environments of the host gut and tolerates oxidative stress by converting lysine to cadaverine and $\mathrm{CO}_{2}$ using lysine decarboxylase and manganese superoxide dismutase (SOD) respectively (Rhee et al., 2002; Kim et al., 2005; Jones and Oliver, 2009). Invasion and inter-microbial competition of $V$. cholerae in the gut of zebrafish is mediated by a T6SS where the syringe-like system plays a role in intensifying the host gut contractions which lead to expulsion of resident microorganisms (Logan et al., 2018).

Several Vibrionaceae possess finely regulated and highaffinity siderophore or heme-dependent iron acquisition systems to compete for iron sequestered by iron-binding proteins such as transferrins or in heme in host organisms (Thode et al., 2018; Richard et al., 2019). Siderophore-dependent iron acquisition systems synthesize and secrete siderophores into the environment to chelate ferric iron. The secretion mechanisms for siderophores are not fully understood in the Vibrionaceae but a major facilitator superfamily protein (MFS)-mediated efflux pump seems to play an important role (Li and Ma, 2017). No hemophores to chelate iron from hemoproteins have yet been identified in fish-pathogenic species from the Vibrionaceae family (Wandersman and Delepelaire, 2004).

Vibrio anguillarum, V. vulnificus, $V$. ordalii, $V$. harveyi, Photobacterium damselae, V. parahaemolyticus, V. alginolyticus, A. salmonicida, and $V$. splendidus utilize siderophore-mediated iron acquisition systems. The uptake of both ferric-siderophore 
complex and heme across the membrane is performed by $\mathrm{ABC}$ transporters which utilize TonB complex as energy transducers (Stork et al., 2004; Thode et al., 2018).

Depending on the serotype, $V$. anguillarum produce three distinct iron-uptake systems: anguibactin and its outer membrane receptor FatA (Lopez and Crosa, 2007; López et al., 2007; Naka et al., 2013), piscibactin and its outer membrane receptor FrpA (Balado et al., 2018; Valderrama et al., 2019) and vanchrobactin and its outer membrane transport FvtA (Soengas et al., 2006, 2008; Balado et al., 2008, 2009). Like Vibrio anguillarum, Photobacterium damselae and V. ordalii produce the piscibactin siderophore where the receptor in the former is FrpA and in the latter is unclear (Souto et al., 2012; Ruiz et al., 2019; Valderrama et al., 2019). Vibrio vulnificus synthesize vulnibactin and its uptake is mediated by VuuA (Webster and Litwin, 2000; Kim et al., 2006; Alice et al., 2008). Vibrio harveyi produce amphi-enterobactin and its uptake receptor FapA (Zane et al., 2014; Naka et al., 2018). Vibrio parahaemolyticus produces the siderophore vibrioferrin and its receptor PvuA (Funahashi et al., 2002; Tanabe et al., 2003). Like V. parahaemolyticus, $V$. alaginoluticus contains gene clusters for vibrioferrin biosynthesis (Wang Q. et al., 2007). Allivibrio salmonicida utilize bisucaberin that is recognized by BitA (Winkelmann et al., 2002; Kadi et al., 2008). Vibrio splendidus utilize a hydroxamatebased siderophore and IutA is proposed as a potential receptor (Song et al., 2018). Besides the siderophore iron acquisition system, $V$. vulnificus directly use heme from hemoglobin as host iron sources, where the uptake of heme is facilitated by outer membrane protein HupA (Litwin and Byrne, 1998). Vibrio anguillarum possess a heme-utilizing system where two outer membrane proteins, HuvA and HuvS, perform heme uptake (Mazoy et al., 1996; Mazoy and Lemos, 1996; Mouriño et al., 2005), and where the complex HuvBCD is required for subsequent transport of periplasmic heme into the cytosol (Mouriño et al., 2004).

\section{Proteases and Secretion Systems}

Extracellular proteases are associated with the pathogenesis of several Vibrionacae. The extracellular zinc metalloproteases EmpA and PrtV of V. anguillarum are potent virulence factors with mucinase activities that are required for infecting the gastrointestinal tract of diverse fish species such as salmon, turbot and flounder (Norqvist et al., 1990; Milton et al., 1992; Denkin and Nelson, 1999, 2004; Zhao-lan et al., 2002; Mo et al., 2010; Frans et al., 2011). The secretion of EmpA and PrtV is mediated by a T2SS (Zhang et al., 2006; Rompikuntal et al., 2015). EmpA and PrtV belong to the M4 and M6 family of peptidases, respectively, and are translated in inactive form which passes through a maturation process involving proteolytic cleavages during secretion through the T2SS (Milton et al., 1992; Staroscik et al., 2005; Zhang et al., 2006; Varina et al., 2008; Mo et al., 2010; Rompikuntal et al., 2015). Besides its proteolytic activity, EmpA activates hemolysins promoting disruption of red blood cells in fish (Han et al., 2011). PrtV contains gelatinase, protease and glycosidase activity, and a $\operatorname{prt} V$ mutant of $V$. anguillarum strain show reduced infection, growth and hemolytic activity in turbot and turbot cell lines (Mo et al., 2010).
Vibrio parahaemolyticus produce multiple extracellular metalloproteases such as the tissue-degrading protease VPM, and the collagenases PrtV and VppC. In addition, serine proteases Vpp1/protease A with cytotoxic activity, VpSP37 with gelatinase activity, and PrtA with hemolytic and cytotoxic activity are produced as virulence factors (Osei-Adjei et al., 2018). Similarly, V. alginolyticus produce extracellular alkaline serine protease $\mathrm{A}$ and a $\mathrm{VppC}$ homolog where the former is an exotoxin and lethal to fish (Takeuchi et al., 1992). Vibrio vulnificus produce an extracellular metalloprotease Vvp, however, its involvement in virulence is debatable (Valiente et al., 2008). The secretion mechanisms of these metalloproteases are not yet described.

\section{Hemolysins and Secretion Systems}

Six pore-forming hemolysins, Vah1-5 and Rtx, are responsible for disrupting red blood cells leading to hemorrhagic septicemia in $V$. anguillarum (Hirono et al., 1996; Rodkhum et al., 2005). Vah1-5 belong to the HylA hemolysin family (Hirono et al., 1996; Zhang and Austin, 2005). Secretion factors of Vah1-5 from $V$. anguillarum are not documented; however, HylA hemolysins are generally known to be secreted via T1SS (Thomas et al., 2014). Like the metalloproteases EmpA and PrtV of $V$. anguillarum, hemolysins in the HylA family are translated as pre-proteins where the production of mature hemolysins requires multiple processing steps during secretion (Zhang and Austin, 2005). All Vah hemolysins show hemolytic activity on fish erythrocytes, with Vah4 displaying the strongest virulence effects (Rodkhum et al., 2005). RtxA (repeats-in-toxinA), a multifunctional extracellular protein secreted by diverse Gram-negative fish pathogens, is responsible for cytotoxic and hemolytic attacks in fish (Li L. et al., 2008). The secretion of unfolded Rtxs is performed by a T1SS where folding is initiated only after passage (Linhartova et al., 2018). The expression and secretion of $V$. vulnificus RtxA1 toxin is regulated by a general stress response regulator, RpoS (Guo et al., 2018).

Vibrio parahaemolyticus possess two pathogenic hemolysins, thermostable direct hemolysin (TDH) and TDH-related hemolysin (TRH) (Li L. et al., 2019). Vibrio parahaemolyticus possess multiple secretion systems, a T2SS and two T3SSs (T3SS1 and T3SS2) where the T2SS and T3SS2 export the hemolysins. TDH possesses exotoxin roles and secreted through both, the T2SS and T3SS2 (Matsuda et al., 2019). Like TDH, TRH is secreted through both, the T2SS and T3SS2 (Matsuda et al., 2019). The pathogenicity role of T3SS1 of $V$. parahaemolyticus is described below.

Vibrio alginolyticus express the toxic hemolysins Tdh and TLH where the former has hemolytic activity both on mouse and fish and the latter shows both hemolytic and phospholipase activities in zebrafish (Cai et al., 2007; Jia et al., 2010). Vibrio harveyi produce a cytotoxic hemolysin $\mathrm{VHH}$ with phospholipase $B$ activity, where its native secretion system is not clear; but it has been shown to use T2SS-mediated secretion when recombinantly expressed in E. coli (Zhong et al., 2006; Sun et al., 2007). Several extracellular products (ECPs) from $P$. damselae sp. damselae that have strong hemolytic, lipase, esterase-lipase and phospholipase activity but weak proteolytic activity are reported to be lethal for fish (Fouz et al., 1993; Labella et al., 2010). 


\section{Secretion of Effectors}

T3SSs are ubiquitous in Gram-negative pathogens including fish pathogenic Vibrionaceae such as $V$. parahaemolyticus, $V$. salmonicida, V. alginolyticus, V. harveyi and Photobacterium damselae. They directly deliver both fish and non-fish virulence factors from the pathogen cytosol into host cells where the effect of the virulence factors on fish pathogenesis varies depending on the nature of the Vibrionaceae members (Hueck, 1998; Frey and Origgi, 2016; Osorio, 2018).

As mentioned earlier, $V$. parahaemolyticus harbor a set of two T3SSs (T3SS1 and T3SS2) where T3SS1 is related to cytotoxicity and T3SS2 is associated with both cytotoxic and enterotoxic activities in mice (Hiyoshi et al., 2010). Several effectors such as VopQ [that induces autophagy in mammalian cell lines; (Burdette et al., 2009)], VopS [modification of host Rho family GTPases in HeLa cells (Yarbrough et al., 2009)], VopR (unknown function) and VpA0450 [hydrolyzes plasma membrane-located phosphatidylinositol phosphate in human cells (Broberg et al., 2010)] are secreted through T3SS1. Evidence based on non-fish models show that VopA/VopP [inhibits mitogen-activating protein kinase pathway using acetyl transferase, (Trosky et al., 2007; Pan et al., 2021) VopL (induce stress fiber using actin nucleastion (Ham and Orth, 2012)], VopT [Induce cytotoxicity using ADP-ribosylation (Sun and Barbieri, 2003; Barbieri and Sun, 2004)], VopV [facilitate enterotoxicity by F-actin binding/bundling (Hiyoshi et al., 2011)] and VopC [Promote bacterial invasion using deamidase (Zhang et al., 2012)] are secreted through T3SS2 (Ham and Orth, 2012). Additional contributions of T3SS2 to pathogenicity is discussed above in the section on hemolysins.

Effectors of T3SSs in $V$. alginolyticus promote cell death of fish cells (Zhao et al., 2010). Val1686 and Val168 in V. alginolyticus, homologous to the T3SS1 effector proteins VoPQ (88\%) and VopS (91\%) of $V$. parahaemolyticus, cause apoptosis in fish cell lines (Osorio, 2018). V. alginolyticus harbor two T6SSs, T6SS1 and T6SS2, where T6SS1 secretes multiple effectors such as MIX IV pore- forming effector (Va16152), MIX I (Va01565), LytM, a peptidoglycan hydrolase and lysozyme-like domain (Va01435), OmpA_C (Va01555) and VopQ (Va17542) (Salomon et al., 2015). Also V. splendidus produce a virulence effector, Hop, with cytotoxic effects that is secreted by a T3SS (Zhuang et al., 2020, 2021).

\section{Enterobacteriales}

Yersiniaceae, Hafniaceae, and Enterobacteriaceae are three of the seven families classified under the order Enterobacteriales that contain common fish pathogens, causing mild to severe fish diseases.

Yersinia ruckeri is a member of the Yersiniaceae family, and strains from different biotypes are reported as causative agents of enteric redmouth disease (ERM). ERM, also known as yersiniosis, dominantly infects salmonids causing serious economic threats to the salmonid aquaculture industry worldwide (Austin D. A. et al., 2003; Fouz et al., 2006; Arias et al., 2007; Wheeler et al., 2009; Calvez et al., 2014; Hjeltnes et al., 2017; Wrobel et al., 2019). Yersinia ruckeri is a rod-shaped, nonencapsulated facultative anaerobe (Tobback et al., 2007). Typical symptoms of yersiniosis include septicemia and subsequent development of hemorrhages on the body surface and internal organs (Tobback et al., 2007). Alike some Yersinia species infecting other animals and humans, Y. ruckeri contain plasmids that encode virulence-related factors such as type IV pilus and T4SS (Wrobel et al., 2018).

Edwardsiella tarda [current name E. piscicida (Abayneh et al., 2013)] and Edwardsiella ictaruli belong to the genus Edwardsiella within the Hafniaceae family. They are economically important fish pathogens predominant in aquaculture industries worldwide (Thune et al., 1993; Mohanty and Sahoo, 2007). Edwardsiellosis is the general term used for the septicemic diseases caused by E. tarda and E. ictaluri leading to severe skin, muscle and internal organ lesions and causing high levels of mortality (Ewing et al., 1965; Abbott and Janda, 2006; Kerie et al., 2019). Edwardsiella tarda is a. short, mostly motile and rod-shaped facultative anaerobe that infects wide ranges of fish species (Matsuyama et al., 2005; Park et al., 2012). Edwardsiella ictaruli is a short and pleomorphic rod-shaped, motile species that is primarily recognized as a causative agent of enteric septicemia of catfish species. E. ictaluri was isolated from kidney and livers of several catfish with signs of enteric septicemia (Hawke et al., 1981). Edwardsiella tarda and E. ictaruli share common virulence strategies (see below).

Citrobacter freundii a member of the genus Citrobacter, is a long, rod shaped, facultative anaerobic bacterium of the family Enterobacteriaceae. Several C. freundii strains contain flagella used for locomotion while some are non-motile. Citrobacter freundii is closely related to E.coli and Salmonella and is prevalent in diverse ecological niches such as soil, water, sewage, food and the gut of animals including humans (Knirel et al., 2002; Murray et al., 2010; Abbott, 2011; Bandeira Junior et al., 2018). Citrobacter freundii, a causative agent of gastroenteritis and hemorrhagic septicemia, is a common pathogen of diverse freshwater fish where infected fish show symptoms such as skin ulceration, systemic infectious signs on the liver, kidney, muscles and gills (Jeremić et al., 2003; Baldissera et al., 2018; Sun et al., 2018).

\section{Transmission Routes and Adherence}

Host cell adherence by $Y$. ruckeri is promoted through the pathogen's variable motility that depends on the presence and absence of flagella (Davies and Frerichs, 1989). Bacterial adherence in $Y$. ruckeri may also involve type IV pili, a hairlike multi-subunit surface appendage which its function is not restricted to surface biding and twitching motility, but also DNAuptake, and micro-colony or biofilm formation (Mattick, 2002; Craig et al., 2019).

Experimental evidence shows that the site of entry for virulent E. tarda and E. ictaluri are gills, gastrointestinal tract and body surface (Ling et al., 2001; Pirarat et al., 2016). Edwardsiella tarda is shown to involve actin and microtubules for entry to host cells (Ling et al., 2001; Sui et al., 2017). Motility is critical during the initial phase of colonization for several aquaculture pathogens (Ormonde et al., 2000). Two types, motile and non-motile strains, of E. tarda exist where there is apparent differences in the pathogenicity between these variants (Park et al., 2012), however, the difference in colonization mechanisms of these variants are 
not clear. Furthermore, secretion systems such as T3SS and T6SS play pivotal roles in adherence and cell-diffusion (Tan et al., 2005; Park et al., 2012). For instance, EvpP, a component of T6SS, is shown to control the internalization process in invasion suggesting that this secretion system plays a key role in the pathogenesis of E. tarda (Wang X. et al., 2009).

The site of infection of $C$. freundii are the mucosal layers of the intestine which suffer severe damage during infection (Pan et al., 2021). A whole genome analysis of C. freundii indicates the presence of multiple virulence factors that are potentially involved in colonization and in-host cell survival. C. freundii displays strong adhesion to the hepatic fish cell line L8824 and can cause distinctive lesions known as A/E lesions (Pan et al., 2021), similar to A/E lesions caused by E.coli on the intestinal mucosa. This effect requires strong attachment of the pathogen to the surface of the enterocyte and involves a T3SS which injects multiple effector proteins into the cell (Wong et al., 2011; Hartland and Leong, 2013). An adhesin named EaeA of $C$. freundii has previously been identified as key element for colonization in mice but its role in colonization of fish is not clear (Schauer and Falkow, 1993). EaeA itself is an autotransporter, a member of the type Vc secretion systems (Leo et al., 2015).

Survival mechanisms in the hostIt is crucial for pathogens to avoid host defense mechanisms, in order to survive, proliferate and maintain infection in the host. Key to Y. ruckeri survival, growth and pathogenicity in the host is its iron acquisition system that produces an enterobactin-like siderophore known as ruckerbactin; the gene encoding ruckerbactin is upregulated during infection (Fernández et al., 2004; Tobback et al., 2007). The secretion and uptake systems for ruckerbactin and ferricruckerbactin, respectively, are not yet elucidated in detail, however, the ruckerbactin receptor has a high degree of similarity with the ferrichrysobactin receptor of Dickeya dadantii (Fernández et al., 2004).

Edwardsiella tarda has evolved several mechanisms to survive immune responses. One of these mechanisms involves the neutralization of reactive oxygen species using redox enzymes such as superoxide dismutase (SodB) and catalase KatB (Han et al., 2006). Edwardsiella tarda has the ability to survive in host serum, to resist acidic milieu and to replicate in phagocytes with the help of a serum-induced, putative hydrogenase protein named Sip2 (Li and Sun, 2018). In serum, the complement system has a significant role in host defense against infection via mechanisms involving both innate and adaptive immunity (Walport, 2001; Merle et al., 2015). Activation of the complement system lead to bacterial membrane damage and subsequent lyses using membrane attack complex (MAC) (Endo et al., 2006; Sarma and Ward, 2011). Edwardsiella tarda has the ability to evade the bactericidal effect of host serum through blocking the activation of the complement using the zinc metalloprotease Sip1 (Zhou et al., 2015). Besides, serum enhances the tricarboxylic acid cycle of $E$. tarda which increases membrane potential and decreases the formation of MAC, leading to serum resistance (Cheng et al., 2017). Furthermore, the chaperone protein HtpG is shown to help E. tarda to cope with stress conditions during infection (Dang et al., 2011).
Like E. tarda, E. ictaluri has the ability to survive and grow within host macrophages (Miyazaki and Plumb, 1985; Baldwin and Newton, 1993; Pirarat et al., 2016). A T3SS translocates several effectors from E. tarda and E. ictaluri directly into the host cytoplasm, where they have essential roles for internal replication and virulence (Dubytska et al., 2016). The T3SS of E. tarda plays important roles in phagocyte survival, in host proliferation and virulence (Tan et al., 2005). For instance, the T3SS effector EseJ facilitates cell proliferation in host cells by inhibiting the oxidative stress produced by host macrophages (Xie et al., 2015). Like the T3SS, a T6SS has a pivotal role in survival and replication of E. tarda in host epithelial cells and phagocytes (Park et al., 2012). However, the mechanisms of the two secretion systems are antagonistic, where the T3SS promotes bacterial replication in host cells while the T6SS protects the pathogens from attack by the activated innate immune system through suppressing replication (Xie et al., 2015; Hu et al., 2019).

Iron acquisition systems such as siderophore biosynthesis and iron uptake systems are necessary for pathogenicity of E. tarda (Castro et al., 2016). The genome of E. tarda contains genes encoding for multiple factors putatively involved in iron utilization including ferric uptake regulator, ferric reductase, ferritin and TonB (Wang Q. et al., 2009). It also includes a gene cluster sharing high similarity to the pvsABCDE-psuA$p v u A$ operon which encodes proteins for synthesis and utilization of vibrioferrin siderophore of the two fish pathogen vibrios $V$. parahaemolyticus and V. alginolyticus (Tanabe et al., 2003; Wang Q. et al., 2007).

In contrary, there are no dedicated siderophore biosynthesis genes detected in the genome of E. ictaluri (Santander et al., 2012), however, the pathogen carries a ferric hydroxamate uptake (Fhu) system involved in uptake of hydroxamate-type siderophores. Experimental evidence shows that the Fhu-system is indeed involved in pathogenicity, suggesting that the system may be utilized to uptake hydroxamates secreted by other bacteria (Abdelhamed et al., 2016). In addition, the genome of E. ictaluri contains an alternative ferric uptake system (afuABC) and the general TonB energy transducing system (TonB-ExbBExbD) which may be involved in iron uptake (Abdelhamed et al., 2013, 2017). Furthermore, E. ictaluri utilizes a Fur-regulated heme-hemoglobin uptake system (Santander et al., 2012).

In addition to the siderophore-dependent systems, E. tarda can utilize hemin, hemoglobin and hematin as iron sources (Abbott and Janda, 2006). A heme utilization operon in its genome that encodes for three proteins identified as HutW $\mathrm{W}_{E t}$, Hut $\mathrm{X}_{E t}$ and HutZ $Z_{E t}$ is highly similar to the heme utilization operon in $V$. cholera (Shi et al., 2019). In V. cholera Hut $\mathrm{X}_{V c}$ functions as an electron carrier to the heme-degrading HutZ $Z_{V c}$ while $\mathrm{HutW}_{V c}$ may be a reductase for HuyZ $Z_{V c}$ (Sekine et al., 2016). HutZ $Z_{E t}$ has been shown to be involved in biofilm formation and motility (Shi et al., 2019). Furthermore, E. tarda produce an iron-mediated hemolysin that is released under ironlimited conditions (Janda and Abbott, 1993; Hirono et al., 1997). All in all, iron depletion in host cells is a signal for pathogens to turn on the expression of virulence genes. The ferric uptake regulator (Fur) protein senses iron depletion in, for example, E. tarda to regulate expression of key virulence factors such 
as T3SS and T6SS through secretion regulator protein EsrC (Chakraborty et al., 2011).

Citrobacter freundii harbor genes that could be utilized in diverse mechanisms and virulence factors to maintain infection, including a T3SS that plays a crucial role in the injection of effector proteins such as HopAJ2 family member that mediate survival against host immune response (Galán et al., 2014; Pan et al., 2021). Iron acquisition in C. freundii is facilitated by FepE, a component of the ferric enterobactin siderophore transport system (Wang et al., 2019). In addition to the siderophoredependent iron transport system, an hemophore-mediated heme uptake apparatus is present that includes an outer membrane channel protein HasF (Létoffé et al., 2001). In addition, surface lipopolysaccharides (LPS) of some serogroups of C. freundii have been shown to play vital roles in colonization and host survival (Denkin and Nelson, 1999).

\section{Proteases and Their Secretion Systems}

Yersinia ruckeri produce a serralysin metalloprotease named Yrp1 that is secreted via an ATP-dependent T1SS composed of three genes, $y r p D-F$, and a protease inhibitor inh. Yip1 seems to have pivotal roles in the development of ERM due to its ability to disrupt several extracellular matrix proteins of fish such as laminin and fibronectin, and proteins important in muscle function such as actin and myosin (Fernández et al., 2002). Furthermore, Y. ruckeri produce two additional peptidases, YrpA and $\mathrm{YrpB}$ encoded by the $y r p A B$ operon. Toxicity tests indicate that at least YrpA is involved in Y. ruckeri pathogenicity, as deletion of the gene encoding $\operatorname{YrpA}$ drastically reduces the virulence of the bacteria (Navais et al., 2014).

Edwardsiella tarda produce multiple virulence-related proteases that are engaged in diverse processes of infection. For instance, the above mentioned zinc metalloprotease Sip1 of $E$. tarda is secreted to effectively prevent complement-mediated serum killing through blocking the activation of the complement system (Zhou et al., 2015). A serine protease autotransporter $\mathrm{Tsh}_{E T}$, which is a temperature-sensitive hemagglutinin, belongs to the Type V secretion systems (T5SS) and contributes to the virulence of $E$. tarda. Tsh has multiple functions; mutations in the tsh gene led to hindrance of biofilm growth, reduction of resistance against serum killing, impairment of the ability to block the host immune response, and attenuation of tissue invasion and cellular infectivity (Hu et al., 2016). In addition, the periplasmic serine protease $\operatorname{DegP} \mathrm{P}_{E T}$ is presumably involved in virulence of E. tarda, similar to DegP in Salmonella enterica, Streptococcus pyogenes and Legionella (Johnson et al., 1991; Jones et al., 2001, 2002; Pedersen et al., 2001; Wilson et al., 2006; Flannagan et al., 2007; Jiao et al., 2010).

\section{Hemolysins and Their Secretion Systems}

The gene cluster $y$ hlBA of $Y$. ruckeri encodes for a hemolysin (YhlA) and a protein involved in its secretion/activation (YhlB). The expression of YhlA is upregulated in iron-limited conditions suggesting that the hemolysin may be directly involved in acquisition of iron from the host cell (Fernández et al., 2007; Wrobel et al., 2019). Both $y h l A$ and $y h l B$ genes have high sequence similarity with a type $\mathrm{Vb}$ secretion system with hemolysin activity in Serratia sp. (Wrobel et al., 2019).

Edwardsiella tarda produce two different hemolysins, the iron-mediated cell associated hemolysin EthA, secreted under iron limited conditions, and an extracellular pore-forming hemolysin district from EthA (Janda and Abbott, 1993; Chen et al., 1996; Hirono et al., 1997). Similar to the hemolysin YhlA of Y. ruckeri and its activation/secretion protein YhlB (described above), the hemolysin EthA from E. tarda needs an activation/secretion protein EthB encoded in an operon. EthA and $\mathrm{EthB}$, are prevalent in hemolytic E. tarda strains isolated from diseased fish (Hirono et al., 1997) which may indicate that they are among the key virulence mechanisms utilized by the pathogenic E. tarda.

\section{Polysaccharide Degrading Enzymes}

Chondroitinases are involved in the pathogenicity of infectious bacteria (Schaechter et al., 1993). Chondroitinase activity is known to be virulence factor in Edwardsiella spp. including E. tarda and E. ictaruli. These species produce chondroitinase that mediates cartilage degradation in the process of invasion (Waltman et al., 1986; Shotts and Cooper, 1996). The Sialidase NanA from E. tarda also promotes tissue invasion, and mutations of the gene encoding for the enzyme led to drastic attenuation of the pathogen, by limiting its ability for invasion and colonization (Jin et al., 2012).

\section{Secretion of Other Toxin Proteins or Toxins and Their Secretion Pathway}

Distinct strains of Y. ruckeri produce TcpA, a Toll/interleukin-1 (TIR) domain containing protein that inhibits Toll-like receptor signaling and promotes immune evasion. TcpA is also known to increase tissue damage in fish. The gene for TcpA is located adjacent to a T4SS gene cluster which may indicate that the secretion of TcpA is related to this T4SS (Liu et al., 2019). As discussed above, T3SS are a crucial and multipurpose system in E. tarda and E. ictaluri. The T3SS of E. tarda belongs to the Ssa-Esc family which includes T3SS encoded by Salmonella pathogenicity island 2 (SPI-2) in Salmonella enterica serover Typhimurium, the causative agent of foodborne illness worldwide (Anderson and Kendall, 2017). The core components of the T3SS are encoded by 34 genes, where all obtain different functions (Tan et al., 2005; Sadarangani et al., 2013). Among these are the three translocon proteins $\mathrm{EseB}, \mathrm{EseC}$ and $\mathrm{EseD}$ that are essential for delivery of effectors into host cells (Tan et al., 2005).

\section{Aeromonadales}

The order Aeromonadales contains only two families, the Succinivibrionaceae and the Aeromonadaceae. Species of the family Aeromonadaceae are known to cause acute hemorrhagic septicemia in fish (Colwell et al., 1986; Stackebrandt and Hespell, 2006). Aeromonas species, ubiquitous in aquatic environments, are classified into two groups; motile mesophilic aeromonads with optimal growth temperature around $37^{\circ} \mathrm{C}$, and non-motile psychrophilic strains with an optimal growth temperature range of $22-28^{\circ} \mathrm{C}$ where the latter are cold-water fish pathogens. Aeromonas bestiarum, Aeromonas sobria, Aeromonas hydrophila 
and Aeromonas veronii, all categorized as motile and mesophilic, are responsible for motile Aeromonas septicemia (MAS), an acute hemorrhagic septicemia, or for chronic skin ulcers (Ali, 1996; Stratev and Odeyemi, 2017). Aeromonas salmonicida comprising both non-motile psychrophilic and motile mesophilic strains is a causative agent for systemic furunculosis, a disease that causes sepsis, hemorrhages, muscle lesions, inflammation of the lower intestine, spleen enlargement, and death in freshwater fish populations (Beaz-Hidalgo and Figueras, 2013). Genome information of diverse Aeromonas species is available and indicates specialized pathogenic mechanisms (Seshadri et al., 2006; Reith et al., 2008; Li et al., 2011; Beaz-Hidalgo and Figueras, 2013). Virulence by Aeromonas is a complex succession of processes, where successful infection requires potential for the formation of biofilms, production and secretion of virulence factors such as adhesins, proteases, hemolysins, lipases, DNases and effector proteins as well as regulation of virulence factors through quorum sensing (Allan and Stevenson, 1981; Cahill, 1990; Thornley et al., 1997; Beaz-Hidalgo and Figueras, 2013).

\section{Transmission Routes and Adherence}

The important initial infection sites for Aeromonas such as A. salmonicida include skin, gills and the gastrointestinal tract (Ringø et al., 2004; Bartkova et al., 2017). Tissue invasion in the gastrointestinal tract is mediated by extracellular virulence factors that are utilized to damage the tissue (Ringø et al., 2004). Adhesion, a prerequisite for successful colonization by pathogens, is executed by different factors in Aeromonas species. Outer membrane proteins such as OmpA and AHA1 function as adhesins in $A$. veronii and $A$. hydrophila (Fang et al., 2004; Namba et al., 2008). A tight adherence system (TaD) is present in the majority of $A$. hydrophila strains (Tekedar et al., 2019a). A. hydrophila and A. sobria use pili (Lallier and Daigneault, 1984; Ho et al., 1990), lipopolysaccharides (LPS) is used by A. hydrophila (Merino et al., 1996), and cell-associated lectins are used by A. veronii (Guzman-Murillo et al., 2000) to bind to host cells and tissues. Paracrystalline surface protein layers in A. salmonicida and A. hydrophila display significant hydrophobicity and contribute to adhesion (Chu et al., 1991; Beveridge et al., 1997).

\section{Survival Mechanism in the Host}

Survival of $A$. salmonicida and $A$. hydrophila in the host is achieved by $S$-layers that bind to extracellular matrix components such as laminin, fibronectin and vibronectin providing resistance to serum killing and protease digestion (Beveridge et al., 1997; Noonan and Trust, 1997). Most Aeromonas sequester iron from their hosts through utilization of siderophore-dependent or siderophore-independent (heme-binding) mechanisms (Byers et al., 1991; Reith et al., 2008; Lange et al., 2020). The siderophoredependent mechanisms rely on the synthesis of enterobactin or amonabactin and some A. salmonicida species are capable of synthesizing anguibactin-like siderophores (Barghouthi et al., 1989a,b; Byers et al., 1991; Telford and Raymond, 1998; Reith et al., 2008). Allivibrio salmonicida and A. hydrophila synthesize both ferric and heme iron acquisition systems (Ishiguro et al., 1986; Najimi et al., 2008b). In most cases, two catechol siderophores; acinetobactin and amonabactin, are produced simultaneously (Balado et al., 2015) and their uptake is facilitated by the TonB-dependent outer membrane proteins FstB and FstC that function as receptors for ferric-acinetobactin and ferric-amonabactin, respectively (Balado et al., 2017; Rey-Varela et al., 2019). Ferric-siderophore uptake is mediated by FstA in some species of $A$. bestiarum and A. salmonicida (BeazHidalgo et al., 2008, 2013). An multifunctional amonabactin receptor of $A$. hydrophila is reported to transport several different siderophores across the membrane (Stintzi and Raymond, 2000). Heme uptake is performed by the membrane receptors HgpB in A. veronii and HutA in A. salmonicida and A. hydrophila, (Najimi et al., 2008a; Maltz et al., 2015).

\section{Virulence Factors and Their Secretion Systems}

Aeromonas utilize several secretion systems such as the secdependent systems T1SS, T2SS, and the sec independent T3SS and T6SS to transport virulence factors, toxins and effectors for infecting diverse fish species (Burr et al., 2002; Tekedar et al., 2019b). The T1SS and T2SS are prominent in almost all Aeromonas species, and a T3SS is detected in species such as A. salmonicida, A. hydrophila, and A. veronii (Citterio and Biavasco, 2015; Tekedar et al., 2019b; Barger et al., 2020). A T6SS was detected for the first time in the genomes of $A$. hydrophila and A. salmonicida (Seshadri et al., 2006; Reith et al., 2008).

\section{Proteases and Their Secretion Systems}

Proteases are among the main virulence factors in Aeromonas (Sakai, 1985). Three types of proteases, metalloproteases, acetylcholinesterases and serineproteases are produced by Aeromonas (Seshadri et al., 2006). Both metallo- and serine proteases are secreted trough a T2SS by A. hydrophila (Sandkvist, 2001). A serine protease (AspA) as well as a glycerophospholipid:cholesterol acetyltransferase (GCAT; a lipase; see below) are secreted by $A$. salmonicida and were previously thought to be main virulence determinants (Buckley et al., 1982; Lee and Ellis, 1990; Whitby et al., 1992; Coleman and Whitby, 1993; Bernoth et al., 1997), however, it has later been shown that their deletion has minor effects on pathogenicity (Vipond et al., 1998).

\section{Hemolysins and Their Secretion Systems}

The presence of hemolytic capability in Aeromonas is associated with the development of lesions and mortality in fish species such as rainbow trout (Ellis et al., 1988). Aeromonas species such as $A$. hydrophila produce $\alpha$-hemolysin (HlyA), a pivotal virulence factor causing cell-rounding and apoptosis (Tekedar et al., 2019a). HlyA is an Rtx-type toxin that are known to be secreted through T1SS in Vibrio species (Boardman and Satchell, 2004). Other pore-forming Hemolysins including H-lysin, T-lysin, salmolysin, ASH1, ASH3 and ASH4 are produced by $A$. salmonicida to lyse erythrocytes (Titball and Munn, 1981, 1985; Nomura et al., 1988; Hirono and Aoki, 1993). Secretion mechanisms of most of the hemolysins discussed here are not yet investigated. However, mutation of a T2SS in A. hydrophila led to impaired hemolytic activity suggesting that the T2SS may be one of a secretion mechanism for at least some 
hemolysins in some members of the Aeromonas species (Barger et al., 2020). Aerolysin, a hemolysin, is a cytolytic pore-forming toxin produced by $A$. hydrophila, A. salmonicida and A. sobria (Chakraborty et al., 1990; Wilmsen et al., 1990; Hirono and Aoki, 1993; Fivaz et al., 2001) which binds to host cells and leads to increased membrane permeability. Aerolysin from A. hydrophila is known to be secreted through a T2SS (Ast et al., 2002).

\section{Lipases and Their Secretion Systems}

Glycerophospholipid:cholesterol acetyltransferase (GCAT) is an unusual lipase involved in the pathogenicity of A. salmonicida (Lee and Ellis, 1990). Combinations of GCAT and lipopolysaccharide (LPS) from A. salmonicida have lethal effects on salmon and rainbow trout (Røsjø et al., 1993; Lachmann et al., 1998). Glycerophospholipid:cholesterol acetyltransferase is secreted through T2SS (Sandkvist, 2001).

\section{Elastase and Their Secretion Systems}

The role of elastases from numerous bacterial pathogens as virulence factor is well documented (Kamath et al., 1998; Cascón et al., 2000; Bleves et al., 2010; Li J. et al., 2019). Among these, an extracellular elastase AhyB produced by A. hydrophila has high elastolytic activity in non-fish model and is essential for pathogenicity (Cascón et al., 2000). AhyB is secreted through T2SS (Cascón et al., 2000; Barger et al., 2020).

\section{DNase and Their Secretion Systems}

A DNase produced and secreted through a T2SS is present in the genome of A. hydrophila (Sandkvist, 2001), which is not yet fully characterized but is predicted to have an impact in virulence.

\section{Toxins and Their Secretion Systems}

An extracellular ADP-ribosylating toxin (AexT) is produced by A. salmonicida, similar to the mechanism of Exoenzyme S (ExoS) in Pseudomonas aeruginosa (Yahr et al., 1996a,b) to modify host cell proteins hence induce disease. One example of this is AexT from A. salmonicida (Burr et al., 2003; Dacanay et al., 2006) where experimental evidence confirmed that this ADPribosylating toxin is directly translocated into the host cytosol by T3SS, similar to its $P$. aeruginosa homolog ExoS (Yahr et al., 1996a,b; Braun et al., 2002; Dacanay et al., 2006; Silver and Graf, 2009).

\section{Effectors and Their Secretion Systems}

T3SSs are generally considered as a key virulence factor in many bacterial pathogens including Aeromonas due to their needle structure enabling injection of specific toxins directly into the host cytosol (Vilches et al., 2004; Dacanay et al., 2006; Coburn et al., 2007; Fast et al., 2009; Austin and Austin, 2016). Several T3SS effectors of Aeromonas are reported to affect the host immune response. AopH and AopO are effectors secreted by A. salmonicida that are secreted via the T3SS and that are highly similar to the effector proteins YopH and YopO from Yersinia species that influence cytoskeleton functions. $\mathrm{YopH}$ dephosphorylates tyrosines in focal adhesion proteins while YopO modulate the function of Rho GTPase to impair its roles in gene transcription, regulate actin cytoskeleton, control cell cycle and intracellular vesicle transport (Aepfelbacher, 2004).
AopP is injected directly into host cells via T3SS to influence the host inflammatory response through inhibiting the nuclear factor- $\kappa B(N F-\kappa B)$ signaling pathway (Fehr et al., 2006; Frey and Origgi, 2016). Other T3SS effector proteins such as the inositol polyphosphate 5-phosphatase Ati2 (Dallaire-Dufresne et al., 2013), HrpJ or BopN-like effector protein (AopN) (Nagamatsu et al., 2009; Crabill et al., 2012; Bergh and Frey, 2014), and ExsE of $A$. salmonicida have been shown to down-regulate host inflammatory responses (Bergh and Frey, 2014). In contrast to this, Aerolysin produced by A. hydrophila is secreted by a T2SS (Sandkvist, 2001).

The T3SS in A. salmonicida can be lost through genome modifications triggered by mobile elements such as insertion sequence (IS) elements when the bacteria are grown at temperatures exceeding $25^{\circ} \mathrm{C}$, changing the strain phenotype from virulent to non-virulent (Tanaka et al., 2012, 2017). Whole genome analysis of 33 strains of A. hydrophila indicate the presence of T3SS, and mutation of two of the T3SS genes $a \circ p B$ (a translator) and aopD (a transmembrane protein) decreases cytotoxicity in carp epithelial cells, reduces virulence in blue gourami and increases phagocytosis (Yu et al., 2004). However, some hyper-virulent strains of $A$. hydrophila lack core components of the T3SS, which may indicate that these pathogens have an alternative secretion mechanism for virulence factors (Hossain et al., 2013; Pang et al., 2015).

\section{Others Fish Pathogens From the Proteobacteria Thiotrichales}

Piscirickettsia salmonis, a member of Piscirickettsiaceae family, genus Piscirickettsia is the causative agent of piscirickettsiosis, also known as salmon rickettsial syndrome (SRS), a disease with high mortality that affects several seawater fish species. $P$. salmonis is non-motile, aerobic, encapsulated and pleomorphic (Fryer et al., 1990, 1992). Piscirickettsia salmonis is an intracellular pathogen causing remarkable economic loss in the aquaculture industry worldwide (Rozas and Enríquez, 2014; Figueroa et al., 2019). Diseased fish are dark in color, anemic where their kidney is swollen and the liver develops lesions (Fryer et al., 1992).

\section{Transmission Routes and Adherence}

The main routes of entry of $P$. salmonis in rainbow trout is through skin and gills (Smith et al., 1999). Studies on $P$. salmonis adherence and mode of invasion using fish eggs show that the pathogen attaches to the ova by means of membrane extension which allows penetration into the cell (Larenas et al., 2003). P. salmonis replicates within membranebound cytoplasmic vacuoles in host cells (Fryer et al., 1992). In stress conditions, $P$. salmonis form a biofilm-like cell aggregate that disintegrates when treated with cellulase, which indicates the presence of polysaccharides that are common for biofilm formation (Marshall et al., 2012). In addition, some lectins show strong binding to the biofilm-like structure, which confirms the presence of an exopolysaccharide (Rozas and Enríquez, 2014).

Piscirickettsia salmonis is capable of growing and surviving in fish macrophages where the bacteria are partially enclosed into vacuole membrane vesicles which escape destruction within 
phagolysosomes (Almendras and Fuentealba, 1997; McCarthy et al., 2005, 2008). Piscirickettsia salmonis possess genes belonging to the Dot/Icm-type IV secretion system (T4SS) which is a type of secretion system utilized as major virulence mechanism in related intracellular pathogens such as Legionella pneumophila and Coxiella burnetii where the system is used for intracellular survival and replication (Thomas et al., 2020). It is shown that $P$. salmonis-containing vacuoles do not fuse with lysosomes, which suggests the presence of bacteria-mediated interference with the endosomal maturation process to ensure bacterial survival. This process depends on the Dot/Icm-type IV secretion system that delivers effector proteins into the host cytosol (Rozas and Enríquez, 2014; Zúñiga et al., 2020). As an additional virulence factor, $P$. salmonis contains lipopolysaccharides with endotoxin activity (Cvitanich et al., 1991). Moreover, P. salmonisinfected fish show a downregulation of genes involved in the adaptive immune response (Tacchi et al., 2011).

The molecular virulence mechanisms of $P$. salmonis are poorly described. However, it is known that extracellular extracts of P. salmonis contain products with cytotoxic and exotoxin effects (Rojas et al., 2013). Outer membrane vesicles containing several outer membrane proteins are released by $P$. salmonis during intracellular replication, including OmpA, which is involved in biofilm formation, adherence or invasion in other species. The chaperonin Hsep60, which is a cytoplasmic component but has been shown to be secreted by some pathogenic bacteria (Garduño et al., 1998; González-López et al., 2013) is presumably involved in adherence to host cell membranes (Ensgraber and Loos, 1992; Huesca et al., 1996). The chaperone HtpG that is involved in pathogenesis of E. tarda (Dang et al., 2011) is detected in the vacuoles during $P$. salmonis infections (Oliver et al., 2016).

Genome analysis of $P$. salmonis shows the presence of several other potential virulence factors (Ortiz-Severín et al., 2019). These include a Phospholipase D-like domain protein similar to the toxin Ymt from Yersinia pestis (Otsuka, 2016); three PipB2 pentapeptide repeate-containing proteins that potentially contribute to replication in intracellular vesicles as described for their homologs in Salmonella enterica (Knodler and SteeleMortimer, 2005), an ATPase related to the flhG ATPase of Campylobacter fetus, which is part of the flagellar apparatus (Henderson et al., 2020), and a glutamate-1-semialdehyde-2,1aminomutase whose Haemophilus somnus homolog is incolved in heme-dependent iron uptake (Villarreal, 2008).

\section{Alteromonadales}

Moritella viscosa, a member of Moritellaceae family, is a rodshaped psychotrophic bacterium that is a main causative agent of winter ulcer, a cold season disease that infects a wide variety of salmonid fish in sea water. Diseased fish shown swelled skin, and develop lesions, hemorrhages and tissue necrosis. The mortality rate of winter ulcer is relatively low but the disease represents a significant fish welfare problem (Bruno et al., 1998; Løvoll et al., 2009).

Adherence of M. viscosa to various mucosal surface has been reported (Tunsjø et al., 2009). Gills are reported as the site of entry of $M$. viscosa from where the pathogens penetrate further into muscles, kidney, spleen and liver, a sign that the pathogen can cause systemic infections (Løvoll et al., 2009). The genome of M. viscosa comprises both flagella and type IV pili system genes. Adherence to fish cells is facilitated by flagella and higher level of adherence is recoded at low temperature. During adhesion by $M$. viscosa, aggregation of F-actin microfilaments of the cell line CHSE was observed and the host cell membrane disrupted (Tunsjø et al., 2009).

Moritella viscosa seem to survive in the host using escape mechanisms that suppress immune responses and help to evade the host immune system (Løvoll et al., 2009). Moritella viscosa contains lipopolysaccharides (LPS) and other outer membrane antigens with potential to protect the pathogen in host cells (Heidarsdottir et al., 2008). Moritella viscosa uses a metallopeptidase, MvP1 (see below for details) that is involved in invasion and dispersion of the pathogen (Bjornsdottir et al., 2009).

The virulence mechanisms of $M$. viscosa have not been extensively studied. The extracellular products (ECP) of the pathogen contain several secreted virulence factors with both cytotoxic and hemolytic activities that lead to the disease phenotype in Atlantic salmon (Bjornsdottir et al., 2009). The ECP contains enzymes and toxins (Benediktsdóttir and Heidarsdóttir, 2007). Genome analysis of $M$. viscosa shows the presence of three types of secretion systems: T1SS, T2SS and T6SS. In addition, vesicle-like structures have been observed by electro-microscopy (Tunsjø et al., 2009; Bjornsdottir et al., 2012).

The metallopeptidase $\mathrm{MvP1}$ is an extracellular protease secreted by $M$. viscosa, formerly identified as vibrolysin with virulence related activities. By itself it is non-lethal to salmon at low concentrations. But MvP1 causes severe hemorrhages and degrades host tissues leading to necrosis, and affecting adhesion. MvP1 is suggested to be involved in invasion and dispersion in the host (Bjornsdottir et al., 2009; Björnsdóttir, 2011).

Virulence-related genes detected in several M. viscosa strains include the T6SS ATPase (clpV) and hemolysis co-regulated proteins (hcp) (Bjornsdottir et al., 2012) as well as Bacterioferritin homologs, which are known to enhance Pseudomonas putida survival in iron depleted environments (Chen et al., 2010). Further examples include a Hemagglutinin (hemG), a lectin that is produced during cell aggregation (Romeo et al., 1986) and a multifunctional autoprocessing repeats-in-toxin (martxA) from the RTX family of toxins that are secreted via a T1SS (Satchell, 2007).

\section{Pseudomonadales}

Pseudomonas anguilliseptica, is a rod-shaped and flagellated member of the Pseudomonadaceae family (Palleroni, 2010). Pseudomonas anguilliseptica is a known pathogen and a serious threat to the production of a variety of fish species cultured in marine and brackish water in different parts of the world (Stewart et al., 1983; Wiklund and Bylund, 1990; Toranzo and Barja, 1993; Lönnström et al., 1994; Berthe et al., 1995; Fernández et al., 2002; Austin and Austin, 2016). The pathogen causes a disease named "red spot disease" also known as "sekitenbyo," a hemorrhagic septicemia that was first discovered in Japan (Wakabayashi and Egusa, 1972). The disease caused by $P$. anguilliseptica is sometimes associated to winter disease; however, 
this is considered as misrepresentation as some authors consider winter disease as multifactorial condition linked with cold and stressful environments (Tort et al., 1998; Contessi et al., 2006).

Despite the seriousness of the threat of $P$. anguilliseptica to the aquaculture industry worldwide, knowledge on virulence mechanisms of this pathogen is scarce. The site of entry for $P$. anguilliseptica is not clear, but the presence of flagella indicates that the pathogen has the capacity for motility and host cell adhesion (Berthe et al., 1995). P. anguilliseptica possesses capsular $(\mathrm{K})$ antigens, which was first observed in a case of eel infection. This antigen may be used for escaping complement mediated killing by fish serum (Nakai, 1985; López-Romalde et al., 2003b).

\section{DISCUSSION}

This review can only give a glimpse on the many variations of protein secretion in commercially relevant fish pathogens. Molecular information is extremely scarce in many cases, despite the importance of the diseases caused. Part of this problem is that in most cases, the researchers working with fish diseases by tradition are not molecular biologists, but veterinarians more interested in the treatment of acute conditions using traditional antimicrobial therapies. Vaccine development in the aquaculture industry is also not based on molecular targets and studies, but rather relies on heat-killed bacterial extracts for cost reasons. The information is even more scarce for Gram-positive fish pathogens, where almost all molecular information on virulence

\section{REFERENCES}

Abayneh, T., Colquhoun, D. J., and Sørum, H. (2013). Edwardsiella piscicida sp. nov., a novel species pathogenic to fish. J. Appl. Microbiol. 114, 644-654. doi: 10.1111/jam.12080

Abbott, S. L. (2011). Klebsiella, Enterobacter, Citrobacter, Serratia, Plesiomonas, And Other Enterobacteriaceae, Manual Clinical Microbiology, 10th Edn. Washington, DC: American Society of Microbiology, 639-657.

Abbott, S. L., and Janda, J. M. (2006). The genus edwardsiella. Prokaryotes 6, 72-89. doi: 10.1007/0-387-30746-x_4

Abby, S. S., Cury, J., Guglielmini, J., Néron, B., Touchon, M., and Rocha, E. P. C. (2016). Identification of protein secretion systems in bacterial genomes. Sci. Rep. 6:23080.

Abdelhamed, H., Lawrence, M. L., and Karsi, A. (2017). The role of TonB gene in edwardsiella ictaluri virulence. Front. Physiol. 8:1066. doi: 10.3389/fphys.2017. 01066

Abdelhamed, H., Lu, J., Lawrence, M. L., and Karsi, A. (2016). Ferric hydroxamate uptake system contributes to Edwardsiella ictaluri virulence. Microb. Pathog. 100, 195-200. doi: 10.1016/j.micpath.2016.09.018

Abdelhamed, H., Lu, J., Shaheen, A., Abbass, A., Lawrence, M. L., and Karsi, A. (2013). Construction and evaluation of an Edwardsiella ictaluri fhuC mutant. Vet. Microbiol. 162, 858-865. doi: 10.1016/j.vetmic.2012. 11.006

Aepfelbacher, M. (2004). Modulation of Rho GTPases by type III secretion system translocated effectors of Yersinia. Rev. Physio. Biochem. Pharmacol. 152, 65-77. doi: 10.1007/s10254-004-0035-3

Ali, A. (1996). Aeromonas bestiarum sp. nov. (formerly genomospecies DNA group 2 A. hydrophila), a new species isolated from non-human sources. Med. Microbiol. Lett. 5, 156-165.

Alice, A. F., Naka, H., and Crosa, J. H. (2008). Global gene expression as a function of the iron status of the bacterial cell: influence of differentially expressed genes mechanisms is only inferred from closely related humanpathogenic species. This is especially true for fish diseases with very broad and general symptoms that are hard to connect to a single pathogenic species or strain, such as streptococcosis, that is caused by diverse Streptococcus species depending on the host fish (Buller, 2004). A notable exception is Mycobacterium marinum, the causative agent of fish tuberculosis, that has received a lot of attention because it infects the model species zebrafish and thus makes a formidable model system for the study of human tuberculosis disease mechanisms (Bouz and Al Hasawi, 2018).

We strongly believe that a better molecular understanding of protein secretion in fish pathogens can help to develop more targeted therapies for the aquaculture industry, with the aim to avoid the use of antibiotics in aquatic habitats, and hope that this overview helps interested researchers in their quest to develop new vaccines or drugs.

\section{AUTHOR CONTRIBUTIONS}

SM wrote the manuscript. DL edited the manuscript. Both authors contributed to the article and approved the submitted version.

\section{FUNDING}

This work was supported by the Research Council of Norway, grant 302723.

in the virulence of the human pathogen Vibrio vulnificus. Infect. Immun. 76, 4019-4037. doi: 10.1128/IAI.00208-08

Allan, B. J., and Stevenson, R. M. W. (1981). Extracellular virulence factors of Aeromonas hydrophila in fish infections. Can. J. Microbiol. 27, 1114-1122. doi: $10.1139 / \mathrm{m} 81-174$

Almendras, F. E., and Fuentealba, I. C. (1997). Salmonid rickettsial septicemia caused by Piscirickettsia salmonis: a review. Dis. Aquat. Org. 29, 137-144. doi: $10.3354 /$ dao029137

Alteri, C. J., and Mobley, H. L. T. (2016). The versatile type VI secretion system . Microbiol. Spectr 4. doi: 10.1128/microbiolspec.VMBF-0026-2015

Alvarez, B., Alvarez, J., Menendez, A., and Guijarro, J. A. (2008). A mutant in one of two exbD loci of a TonB system in Flavobacterium psychrophilum shows attenuated virulence and confers protection against cold water disease. Microbiology 154, 1144-1151. doi: 10.1099/mic.0.2007/010900-0

Alvarez, B., Secades, P., Prieto, M., McBride, M. J., and Guijarro, J. A. (2006). A mutation in Flavobacterium psychrophilum tlpB inhibits gliding motility and induces biofilm formation. Appl. Environ. Microbiol. 72, 4044-4053. doi: 10.1128/AEM.00128-06

Amaro, C., Sanjuán, E., Fouz, B., Pajuelo, D., Lee, C. T., Hor, L. I., et al. (2015). The Fish Pathogen Vibrio vulnificus biotype 2: epidemiology, phylogeny, and virulence factors involved in warm-water vibriosis. Microbiol. Spectr. 3. doi: 10.1128/microbiolspec.VE-0005-2014

An, S., Couteau, C., Luo, F., Neveu, J., and DuBow, M. S. (2013). Bacterial diversity of surface sand samples from the gobi and taklamaken deserts. Microb. Ecol. 66, 850-860. doi: 10.1007/s00248-013-0276-2

Anderson, C. J., and Kendall, M. M. (2017). Salmonella enterica serovar typhimurium strategies for host adaptation. Front. Microbiol. 8:1983. doi: 10. 3389/fmicb.2017.01983

Arias, C. R., Olivares-Fuster, O., Hayden, K., Shoemaker, C. A., Grizzle, J. M., and Klesius, P. H. (2007). First report of Yersinia ruckeri biotype 2 in the USA. J. Aquat. Anim. Health 19, 35-40. doi: 10.1577/H06-011.1 
Ast, V. M. I, Schoenhofen, C., Langen, G. R., Stratilo, C. W., Chamberlain, M. D., and Howard, S. P. (2002). Expression of the ExeAB complex of Aeromonas hydrophila is required for the localization and assembly of the ExeD secretion port multimer. Mol. Microbiol. 44, 217-231. doi: 10.1046/j.1365-2958.2002. 02870.x

Austin, B., and Austin, D. A. (2012). Bacterial Fish Pathogens. Cham: Springer.

Austin, B., and Austin, D. A. (2016). Bacterial Fish Pathogens: Disease Of Farmed And Wild Fish. Cham: Springer.

Austin, B., Pride, A. C., and Rhodie, G. A. (2003). Association of a bacteriophage with virulence in Vibrio harveyi. J. Fish. Dis. 26, 55-58. doi: 10.1046/j.13652761.2003.00413.x

Austin, D. A., Robertson, P. A., and Austin, B. (2003). Recovery of a new biogroup of Yersinia ruckeri from diseased rainbow trout (Oncorhynchus mykiss, Walbaum). Syst. Appl. Microbiol. 26, 127-131. doi: 10.1078/ 072320203322337416

Avendaño-Herrera, R., Toranzo, A. E., Romalde, J. L., Lemos, M. L., and Magariños, B. (2005). Iron uptake mechanisms in the fish pathogen Tenacibaculum maritimum. Appl. Environ. Microbiol. 71, 6947-6953. doi: 10. 1128/AEM.71.11.6947-6953.2005

Balado, M., Lages, M. A., Fuentes-Monteverde, J. C., Martínez-Matamoros, D., Rodríguez, J., Jiménez, C., et al. (2018). The siderophore piscibactin is a relevant virulence factor for Vibrio anguillarum favored at low temperatures. Front. Microbiol. 9:1766. doi: 10.3389/fmicb.2018.01766

Balado, M., Osorio, C. R., and Lemos, M. L. (2008). Biosynthetic and regulatory elements involved in the production of the siderophore vanchrobactin in Vibrio anguillarum. Microbiology 154, 1400-1413. doi: 10.1099/mic.0.2008/016618-0

Balado, M., Osorio, C. R., and Lemos, M. L. (2009). FvtA is the receptor for the siderophore vanchrobactin in Vibrio anguillarum: utility as a route of entry for vanchrobactin analogues. Appl. Environ. Microbiol. 75, 2775-2783. doi: 10.1128/AEM.02897-08

Balado, M., Segade, Y., Rey, D., Osorio, C. R., Rodríguez, J., Lemos, M. L., et al. (2017). Identification of the ferric-acinetobactin outer membrane receptor in Aeromonas salmonicida subsp. salmonicida and structure-activity relationships of synthetic acinetobactin analogues. ACS Chem. Biol. 12, 479-493. doi: 10. 1021/acschembio.6b00805

Balado, M., Souto, A., Vences, A., Careaga, V. P., Valderrama, K., Segade, Y., et al. (2015). Two catechol siderophores, acinetobactin and amonabactin, are simultaneously produced by Aeromonas salmonicida subsp. salmonicida sharing part of the biosynthetic pathway. ACS Chem. Biol. 10, 2850-2860. doi: 10.1021/acschembio.5b00624

Baldissera, M. D., Souza, C. F., Junior, G. B., Moreira, K. L. S., da Veiga, M. L., da Rocha, M. I. U. M., et al. (2018). Citrobacter freundii impairs the phosphoryl transfer network in the gills of Rhamdia quelen: impairment of bioenergetics homeostasis. Microb. Pathog. 117, 157-161. doi: 10.1016/j.micpath.2018. 02.040

Baldwin, T. J., and Newton, J. C. (1993). Pathogenesis of enteric septicemia of channel catfish, caused by Edwardsiella ictaluri: bacteriologic and light and electron microscopic findings. J. Aquat. Anim. Health 5, 189-198. doi: 10.1577/ 1548-8667(1993)005<0189:poesoc > 2.3.co;2

Balebona, M. C., Andreu, M. J., Bordas, M. A., Zorrilla, I., Moriñigo, M. A., and Borrego, J. J. (1998). Pathogenicity of Vibrio alginolyticus for cultured gilthead sea bream (Sparus aurata L.). Appl. Environ. Microbiol. 64, 4269-4275. doi: 10.1128/AEM.64.11.4269-4275.1998

Bandeira Junior, G., Dos Santos, A. C., Souza, C. F., Baldissera, M. D., Moreira, K., da Veiga, M. L., et al. (2018). Citrobacter freundii infection in silver catfish (Rhamdia quelen): hematological and histological alterations. Microb. Pathog. 125, 276-280. doi: 10.1016/j.micpath.2018.09.038

Barbier, P., Rochat, T., Mohammed, H. H., Wiens, G. D., Bernardet, J.-F., Halpern, D., et al. (2020). The type IX secretion system is required for virulence of the fish pathogen Flavobacterium psychrophilum. Appl. Environ. Microbiol. 86:e01769-17.

Barbieri, J. T., and Sun, J. (2004). Pseudomonas aeruginosa exos and exot. Rev. Physiol. Biochem. Pharmacol. 152, 79-92. doi: 10.1007/s10254-004-0031-7

Barger, P. C., Liles, M. R., and Newton, J. C. (2020). Type II secretion is essential for virulence of the emerging fish pathogen, hypervirulent Aeromonas hydrophila. Front. Vet. Sci. 7:706. doi: 10.3389/fvets.2020.574113

Barghouthi, S., Young, R., Olson, M. O., Arceneaux, J. E., Clem, L. W., and Byers, B. R. (1989b). Amonabactin, a novel tryptophan-or phenylalanine-containing phenolate siderophore in Aeromonas hydrophila. J. Bacteriol. 171, 1811-1816. doi: 10.1128/jb.171.4.1811-1816.1989

Barghouthi, S., Young, R., Arceneaux, J. E. L., and Byers, B. R. (1989a). Physiological control of amonabactin biosynthesis in Aeromonas hydrophila. Biol. Metals 2, 155-160. doi: 10.1007/BF01142554

Bartkova, S., Kokotovic, B., and Dalsgaard, I. (2017). Infection routes of Aeromonas salmonicida in rainbow trout monitored in vivo by real-time bioluminescence imaging. J. Fish Dis. 40, 73-82. doi: 10.1111/jfd.12491

Beaz-Hidalgo, R., and Figueras, M. J. (2013). Aeromonas spp. whole genomes and virulence factors implicated in fish disease. J. Fish Dis. 36, 371-388. doi: 10.1111/jfd. 12025

Beaz-Hidalgo, R., Latif-Eugenín, F., and Figueras, M. J. (2013). The improved PCR of the fstA (ferric siderophore receptor) gene differentiates the fish pathogen Aeromonas salmonicida from other Aeromonas species. Vet. Microbiol. 166, 659-663. doi: 10.1016/j.vetmic.2013.06.028

Beaz-Hidalgo, R., Magi, G. E., Balboa, S., Barja, J. L., and Romalde, J. L. (2008). Development of a PCR protocol for the detection of Aeromonas salmonicida in fish by amplification of the fstA (ferric siderophore receptor) gene. Vet. Microbiol. 128, 386-394. doi: 10.1016/j.vetmic.2007.10.004

Benediktsdóttir, E., and Heidarsdóttir, K. J. (2007). Growth and lysis of the fish pathogen Moritella viscosa. Lett. Appl. Microbiol. 45, 115-120. doi: 10.1111/j. 1472-765X.2007.02161.x

Bergh, P. V., and Frey, J. (2014). Aeromonas salmonicida subsp. salmonicida in the light of its type-three secretion system. Microb. Biotechnol. 7, 381-400. doi: 10.1111/1751-7915.12091

Bernardet, J. F., and Bowman, J. P. (2006). The genus flavobacterium. Prokaryotes 7, 481-531.

Bernardet, J.-F., Segers, P., Vancanneyt, M., Berthe, F., Kersters, K., and Vandamme, P. (1996). Cutting a gordian knot: emended classification and description of the genus Flavobacterium, emended description of the family Flavobacteriaceae, and proposal of Flavobacterium hydatis nom. nov. (basonym, Cytophaga aquatilis Strohl and Tait 1978). Int. J. Syst. Evol. Microbiol. 46, 128-148. doi: 10.1099/00207713-46-1-128

Bernoth, E. M., Ellis, A. E., Midtlyng, P. J., Olivier, G., and Smith, P. (1997). Furunculosis: Multidisciplinary Fish Disease Research. Amsterdam: Elsevier.

Berthe, F. C. J., Michel, C., and Bernardet, J.-F. (1995). Identification of Pseudomonas anguilliseptica isolated from several fish species in France. Dis. Aquat. Org. 21, 151-155.

Bertolini, J. M., Wakabayashi, H., Watral, V. G., Whipple, M. J., and Rohovec, J. S. (1994). Electrophoretic detection of proteases from selected strains of Flexibacter psychrophilus and assessment of their variability. J. Aquat. Anim. Health 6, 224-233. doi: 10.1577/1548-8667(1994)006<0224:edopfs >2.3.co;2

Beveridge, T. J., Pouwels, P. H., Sára, M., Kotiranta, A., Lounatmaa, K., Kari, K., et al. (1997). Functions of S-layers. FEMS Microbiol. Rev. 20, 99-149.

Bhoite, S., van Gerven, N., Chapman, M. R., Remaut, H., Sandkvist, M., Cascales, E., et al. (2019). Curli biogenesis: bacterial amyloid assembly by the Type VIII secretion pathway. EcoSal Plus 8. doi: 10.1128/ecosalplus.ESP-0037-2018

Björnsdóttir, B. (2011). Moritella viscosa Virulence - Extracellular Products And Host-Pathogen Interaction. Ph.D. thesis. Reykjavík: University of Iceland.

Bjornsdottir, B., Fridjonsson, O. H., Magnusdottir, S., Andresdottir, V., Hreggvidsson, G. O., and Gudmundsdottir, B. K. (2009). Characterisation of an extracellular vibriolysin of the fish pathogen Moritella viscosa. Vet. Microbiol. 136, 326-334. doi: 10.1016/j.vetmic.2008.11.020

Bjornsdottir, B., Hjerde, E., Bragason, B. T., Gudmundsdottir, T., Willassen, N. P., and Gudmundsdottir, B. K. (2012). Identification of type VI secretion systems in Moritella viscosa. Vet. Microbiol. 158, 436-442.

Bleves, S., Viarre, V., Salacha, R., Michel, G. P. F., Filloux, A., and Voulhoux, R. (2010). Protein secretion systems in Pseudomonas aeruginosa: a wealth of pathogenic weapons. Int. J. Med. Microbiol. 300, 534-543. doi: 10.1016/j.ijmm. 2010.08.005

Boardman, B. K., and Satchell, K. J. F. (2004). Vibrio cholerae strains with mutations in an atypical type I secretion system accumulate RTX toxin intracellularly. J. Bacteriol. 186, 8137-8143. doi: 10.1128/JB.186.23.8137-8143.2004

Bouz, G., and Al Hasawi, N. (2018). The zebrafish model of tuberculosis - no lungs needed. Crit. Rev. Microbiol. 44, 779-792. doi: 10.1080/1040841x.2018.1523132

Boyd, A. P., and Cornelis, G. R. (2001). "Chapter 6 - yersinia," in Principles of Bacterial Pathogenesis, ed. E. A. Groisman (San Diego, CA: Academic Press), 227-264. 
Braun, M., Stuber, K., Schlatter, Y., Wahli, T., Kuhnert, P., and Frey, J. (2002). Characterization of an ADP-ribosyltransferase toxin (AexT) from Aeromonas salmonicida subsp. salmonicida. J. Bacteriol. 184, 1851-1858. doi: 10.1128/JB. 184.7.1851-1858.2002

Braun, T. F., and McBride, M. J. (2005). Flavobacterium johnsoniae GldJ is a lipoprotein that is required for gliding motility. J. Bacteriol. 187, 2628-2637. doi: 10.1128/JB.187.8.2628-2637.2005

Braun, T. F., Khubbar, M. K., Saffarini, D. A., and McBride, M. J. (2005). Flavobacterium johnsoniae gliding motility genes identified by mariner mutagenesis. J. Bacteriol. 187, 6943-6952. doi: 10.1128/JB.187.20.6943-6952. 2005

Braun, V., Hantke, K., and Koester, W. (1998). Bacterial iron transport: mechanisms, genetics, and regulation. Met. Ions Biol. Syst. 35, 67-146.

Broberg, C. A., Zhang, L., Gonzalez, H., Laskowski-Arce, M. A., and Orth, K. (2010). A Vibrio effector protein is an inositol phosphatase and disrupts host cell membrane integrity. Science 329, 1660-1662. doi: 10.1126/science.1192850

Broeck, D. V., Horvath, C., and De Wolf, M. J. (2007). Vibrio cholerae: cholera toxin. Internat. J. Biochem. Cell Biol. 39, 1771-1775. doi: 10.1016/j.biocel.2007. 07.005

Bruno, D. W., Griffiths, J., Petrie, J., and Hastings, T. S. (1998). Vibrio viscosus in farmed Atlantic salmon Salmo salar in Scotland: field and experimental observations. Dis. Aquat. Org. 34, 161-166. doi: 10.3354/dao034161

Buckley, J. T., Halasa, L. N., and MacIntyre, S. (1982). Purification and partial characterization of a bacterial phospholipid: cholesterol acyltransferase. J. Biol. Chem. 257, 3320-3325.

Buller, N. B. (2004). Bacteria From Fish And Other Aquatic Animals: A Practical Identification Manual. Wallingford: CABI.

Burdette, D. L., Seemann, J., and Orth, K. (2009). Vibrio VopQ induces PI3kinase-independent autophagy and antagonizes phagocytosis. Mol. Microbiol. 73, 639-649. doi: 10.1111/j.1365-2958.2009.06798.x

Burdette, L. A., Leach, S. A., Wong, H. T., and Tullman-Ercek, D. (2018). Developing Gram-negative bacteria for the secretion of heterologous proteins. Microb. Cell Fact. 17, 196-196.

Burr, S. E., Stuber, K., and Frey, J. (2003). The ADP-ribosylating toxin, AexT, from Aeromonas salmonicida subsp. salmonicida is translocated via a type III secretion pathway. J. Bacteriol. 185, 6583-6591. doi: 10.1128/JB.185.22.65836591.2003

Burr, S. E., Stuber, K., Wahli, T., and Frey, J. (2002). Evidence for a type III secretion system in Aeromonas salmonicida subsp. salmonicida. J. Bacteriol. 184, 5966-5970. doi: 10.1128/jb.184.21.5966-5970.2002

Byers, B. R., Massad, G., Barghouthi, S., and Arceneaux, J. E. (1991). Iron acquisition and virulence in the motile aeromonads: siderophore-dependent and -independent systems. Experientia 47, 416-418.

Cahill, M. M. (1990). A review virulence factors in motile Aeromonas species. J. Appl. Bacteriol. 69, 1-16. doi: 10.1501/vetfak_0000000684

Cai, S. H., Wu, Z. H., Jian, J. C., and Lu, Y. S. (2007). Cloning and expression of gene encoding the thermostable direct hemolysin from Vibrio alginolyticus strain HY9901, the causative agent of vibriosis of crimson snapper (Lutjanus erythopterus). J. Appl. Microbiol. 103, 289-296. doi: 10.1111/j.1365-2672.2006. 03250.x

Calvez, S., Gantelet, H., Blanc, G., Douet, D. G., and Daniel, P. (2014). Yersinia ruckeri Biotypes 1 and 2 in France: presence and antibiotic susceptibility. Dis. Aquat. Organ. 109, 117-126. doi: 10.3354/dao02725

Cascón, A., Yugueros, J., Temprano, A., Sánchez, M., Hernanz, C., Luengo, J. M., et al. (2000). A major secreted elastase is essential for pathogenicity of Aeromonas hydrophila. Infect. Immun. 68, 3233-3241. doi: 10.1128/IAI.68.6. 3233-3241.2000

Castillo, D., Christiansen, R. H., Dalsgaard, I., Madsen, L., and Middelboe, M. (2015). Bacteriophage resistance mechanisms in the fish pathogen Flavobacterium psychrophilum: linking genomic mutations to changes in bacterial virulence factors. Appl. Environ. Microbiol. 81, 1157-1167. doi: 10. 1128/AEM.03699-14

Castro, N., Osorio, C. R., Buján, N., Fuentes, J. C., Rodríguez, J., Romero, M., et al. (2016). Insights into the virulence-related genes of Edwardsiella tarda isolated from turbot in Europe: genetic homogeneity and evidence for vibrioferrin production. J. Fish Dis. 39, 565-576. doi: 10.1111/jfd.12389

Cavaillon, J. M. (2018). Exotoxins and endotoxins: inducers of inflammatory cytokines. Toxicon 149, 45-53. doi: 10.1016/j.toxicon.2017.10.016
Chakraborty, S., Sivaraman, J., Leung, K. Y., and Mok, Y.-K. (2011). Twocomponent PhoB-PhoR regulatory system and ferric uptake regulator sense phosphate and iron to control virulence genes in type III and VI secretion systems of Edwardsiella tarda. J. Biol. Chem. 286, 39417-39430. doi: 10.1074/ jbc.M111.295188

Chakraborty, T., Schmid, A., Notermans, S., and Benz, R. (1990). Aerolysin of Aeromonas sobria: evidence for formation of ion-permeable channels and comparison with alpha-toxin of Staphylococcus aureus. Infect. Immun. 58, 2127-2132. doi: 10.1128/iai.58.7.2127-2132.1990

Chen, J. D., Lai, S. Y., and Huang, S. L. (1996). Molecular cloning, characterization, and sequencing of the hemolysin gene from Edwardsiella tarda. Arch. Microbiol. 165, 9-17. doi: $10.1007 / \mathrm{s} 002030050290$

Chen, S., Bleam, W. F., and Hickey, W. J. (2010). Molecular analysis of two bacterioferritin genes, bfralpha; and bfrbeta, in the model rhizobacterium Pseudomonas putida KT2440. Appl. Environ. Microbiol. 76, 5335-5343. doi: 10.1128/AEM.00215-10

Chen, S., Blom, J., Loch, T. P., Faisal, M., and Walker, E. D. (2017). The emerging fish pathogen Flavobacterium spartansii isolated from Chinook salmon: comparative genome analysis and molecular manipulation. Front. Microbiol. 8:2339. doi: 10.3389/fmicb.2017.02339

Cheng, Z.-X., Gong, Q.-Y., Wang, Z., Chen, Z.-G., Ye, J.-Z., Li, J., et al. (2017). Edwardsiella tarda tunes tricarboxylic acid cycle to evade complementmediated killing. Front. Immunol. 8:1706. doi: 10.3389/fimmu.2017.01706

Chopra, A. K., Houston, C. W., Peterson, J. W., and Jin, G.-F. (1993). Cloning, expression, and sequence analysis of a cytolytic enterotoxin gene from Aeromonas hydrophila. Can. J. Microbiol. 39, 513-523. doi: 10.1139/m93-073

Christie, P. J., Whitaker, N., and González-Rivera, C. (2014). Mechanism and structure of the bacterial type IV secretion systems. Biochim. Biophys. Acta Mol. Cell Res. 1843, 1578-1591.

Chu, S., Cavaignac, S., Feutrier, J., Phipps, B. M., Kostrzynska, M., Kay, W. W., et al. (1991). Structure of the tetragonal surface virulence array protein and gene of Aeromonas salmonicida. J. Biol. Chem. 266, 15258-15265.

Cianciotto, N. P., and White, R. C. (2017). Expanding role of type II secretion in bacterial pathogenesis and beyond. Infect. Immun. 85:e00014-e17.

Citterio, B., and Biavasco, F. (2015). Aeromonas hydrophila virulence. Virulence 6, $417-418$.

Coburn, B., Sekirov, I., and Finlay, B. B. (2007). Type III secretion systems and disease. Clin. Microbiol. Rev. 20, 535-549.

Coleman, G., and Whitby, P. W. (1993). A comparison of the amino acid sequence of the serine protease of the fish pathogen Aeromonas salmonicida subsp. salmonicida with those of other subtilisin-type enzymes relative to their substrate-binding sites. J. Gen. Microbiol. 139, 245-249. doi: 10.1099/00221287139-2-245

Colwell, R. R., MacDonell, M. T., and De Ley, J. (1986). Proposal to recognize the family Aeromonadaceae fam. nov. Int. J. Syst. Evol Microbiol. 36, 473-477.

Contessi, B., Volpatti, D., Gusmani, L., and Galeotti, M. (2006). Evaluation of immunological parameters in farmed gilthead sea bream, Sparus aurata L., before and during outbreaks of 'winter syndrome'. J. Fish Dis. 29, 683-690. doi: $10.1111 / \mathrm{j} .1365-2761.2006 .00765 . \mathrm{x}$

Costa, T. R. D., Felisberto-Rodrigues, C., Meir, A., Prevost, M. S., Redzej, A., Trokter, M., et al. (2015). Secretion systems in Gram-negative bacteria: structural and mechanistic insights. Nat. Rev. Microbiol. 13, 343-359. doi: 10.1038/nrmicro3456

Crabill, E., Karpisek, A., and Alfano, J. R. (2012). The Pseudomonas syringae HrpJ protein controls the secretion of type III translocator proteins and has a virulence role inside plant cells. Mol. Microbiol. 85, 225-238. doi: 10.1111/j. 1365-2958.2012.08097.x

Craig, L., Forest, K. T., and Maier, B. (2019). Type IV pili: dynamics, biophysics and functional consequences. Nat. Rev. Microbiol. 17, 429-440. doi: 10.1038/ s41579-019-0195-4

Cress, B. F., Englaender, J. A., He, W., Kasper, D., Linhardt, R. J., and Koffas, M. A. G. (2014). Masquerading microbial pathogens: capsular polysaccharides mimic host-tissue molecules. FEMS Microbiol. Rev. 38, 660-697. doi: 10.1111/ 1574-6976.12056

Croxatto, A., Lauritz, J., Chen, C., and Milton, D. L. (2007). Vibrio anguillarum colonization of rainbow trout integument requires a DNA locus involved in exopolysaccharide transport and biosynthesis. Environ. Microbiol. 9, 370-382. doi: 10.1111/j.1462-2920.2006.01147.x 
Cvitanich, J. D., Garaten, O., and Smith, C. E. (1991). The isolation of a rickettsialike organism causing disease and mortality in Chilean salmonids and its confirmation by Koch's postulate. J. Fish Dis. 14, 121-145. doi: 10.1111/j.13652761.1991.tb00584.x

Dacanay, A., Knickle, L., Solanky, K. S., Boyd, J. M., Walter, J. A., Brown, L. L., et al. (2006). Contribution of the type III secretion system (TTSS) to virulence of Aeromonas salmonicida subsp. salmonicida. Microbiology 152, 1847-1856. doi: 10.1099/mic.0.28768-0

Dai, F., Li, Y., Shao, Y., Li, C., and Zhang, W. (2020). FliC of Vibrio splendidusrelated strain involved in adhesion to Apostichopus japonicus. Microb. Pathog. 149:104503. doi: 10.1016/j.micpath.2020.104503

Dai, F., Zhang, W., Zhuang, Q., Shao, Y., Zhao, X., Lv, Z., et al. (2019). Dihydrolipoamide dehydrogenase of Vibrio splendidus is involved in adhesion to Apostichopus japonicus. Virulence 10, 839-848. doi: 10.1080/21505594.2019. 1682761

Dallaire-Dufresne, S., Barbeau, X., Sarty, D., Tanaka, K. H., Denoncourt, A. M., Lagüe, P., et al. (2013). Aeromonas salmonicida Ati2 is an effector protein of the type three secretion system. Microbiology 159, 1937-1945. doi: 10.1099/mic.0. 067959-0

Dalsgaard, I., and Madsen, L. (2000). Bacterial pathogens in rainbow trout, Oncorhynchus mykiss (Walbaum), reared at Danish freshwater farms. J. Fish Dis. 23, 199-209. doi: 10.1046/j.1365-2761.2000.00242.x

Dang, W., Hu, Y., and Sun, L. (2011). HtpG is involved in the pathogenesis of Edwardsiella tarda. Vet. Microbiol. 152, 394-400. doi: 10.1016/j.vetmic.2011. 05.030

Davies, R. L., and Frerichs, G. N. (1989). Morphological and biochemical differences among isolates of Yersinia ruckeri obtained from wide geographical areas. J. Fish Dis. 12, 357-365.

de Haan, L., and Hirst, T. R. (2000). Cholera toxin and related enterotoxins: a cell biological and immunological perspective. J. Nat. Toxins 9, 281-297.

Declercq, A. M., Haesebrouck, F., Van den Broeck, W., Bossier, P., and Decostere, A. (2013). Columnaris disease in fish: a review with emphasis on bacterium-host interactions. Vet. Res. 44:27. doi: 10.1186/1297-9716-44-27

Decostere, A., Haesebrouck, F., Van Driessche, E., Charlier, G., and Ducatelle, R. (1999). Characterization of the adhesion of Flavobacterium columnare (Flexibacter columnaris) to gill tissue. J. Fish Dis. 22, 465-474.

Deng, W., Marshall, N. C., Rowland, J. L., McCoy, J. M., Worrall, L. J., Santos, A. S., et al. (2017). Assembly, structure, function and regulation of type III secretion systems. Nat. Rev. Microbiol. 15, 323-337. doi: 10.1038/nrmicro.2017.20

Denkin, S. M., and Nelson, D. R. (1999). Induction of protease activity in Vibrio anguillarum by gastrointestinal mucus. Appl. Environ. Microbiol. 65, 35553560. doi: 10.1128/AEM.65.8.3555-3560.1999

Denkin, S. M., and Nelson, D. R. (2004). Regulation of Vibrio anguillarum empA metalloprotease expression and its role in virulence. Appl. Environ. Microbiol. 70, 4193-4204. doi: 10.1128/AEM.70.7.4193-4204.2004

Dubytska, L. P., Rogge, M. L., Thune, R. L., and Blokesch, M. (2016). Identification and characterization of putative translocated effector proteins of the Edwardsiella ictaluri Type III secretion system. mSphere 1:e00039-e16. doi: 10.1128/mSphere.00039- 16

Duchaud, E., Boussaha, M., Loux, V., Bernardet, J. F., Michel, C., Kerouault, B. et al. (2007). Complete genome sequence of the fish pathogen Flavobacterium psychrophilum. Nat. Biotechnol. 25, 763-769. doi: 10.1038/nbt1313

Dulberger, C. L., Rubin, E. J., and Boutte, C. C. (2020). The mycobacterial cell envelope - a moving target. Nat. Rev. microbiol. 18, 47-59. doi: 10.1038/ s41579-019-0273-7

Dumetz, F., LaPatra, S. E., Duchaud, E., Claverol, S., and Le Henaff, M. (2007). The Flavobacterium psychrophilum OmpA, an outer membrane glycoprotein, induces a humoral response in rainbow trout. J. Appl. Microbiol. 103, 14611470. doi: 10.1111/j.1365-2672.2007.03359.x

Dumpala, P. R., Gülsoy, N., Lawrence, M. L., and Karsi, A. (2010). Proteomic analysis of the fish pathogen Flavobacterium columnare. Proteome Sci. 8, 26-26.

Ellis, A. E., Burrows, A. S., and Stapleton, K. J. (1988). Lack of relationship between virulence of Aeromonas salmonicida and the putative virulence factors: a-layer, extracellular proteases and extracellular haemolysins. J. Fish Dis. 11, 309-323. doi: 10.1111/j.1365-2761.1988.tb01227.x

Endo, Y., Takahashi, M., and Fujita, T. (2006). Lectin complement system and pattern recognition. Immunobiology 211, 283-293. doi: 10.1016/j.imbio.2006. 01.003
Ensgraber, M., and Loos, M. (1992). A 66-kilodalton heat shock protein of Salmonella typhimurium is responsible for binding of the bacterium to intestinal mucus. Infect. Immun. 60, 3072-3078. doi: 10.1128/iai.60.8.30723078.1992

Espelid, S., Hjelmeland, K., and Jørgensen, T. (1987). The specificity of Atlantic salmon antibodies made against the fish pathogen Vibrio salmonicida, establishing the surface protein VS-P1 as the dominating antigen. Dev. Comp. Immunol. 11, 529-537. doi: 10.1016/0145-305x(87)90042-5

Ewing, W. H., Mcwhorter, A. C., Escobar, M. R., and Lubin, A. H. (1965) Edwardsiella, a new genus of Enterobacteriaceae based on a new species. E. tarda. Int. J. Syst. Evol. Microbiol. 15, 33-38. doi: 10.1099/00207713-15-1-33 Fadl, A. A., Galindo, C. L., Sha, J., Erova, T. E., Houston, C. W., Olano, J. P., et al. (2006). Deletion of the genes encoding the type III secretion system and cytotoxic enterotoxin alters host responses to Aeromonas hydrophila infection. Microb. Pathog. 40, 198-210. doi: 10.1016/j.micpath.2006.01.003

Fang, H. M., Ge, R., and Sin, Y. M. (2004). Cloning, characterisation and expression of Aeromonas hydrophila major adhesin. Fish Shellfish Immunol. 16, 645-658. doi: 10.1016/j.fsi.2003.10.003

FAO (2020). The State Of World Fisheries And Aquaculture (SOFIA) 2020. Rome: FAO.

Fast, M. D., Tse, B., Boyd, J. M., and Johnson, S. C. (2009). Mutations in the Aeromonas salmonicida subsp. salmonicida type III secretion system affect Atlantic salmon leucocyte activation and downstream immune responses. Fish Shellfish Immunol. 27, 721-728. doi: 10.1016/j.fsi.2009.09.009

Fehr, D., Casanova, C., Liverman, A., Blazkova, H., Orth, K., Dobbelaere, D., et al. (2006). AopP, a type III effector protein of Aeromonas salmonicida, inhibits the NF-кB signalling pathway. Microbiology 152, 2809-2818. doi: 10.1099/mic.0. 28889-0

Fernández, L., Márquez, I., and Guijarro, J. A. (2004). Identification of specific in vivo-induced (ivi) genes in Yersinia ruckeri and analysis of ruckerbactin, a catecholate siderophore iron acquisition system. Appl. Environ. Microbiol. 70, 5199-5207. doi: 10.1128/aem.70.9.5199-5207.2004

Fernández, L., Prieto, M., and Guijarro, J. A. (2007). The iron- and temperatureregulated haemolysin YhlA is a virulence factor of Yersinia ruckeri. Microbiology 153, 483-489. doi: 10.1099/mic.0.29284-0

Fernández, L., Secades, P., Lopez, J. R., Márquez, I., and Guijarro, J. A. (2002). Isolation and analysis of a protease gene with an $\mathrm{ABC}$ transport system in the fish pathogen Yersinia ruckeri: insertional mutagenesis and involvement in virulence. Microbiology 148, 2233-2243. doi: 10.1099/00221287-148-72233

Fernández-Gómez, B., Richter, M., Schüler, M., Pinhassi, J., Acinas, S. G., González, J. M., et al. (2013). Ecology of marine Bacteroidetes: a comparative genomics approach. ISME J. 7, 1026-1037. doi: 10.1038/ismej.2012.169

Fierer, N., Leff, J. W., Adams, B. J., Nielsen, U. N., Bates, S. T., Lauber, C. L., et al. (2012). Cross-biome metagenomic analyses of soil microbial communities and their functional attributes. Proc. Natl. Acad. Sci. U.S.A. 109, 21390-21395. doi: $10.1073 /$ pnas. 1215210110

Figueroa, J., Cárcamo, J., Yañez, A., Olavarria, V., Ruiz, P., Manríquez, R., et al. (2019). Addressing viral and bacterial threats to salmon farming in Chile: historical contexts and perspectives for management and control. Rev. Aquac. $11,299-324$.

Finlay, B. B., and Falkow, S. (1997). Common themes in microbial pathogenicity revisited. Microbiol. Mol. Biol. Rev. 61, 136-169. doi: 10.1128/mmbr.61.2.136169.1997

Fivaz, M., Abrami, L., Tsitrin, Y., and Van Der Goot, F. G. (2001). Aerolysin from Aeromonas hydrophila and related toxins. Curr. Top. Microbiol. Immunol. 257, 35-52. doi: 10.1007/978-3-642-56508-3_3

Flannagan, R. S., Aubert, D., Kooi, C., Sokol, P. A., and Valvano, M. A. (2007). Burkholderia cenocepacia requires a periplasmic HtrA protease for growth under thermal and osmotic stress and for survival in vivo. Infect. Immun. 75, 1679-1689. doi: 10.1128/IAI.01581-06

Fouz, B., Barja, J. L., Amaro, C., Rivas, C., and Toranzo, A. E. (1993). Toxicity of the extracellular products of Vibrio damsela isolated from diseased fish. Curr. Microbiol. 27, 341-347. doi: 10.3354/dao02275

Fouz, B., Zarza, C., and Amaro, C. (2006). First description of non-motile Yersinia ruckeri serovar I strains causing disease in rainbow trout, Oncorhynchus mykiss (Walbaum), cultured in Spain. J. Fish Dis. 29, 339-346. doi: 10.1111/j.13652761.2006.00723.x 
Frans, I., Michiels, C. W., Bossier, P., Willems, K. A., Lievens, B., and Rediers, H. (2011). Vibrio anguillarum as a fish pathogen: virulence factors, diagnosis and prevention. J. Fish Dis. 34, 643-661. doi: 10.1111/j.1365-2761.2011. 01279.x

Frey, J., and Origgi, F. C. (2016). Type III secretion system of Aeromonas salmonicida undermining the host's immune response. Front. Mar. Sci. 3:130. doi: $10.3389 /$ fmars. 2016.00130

Fryer, J. L., Lannan, C. N., Garces, L. H., Larenas, J. J., and Smith, P. A. (1990). Isolation of a rickettsiales-like organism from diseased coho salmon (Oncorhynchus kisutch) in Chile. Fish Pathol. 25, 107-114. doi: 10.3147/jsfp. 25.107

Fryer, J., Lannan, C., Giovannoni, S., and Wood, N. (1992). Piscirickettsia salmonis gen. nov., sp. nov., the causative agent of an epizootic disease in salmonid fishes. Int. J. Syst. Evol. Microbiol. 42, 120-126. doi: 10.1099/00207713-42-1-120

Funahashi, T., Moriya, K., Uemura, S., Miyoshi, S. I., Shinoda, S., Narimatsu, S., et al. (2002). Identification and characterization of pvuA, a gene encoding the ferric vibrioferrin receptor protein in Vibrio parahaemolyticus. J. Bacteriol. 184, 936-946. doi: 10.1128/jb.184.4.936-946.2002

Galán, J. E., Lara-Tejero, M., Marlovits, T. C., and Wagner, S. (2014). Bacterial type III secretion systems: specialized nanomachines for protein delivery into target cells. Annu. Rev. Microbiol. 68, 415-438. doi: 10.1146/annurev-micro-092412155725

Gallique, M., Decoin, V., Barbey, C., Rosay, T., Feuilloley, M. G. J., Orange, N., et al. (2017). Contribution of the Pseudomonas fluorescens MFE01 type VI secretion system to biofilm formation. PLoS One 12:e0170770. doi: 10.1371/journal.pone. 0170770

Garduño, R. A., Faulkner, G., Trevors, M. A., Vats, N., and Hoffman, P. S. (1998). Immunolocalization of Hsp60 in Legionella pneumophila. J. Bacteriol. 180, 505-513. doi: 10.1128/jb.180.3.505-513.1998

Gerlach, R. G., and Hensel, M. (2007). Protein secretion systems and adhesins: the molecular armory of Gram-negative pathogens. Int. J. Med. Microbiol. 297, 401-415. doi: 10.1016/j.ijmm.2007.03.017

González-López, M. A., Velázquez-Guadarrama, N., Romero-Espejel, M. E., and Olivares-Trejo, J. D. (2013). Helicobacter pylori secretes the chaperonin GroEL (HSP60), which binds iron. FEBS Lett. 587, 1823-1828. doi: 10.1016/j.febslet. 2013.04.048

Gorasia, D. G., Veith, P. D., and Reynolds, E. C. (2020). The Type IX secretion system: advances in structure, function and organisation. Microorganisms 8:1173. doi: 10.3390/microorganisms 8081173

Gourzioti, E., Kolygas, M. N., Athanassopoulou, F., and Babili, V. (2016). Tenacibaculosis in aquaculture farmed marine fish. J. Hell. Vet. Medical Soc 67, 21-32. doi: 10.12681/jhvms.15620

Grass, S., Buscher, A. Z., Swords, W. E., Apicella, M. A., Barenkamp, S. J., Ozchlewski, N., et al. (2003). The Haemophilus influenzae HMW1 adhesin is glycosylated in a process that requires HMW1C and phosphoglucomutase, an enzyme involved in lipooligosaccharide biosynthesis. Mol. Microbiol. 48, 737-751. doi: 10.1046/j.1365-2958.2003.03450.x

Green, E. R., and Mecsas, J. (2016). Bacterial secretion systems: an overview. Microbiol. Spectr. 4. doi: 10.1128/microbiolspec.VMBF-0012-2015

Griffin, B. R. (1987). Columnaris disease: recent advances in research. Aquac. Mag. $13,48-50$.

Grisez, L., Sorgeloos, P., and Ollevier, F. (1996). Mode of infection and spread of Vibrio anguillarum in turbot Scophthalmus maximus larvae after oral challenge through live feed. Dis. Aqu. Org. 26, 181-187.

Guan, L., Santander, J., Mellata, M., Zhang, Y., and Curtiss, R. I. (2013). Identification of an iron acquisition machinery in Flavobacterium columnare. Dis. Aquat. Organ. 106, 129-138. doi: 10.3354/dao02635

Guardiola, F. A., Mabrok, M., Machado, M., Azeredo, R., Afonso, A., Esteban, M. A., et al. (2019). Mucosal and systemic immune responses in Senegalese sole (Solea senegalensis Kaup) bath challenged with Tenacibaculum maritimum: a time-course study. Fish Shellfish Immunol. 87, 744-754. doi: 10.1016/j.fsi.2019. 02.015

Guerry, P. (2007). Campylobacter flagella: not just for motility. Trends Microbiol. 15, 456-461.

Guo, R. H., Lim, J. Y., My, D.N. Tra, Jo, S. J., Park, J. U., Rhee, J. H., et al. (2018). Vibrio vulnificus RtxA1 toxin expression upon contact with host cells is RpoS-dependent. Front. Cell. Infect. Microbiol 8:70. doi: 10.3389/fcimb.2018. 00070
Guzman-Murillo, M., Merino-Contreras, M. L., and Ascencio, F. (2000). Interaction between Aeromonas veronii and epithelial cells of spotted sand bass (Paralabrax maculatofasciatus) in culture. J. Appl. Microbiol. 88, 897-906. doi: 10.1046/j.1365-2672.2000.01061.x

Hacker, J., and Carniel, E. (2001). Ecological fitness, genomic islands and bacterial pathogenicity. EMBO Rep. 2, 376-381. doi: 10.1093/embo-reports/kve097

Hacker, J., and Kaper, J. B. (1999). "The concept of pathogenicity islands, pathogenicity islands and other mobile virulence elements," in Pathogenicity Islands and Other Mobile Virulence Elements, eds J. B. Kaper and J. Hacker (Washington, DC: ASM Press), 1-11. doi: 10.1128/9781555818173.ch1

Hahnke, R. L., Meier-Kolthoff, J. P., García-López, M., Mukherjee, S., Huntemann, M., Ivanova, N. N., et al. (2016). Genome-based taxonomic classification of bacteroidetes. Front. Microbiol. 7:2003. doi: 10.3389/fmicb.2016.02003

Halpern, M., and Izhaki, I. (2017). Fish as hosts of Vibrio cholerae. Front. Microbiol. 8:282. doi: $10.3389 /$ fmicb.2017.00282

Ham, H., and Orth, K. (2012). The role of type III secretion system 2 in Vibrio parahaemolyticus pathogenicity. J. Microbiol. 50, 719-725. doi: 10.1007/ s12275-012-2550-2

Han, H. J., Kim, D. H., Lee, D. C., Kim, S. M., and Park, S. I. (2006). Pathogenicity of Edwardsiella tarda to olive flounder, Paralichthys olivaceus (temminck \& schlegel). J. Fish Dis. 29, 601-609. doi: 10.1111/j.1365-2761.2006.00754.x

Han, Y., Mo, Z., Xiao, P., Hao, B., Li, J., and Yang, G. (2011). Characterization of EmpA protease in Vibrio anguillarum M3. J. Ocean Univ. China 10, 379-384. doi: $10.1007 / \mathrm{s} 11802-011-1781-\mathrm{x}$

Hartland, E., and Leong, J. (2013). Enteropathogenic and enterohemorrhagic E. coli: ecology, pathogenesis, and evolution. Front. Cell. Infect. Microbiol. 3:15. doi: $10.3389 /$ fcimb.2013.00015

Hawke, J. P., McWhorter, A. C., Steigerwalt, A. G., and Brenner, D. J. (1981). Edwardsiella ictaluri sp. nov., the causative agent of enteric septicemia of catfish. Int. J. Syst. Evol. Microbiol. 31, 396-400. doi: 10.1099/00207713-31-4-396

Heidarsdottir, K. J., Gravningen, K., and Benediktsdottir, E. (2008). Antigen profiles of the fish pathogen Moritella viscosa and protection in fish. J. Appl. Microbiol. 104, 944-951. doi: 10.1111/j.1365-2672.2007.03639.x

Henderson, L. D., Matthews-Palmer, T. R. S., Gulbronson, C. J., Ribardo, D. A., Beeby, M., Hendrixson, D. R., et al. (2020). Diversification of Campylobacter jejuni flagellar C-ring composition impacts its structure and function in motility, flagellar assembly, and cellular processes. mBio 11:e02286-19. doi: 10.1128/mBio.02286-19

Heo, G. J., Wakabayashi, H., and Watabe, S. (1990). Purification and characterization of pili from Flavobacterium branchiophila. Fish Pathol. 25, 21-27. doi: $10.3147 /$ jsfp. 25.21

Hirono, I., and Aoki, T. (1993). Cloning and characterization of three hemolysin genes from Aeromonas salmonicida. Microb. Pathog. 15, 269-282. doi: 10.1006/ mpat.1993.1077

Hirono, I., Masuda, T., and Aoki, T. (1996). Cloning and detection of the hemolysin gene of Vibrio anguillarum. Microb. Pathog. 21, 173-182. doi: 10.1006/mpat. 1996.0052

Hirono, I., Tange, N., and Aoki, T. (1997). Iron-regulated haemolysin gene from Edwardsiella tarda. Mol. Microbiol. 24, 851-856. doi: 10.1046/j.1365-2958. 1997.3971760.x

Hiyoshi, H., Kodama, T., Iida, T., and Honda, T. (2010). Contribution of Vibrio parahaemolyticus virulence factors to cytotoxicity, enterotoxicity, and lethality in mice. Infect. Immun. 78, 1772-1780. doi: 10.1128/IAI.01051-09

Hiyoshi, H., Kodama, T., Saito, K., Gotoh, K., Matsuda, S., Akeda, Y., et al. (2011) VopV, an F-actin-binding Type III secretion effector, is required for Vibrio parahaemolyticus-induced enterotoxicity. Cell Host Microbe 10, 401-409. doi: 10.1016/j.chom.2011.08.014

Hjelmeland, K., Stensvaag, K., Jørgensen, T., and Espelid, S. (1988). Isolation and characterization of a surface layer antigen from Vibrio salmonicida. J. Fish Dis. 11, 197-205. doi: 10.1111/j.1365-2761.1988.tb00540.x

Hjeltnes, B., Bang-Jensen, B., Bornø, G., Haukaas, A., and Walde, C. (2017). The Health Situation In Norwegian Aquaculture 2016. Oslo: The Norwegian Veterinary Institute, 127.

Ho, A. S., Mietzner, T. A., Smith, A. J., and Schoolnik, G. K. (1990). The pili of Aeromonas hydrophila: identification of an environmentally regulated "mini pilin”. J. Exp. Med. 172, 795-806. doi: 10.1084/jem.172.3.795

Högfors-Rönnholm, E., and Wiklund, T. (2010). Hemolytic activity in Flavobacterium psychrophilum is a contact-dependent, two-step mechanism 
and differently expressed in smooth and rough phenotypes. Microb. Pathog. 49, 369-375. doi: 10.1016/j.micpath.2010.08.002

Holland, I. B., Schmitt, L., and Young, J. (2005). Type 1 protein secretion in bacteria, the ABC-transporter dependent pathway (Review). Mol. Membr. Biol. 22, 29-39. doi: 10.1080/09687860500042013

Holt, R. A., Amandi, A., Rohovec, J. S., and Fryer, J. L. (1989). Relation of water temperature to bacterial cold-water disease in coho salmon, chinook salmon, and rainbow trout. J. Aquat. Anim. Health 1, 94-101.

Horne, M. T., and Baxendale, A. (1983). The adhesion of Vibrio anguillarum to host tissues and its role in pathogenesis. J. Fish Dis. 6, 461-471. doi: 10.1111/j. 1365-2761.1983.tb00100.x

Hossain, M. J., Waldbieser, G. C., Sun, D., Capps, N. K., Hemstreet, W. B., Carlisle, K., et al. (2013). Implication of lateral genetic transfer in the emergence of Aeromonas hydrophila isolates of epidemic outbreaks in channel catfish. PLoS One 8:e80943. doi: 10.1371/journal.pone.0080943

Hsieh, Y. C., Liang, S. M., Tsai, W. L., Chen, Y. H., Liu, T. Y., and Liang, C. M. (2003). Study of capsular polysaccharide from Vibrio parahaemolyticus. Infect. Immun. 71, 3329-3336. doi: 10.1128/iai.71.6.3329-3336.2003

Hu, T., Chen, R., Zhang, L., Wang, Z., Yang, D., Zhang, Y., et al. (2019). Balanced role of T3SS and T6SS in contribution to the full virulence of Edwardsiella piscicida. Fish Shellfish Immunol. 93, 871-878. doi: 10.1016/j.fsi.2019.08.014

Hu, Y. H., Zhou, H. Z., Jin, Q. W., and Zhang, J. (2016). The serine protease autotransporter Tsh contributes to the virulence of Edwardsiella tarda. Vet. Microbiol. 189, 68-74. doi: 10.1016/j.vetmic.2016.04.021

Hueck, C. J. (1998). Type III protein secretion systems in bacterial pathogens of animals and plants. Microbiol. Mol. Biol Rev. 62, 379-433.

Huesca, M., Borgia, S., Hoffman, P., and Lingwood, C. A. (1996). Acidic $\mathrm{pH}$ changes receptor binding specificity of Helicobacter pylori: a binary adhesion model in which surface heat shock (stress) proteins mediate sulfatide recognition in gastric colonization. Infect. Immun. 64, 2643-2648. doi: 10.1128/ iai.64.7.2643-2648.1996

Ina-Salwany, M. Y., Al-saari, N., Mohamad, A., Mursidi, F. A., Mohd-Aris, A., Amal, M. N. A., et al. (2019). Vibriosis in fish: a review on disease development and prevention. J. Aqu. Anim. Health 31, 3-22. doi: 10.1002/aah.10045

Ishiguro, E. E., Ainsworth, T., Kay, W. W., and Trust, T. J. (1986). Heme requirement for growth of fastidious atypical strains of Aeromonas salmonicida. Appl. Environ. Microbiol. 51, 668-670. doi: 10.1128/aem.51.3.668-670.1986

Janda, J. M., and Abbott, S. L. (1993). Expression of an iron-regulated hemolysin by Edwardsiella tarda. FEMS Microbiol. Lett. 111, 275-280.

Jang, K. K., Lee, Z. W., Kim, B., Jung, Y. H., Han, H. J., Kim, M. H., et al. (2017). Identification and characterization of Vibrio vulnificus plpA encoding a phospholipase A2 essential for pathogenesis. J. Biol. Chem. 292, 17129-17143. doi: 10.1074/jbc.M117.791657

Jeremić, S., Jakić-Dimić, D., and Veljović, L. J. (2003). Citrobacter freundii as a cause of disease in fish. Acta Vet. 53, 399-410. doi: 10.2298/avb030 $6399 \mathrm{j}$

Jia, A., Woo, N. Y., and Zhang, X. H. (2010). Expression, purification, and characterization of thermolabile hemolysin (TLH) from Vibrio alginolyticus. Dis. Aquat. Organ. 90, 121-127. doi: 10.3354/dao02225

Jiang, W., Han, X., Wang, Q., Li, X., Yi, L., Liu, Y., et al. (2014). Vibrio parahaemolyticus enolase is an adhesion-related factor that binds plasminogen and functions as a protective antigen. Appl. Microbiol. Biotechnol. 98, 49374948. doi: 10.1007/s00253-013-5471-z

Jiao, X. D., Zhang, M., Cheng, S., and Sun, L. (2010). Analysis of Edwardsiella tarda DegP, a serine protease and a protective immunogen. Fish Shellfish Immunol. 28, 672-677. doi: 10.1016/j.fsi.2010.01.004

Jin, R. P., Hu, Y. H., Sun, B. G., Zhang, X. H., and Sun, L. (2012). Edwardsiella tarda sialidase: pathogenicity involvement and vaccine potential. Fish Shellfish Immunol. 33, 514-521. doi: 10.1016/j.fsi.2012.06.002

Johnson, K., Charles, I., Dougan, G., Pickard, D., O’gaora, P., Costa, G., et al. (1991). The role of a stress-response protein in Salmonella typhimurium virulence. Mol. Microbiol. 5, 401-407.

Johnson, T. L., Fong, J. C., Rule, C., Rogers, A., Yildiz, F. H., and Sandkvist, M. (2014). The Type II secretion system delivers matrix proteins for biofilm formation by Vibrio cholerae. J. Bacteriol. 196, 4245-4252. doi: 10.1128/JB. 01944-14

Jones, C. H., Bolken, T. C., Jones, K. F., Zeller, G. O., and Hruby, D. E. (2001). Conserved DegP protease in gram-positive bacteria is essential for thermal and oxidative tolerance and full virulence in Streptococcus pyogenes. Infect. Immun. 69, 5538-5545. doi: 10.1128/IAI.69.9.5538-5545.2001

Jones, C. H., Dexter, P., Evans, A. K., Liu, C., Hultgren, S. J., and Hruby, D. E. (2002). Escherichia coli DegP protease cleaves between paired hydrophobic residues in a natural substrate: the PapA pilin. J. Bacteriol. 184, 5762-5771. doi: 10.1128/JB.184.20.5762-5771.2002

Jones, M. K., and Oliver, J. D. (2009). Vibrio vulnificus: disease and pathogenesis. Infect. Immun. 77, 1723-1733.

Jun, L., and Woo, N. Y. S. (2003). Pathogenicity of vibrios in fish: an overview. J. Ocean Univ. Qingdao 2, 117-128. doi: 10.1007/s11802-003-0039-7

Jyot, J., Balloy, V., Jouvion, G., Verma, A., Touqui, L., Huerre, M., et al. (2011). Type II secretion system of Pseudomonas aeruginosa: in vivo evidence of a significant role in death due to lung infection. J. Infect. Dis. 203, 1369-1377. doi: 10.1093/infdis/jir045

Kadi, N., Song, L., and Challis, G. L. (2008). Bisucaberin biosynthesis: an adenylating domain of the BibC multi-enzyme catalyzes cyclodimerization of N-hydroxy-N-succinylcadaverine. Chem. Commun. 41, 5119-5121. doi: 10. 1039/b813029a

Kamath, S., Kapatral, V., and Chakrabarty, A. M. (1998). Cellular function of elastase in Pseudomonas aeruginosa: role in the cleavage of nucleoside diphosphate kinase and in alginate synthesis. Mol. Microbiol. 30, 933-941. doi: 10.1046/j.1365-2958.1998.01121.x

Kanonenberg, K., Spitz, O., Erenburg, I. N., Beer, T., and Schmitt, L. (2018). Type I secretion system-it takes three and a substrate. FEMS Microbiol. Lett. 365. doi: 10.1093/femsle/fny094

Kayansamruaj, P., Dong, H. T., Hirono, I., Kondo, H., Senapin, S., and Rodkhum, C. (2017). Comparative genome analysis of fish pathogen Flavobacterium columnare reveals extensive sequence diversity within the species. Infect. Genet. Evol. 54, 7-17. doi: 10.1016/j.meegid.2017.06.012

Kerie, Y., Nuru, A., and Abayneh, T. (2019). Edwardsiella species infection in fish population and its status in Ethiopia. Fish. Aquac. J. 10, 1-7.

Kim, C. M., Park, R. Y., Park, J. H., Sun, H. Y., Bai, Y. H., Ryu, P. Y., et al. (2006). Vibrio vulnificus vulnibactin, but not metalloprotease VvpE, is essentially required for iron-uptake from human holotransferrin. Biol. Pharm. Bull. 29, 911-918. doi: 10.1248/bpb.29.911

Kim, J. S., Sung, M. H., Kho, D. H., and Lee, J. K. (2005). Induction of manganesecontaining superoxide dismutase is required for acid tolerance in Vibrio vulnificus. J. Bacteriol. 187, 5984-5995. doi: 10.1128/JB.187.17.5984-5995.2005

Klesius, P. H., Shoemaker, C. A., and Evans, J. J. (2008). Flavobacterium columnare chemotaxis to channel catfish mucus. FEMS Microbiol. Lett. 288, 216-220. doi: 10.1111/j.1574-6968.2008.01348.x

Knirel, Y. A., Kocharova, N. A., Bystrova, O. V., Katzenellenbogen, E., and Gamian, A. (2002). Structures and serology of the O-specific polysaccharides of bacteria of the genus Citrobacter. Arch. Immunol. Ther. Exp. 50, 379-392.

Knodler, L. A., and Steele-Mortimer, O. (2005). The Salmonella effector PipB2 affects late endosome/lysosome distribution to mediate Sif extension. Mol. Biol. Cell 16, 4108-4123. doi: 10.1091/mbc.e05-04-0367

Kondo, M., Kawai, K., Kurohara, K., and Oshima, S. I. (2002). Adherence of Flavobacterium psychrophilum on the body surface of the ayu Plecoglossus altivelis. Microb. Infect. 4, 279-283. doi: 10.1016/s1286-4579(02)01539-3

Krachler, A. M., Ham, H., and Orth, K. (2011). Outer membrane adhesion factor multivalent adhesion molecule 7 initiates host cell binding during infection by gram-negative pathogens. Proc. Natl. Acad. Sci. U.S.A. 108, 11614-11619. doi: $10.1073 /$ pnas. 1102360108

Kumru, S., Tekedar, H. C., Blom, J., Lawrence, M. L., and Karsi, A. (2020). Genomic diversity in flavobacterial pathogens of aquatic origin. Microb. Pathog. 142:104053. doi: 10.1016/j.micpath.2020.104053

Kumru, S., Tekedar, H. C., Gulsoy, N., Waldbieser, G. C., Lawrence, M. L., and Karsi, A. (2017). Comparative analysis of the Flavobacterium columnare genomovar I and II genomes. Front. Microbiol. 8:1375. doi: 10.3389/fmicb.2017. 01375

Kunttu, H. M. T., Runtuvuori-Salmela, A., Sundell, K., Wiklund, T., Middelboe, M., Landor, L., et al. (2021). Bacteriophage resistance affects Flavobacterium columnare virulence partly via mutations in genes related to gliding motility and the Type IX secretion system. Appl. Environ. Microbiol 87:e00812-e821. doi: 10.1128/AEM.00812-21

Labella, A., Sanchez-Montes, N., Berbel, C., Aparicio, M., Castro, D., Manchado, M., et al. (2010). Toxicity of Photobacterium damselae subsp. damselae strains 
isolated from new cultured marine fish. Dis. Aquat. Organ. 92, 31-40. doi: 10.3354/dao02275

Lachmann, I., Wagner, U., Hädge, D., and Drössler, K. (1998). Generation and preliminary characterisation of monoclonal antibodies directed to glycerophospholipid: cholesterol acyltransferase (GCAT) native epitopes of Aeromonas salmonicida. Dis. Aquat. Org. 33, 73-75. doi: 10.3354/dao033073

Lallier, R., and Daigneault, P. (1984). Antigenic differentiation of pili from nonvirulent and fish-pathogenic strains of Aeromonas hydrophila. J. Fish Dis. 7, 509-512. doi: 10.1111/j.1365-2761.1984.tb01177.x

Lange, M. D., Abernathy, J., Shoemaker, C. A., Zhang, D., Kirby, A., Peatman, E., et al. (2020). Proteome analysis of virulent Aeromonas hydrophila reveals the upregulation of iron acquisition systems in the presence of a xenosiderophore. FEMS Microbiol. Lett. 367:fnaa169. doi: 10.1093/femsle/fnaa169

Larenas, J. J., Bartholomew, J., Troncoso, O., Fernández, S., Ledezma, H., Sandoval, N., et al. (2003). Experimental vertical transmission of Piscirickettsia salmonis and in vitro study of attachment and mode of entrance into the fish ovum. Dis Aquat. Org. 56, 25-30. doi: 10.3354/dao056025

Lasica, A. M., Ksiazek, M., Madej, M., and Potempa, J. (2017). The Type IX secretion system (T9SS): highlights and recent insights into its structure and function. Front. Cell. Infect. Microbiol. 7:215. doi: 10.3389/fcimb.2017.00215

Lee, K. K., and Ellis, A. E. (1990). Glycerophospholipid: cholesterol acyltransferase complexed with lipopolysaccharide (LPS) is a major lethal exotoxin and cytolysin of Aeromonas salmonicida: LPS stabilizes and enhances toxicity of the enzyme. J. Bacteriol. 172, 5382-5393. doi: 10.1128/jb.172.9.5382-5393.1990

Lee, K. K., and Yii, K. C. (1996). A comparison of three methods for assaying hydrophobicity of pathogenic vibrios. Lett. Appl. Microbiol. 23, 343-346.

Leo, J. C., Oberhettinger, P., Schütz, M., and Linke, D. (2015). The inverse autotransporter family: intimin, invasin and related proteins. Int. J. Med. Microbiol. 305, 276-282.

Letain, T. E., and Postle, K. (1997). TonB protein appears to transduce energy by shuttling between the cytoplasmic membrane and the outer membrane in Escherichia coli. Mol. Microbiol. 24, 271-283. doi: 10.1046/j.1365-2958.1997. 3331703.x

Létoffé, S., Deniau, C., Wolff, N., Dassa, E., Delepelaire, P., Lecroisey, A., et al. (2001). Haemophore-mediated bacterial haem transport: evidence for a common or overlapping site for haem-free and haem-loaded haemophore on its specific outer membrane receptor. Mol. Microbiol. 41, 439-450. doi: 10.1046/j.1365-2958.2001.02530.x

Letunic, I., and Bork, P. (2006). Interactive tree of life (iTOL): an online tool for phylogenetic tree display and annotation. Bioinformatics 23, 127-128. doi: 10.1093/bioinformatics/btl529

Levipan, H. A., Quezada, J., and Avendaño-Herrera, R. (2018). Stress tolerancerelated genetic traits of fish pathogen Flavobacterium psychrophilum in a mature biofilm. Front. Microbiol. 9:18. doi: 10.3389/fmicb.2018.00018

Li, J., Ramezanpour, M., Fong, S. A., Cooksley, C., Murphy, J., Suzuki, M., et al. (2019). Pseudomonas aeruginosa exoprotein-induced barrier disruption correlates with elastase activity and marks chronic rhinosinusitis severity. Front. Cell. Infect. Microbiol. 9:38. doi: 10.3389/fcimb.2019.00038

Li, L., Meng, H., Gu, D., Li, Y., and Jia, M. (2019). Molecular mechanisms of Vibrio parahaemolyticus pathogenesis. Microbiol. Res. 222, 43-51.

Li, L., Rock, J. L., and Nelson, D. R. (2008). Identification and characterization of a repeat-in-toxin gene cluster in Vibrio anguillarum. Infect. Immun. 76, 2620-2632. doi: 10.1128/IAI.01308-07

Li, M. F., and Sun, L. (2018). Edwardsiella tarda Sip2: a serum-induced protein that is essential to serum survival, acid resistance, intracellular replication, and host infection. Front. Microbiol. 9:1084. doi: 10.3389/fmicb.2018.01084

Li, N., Zhu, Y., LaFrentz, B. R., Evenhuis, J. P., Hunnicutt, D. W., Conrad, R. A., et al. (2017). The Type IX secretion system is required for virulence of the fish pathogen Flavobacterium columnare. Appl. Environ. Microbiol. 83:e01769-17.

Li, Y., and Ma, Q. (2017). Iron acquisition strategies of Vibrio anguillarum. Front. Cell. Infect. Microbiol. 7:342. doi: 10.3389/fcimb.2017.00342

Li, Y., Liu, Y., Zhou, Z., Huang, H., Ren, Y., Zhang, Y., et al. (2011). Complete genome sequence of Aeromonas veronii strain B565. J. Bacteriol. 193, 33893390. doi: 10.1128/JB.00347-11

Lindler, L. E., Plano, G. V., Burland, V., Mayhew, G. F., and Blattner, F. R. (1998). Complete DNA sequence and detailed analysis of the Yersinia pestis KIM5 plasmid encoding murine toxin and capsular antigen. Infect. Immun. 66, 5731-5742. doi: 10.1128/IAI.66.12.5731-5742.1998
Ling, S. H. M., Wang, X. H., Lim, T. M., and Leung, K. Y. (2001). Green fluorescent protein-tagged Edwardsiella tarda reveals portal of entry in fish. FEMS Microbiol. Lett. 194, 239-243. doi: 10.1111/j.1574-6968.2001.tb09476.x

Linhartova, I., Osicka, R., Bumba, L., Masin, J., and Sebo, P. (2018). "Repeats-intoxin (RTX) toxins: a review," in Microbiology Toxins, eds B. Stiles, A. AlapeGirón, J. D. Dubreuil, M. Mandal, and P. Gopalakrishnakone (Dordrecht: Springer Netherlands), 353-381. doi: 10.1007/978-94-007-6449-1_13

Litwin, C. M., and Byrne, B. L. (1998). Cloning and characterization of an outer membrane protein of Vibrio vulnificus required for heme utilization: regulation of expression and determination of the gene sequence. Infect. Immun. 66, 3134-3141. doi: 10.1128/IAI.66.7.3134-3141.1998

Liu, M., and Chen, S. (2015). A novel adhesive factor contributing to the virulence of Vibrio parahaemolyticus. Sci. Rep. 5:14449. doi: 10.1038/srep14449

Liu, T., Wang, E., Wei, W., Wang, K., Yang, Q., and Ai, X. (2019). TcpA, a novel Yersinia ruckeri TIR-containing virulent protein mediates immune evasion by targeting MyD88 adaptors. Fish Shellfish Immunol. 94, 58-65. doi: 10.1016/j.fsi. 2019.08.069

Loch, T. P., and Faisal, M. (2014). Flavobacterium spartansii sp. nov., a pathogen of fishes, and emended descriptions of Flavobacterium aquidurense and Flavobacterium araucananum. Int. J. Syst. Evol. Microbiol. 64, 406-412. doi: 10.1099/ijs.0.051433-0

Logan, S. L., Thomas, J., Yan, J., Baker, R. P., Shields, D. S., Xavier, J. B., et al. (2018). The Vibrio cholerae type VI secretion system can modulate host intestinal mechanics to displace gut bacterial symbionts. Proc. Natl. Acad. Sci. U.S.A. 115, E3779-E3787. doi: 10.1073/pnas.1720133115

Lönnström, L., Wiklund, T., and Bylund, G. (1994). Pseudomonas anguilliseptica isolated from Baltic herring Clupea harengus membras with eye lesions. Dis. Aquat. Org. 18, 143-147.

López, C. S., Alice, A. F., Chakraborty, R., and Crosa, J. H. (2007). Identification of amino acid residues required for ferric-anguibactin transport in the outermembrane receptor FatA of Vibrio anguillarum. Microbiology 153, 570-584. doi: 10.1099/mic.0.2006/001735-0

Lopez, C. S., and Crosa, J. H. (2007). Characterization of ferric-anguibactin transport in Vibrio anguillarum. Biometals 20:393. doi: 10.1007/s10534-0079084-9

López-Romalde, S., Magariños, B., Núñez, S., Toranzo, A. E., and Romalde, J. L. (2003a). Phenotypic and genetic characterization of Pseudomonas anguilliseptica strains isolated from fish. J. Aquat. Anim. Health 15, 39-47.

López-Romalde, S., Magariños, B., Ravelo, C., Toranzo, A. E., and Romalde, J. L. (2003b). Existence of two O-serotypes in the fish pathogen Pseudomonas anguilliseptica. Vet. Microbiol. 94, 325-333. doi: 10.1016/s0378-1135(03) 00124- $\mathrm{x}$

Lorenzen, E., Dalsgaard, I., and Bernardet, J. F. (1997). Characterization of isolates of Flavobacterium psychrophilum associated with coldwater disease or rainbow trout fry syndrome I: phenotypic and genomic studies. Dis. Aquat. Org. 31, 197-208.

Løvoll, M., Wiik-Nielsen, C. R., Tunsjø, H. S., Colquhoun, D., Lunder, T., Sørum, H., et al. (2009). Atlantic salmon bath challenged with Moritella viscosapathogen invasion and host response. Fish Shellfish Immunol. 26, 877-884. doi: 10.1016/j.fsi.2009.03.019

Luo, G., Huang, L., Su, Y., Qin, Y., Xu, X., Zhao, L., et al. (2016). flrA, flrB and flrC regulate adhesion by controlling the expression of critical virulence genes in Vibrio alginolyticus. Emerg. Microbes Infect. 5, 1-11. doi: 10.1038/emi.2016.82

Madsen, L., and Dalsgaard, I. (1998). "Characterization of Flavobacterium psychrophilum; comparison of proteolytic activity and virulence of strains isolated from rainbow trout (Oncorhynchus mykiss)," in Methodology in Fish Diseases Research, eds A. C. Barnes, G. A. Davidson, M. P. Hiney, and D. McIntosh (Aberdeen: Fisheries Research Services), 45-52.

Magarinos, B., Pazos, F., Santos, Y., Romalde, J. L., and Toranzo, A. E. (1995). Response of Pasteurella piscicida and Flexibacter maritimus to skin mucus of marine fish. Dis. Aquat. Org. 21, 103-108. doi: 10.3354/dao021103

Maltz, M., Levarge, B., and Graf, J. (2015). Identification of iron and heme utilization genes in Aeromonas and their role in the colonization of the leech digestive tract. Front. Microbiol. 6:763. doi: 10.3389/fmicb.2015.00763

Marshall, S. H., Gómez, F. A., Ramírez, R., Nilo, L., and Henríquez, V. (2012) Biofilm generation by Piscirickettsia salmonis under growth stress conditions: a putative in vivo survival/persistence strategy in marine environments. Res. Microbiol. 163, 557-566. doi: 10.1016/j.resmic.2012.08.002 
Matsuda, S., Okada, R., Tandhavanant, S., Hiyoshi, H., Gotoh, K., Iida, T., et al. (2019). Export of a Vibrio parahaemolyticus toxin by the Sec and Type III secretion machineries in tandem. Nat. Microbiol. 4, 781-788. doi: 10.1038/ s41564-019-0368-y

Matsuyama, T., Kamaishi, T., Ooseko, N., Kurohara, K., and Iida, T. (2005). Pathogenicity of motile and non-motile Edwardsiella tarda to some marine fish. Fish Pathol. 40, 133-135. doi: 10.3147/jsfp.40.133

Mattick, J. S. (2002). Type IV pili and twitching motility. Annu. Rev. Microbiol. 56, 289-314. doi: 10.1146/annurev.micro.56.012302.160938

Mazoy, R., and Lemos, M. L. (1996). Identification of heme-binding proteins in the cell membranes of Vibrio anguillarum. FEMS Microbiol. Lett. 135, 265-270. doi: 10.1111/j.1574-6968.1996.tb07999.x

Mazoy, R., Vázquez, F., and Lemos, M. L. (1996). Isolation of heme-binding proteins from Vibrio anguillarum using affinity chromatography. FEMS Microbiol. Lett. 141, 19-23. doi: 10.1111/j.1574-6968.1996.tb08357.x

McBride, M. J. (2014). “The family flavobacteriaceae," in The Prokaryotes: Other Major Lineages Of Bacteria And The Archaea, eds E. Rosenberg, E. F. DeLong, S. Lory, E. Stackebrandt, and F. Thompson (Berlin: Springer), 643-676.

McBride, M. J., and Nakane, D. (2015). Flavobacterium gliding motility and the Type IX secretion system. Curr. Opin. Microbiol. 28, 72-77.

McBride, M. J., Braun, T. F., and Brust, J. L. (2003). Flavobacterium johnsoniae GldH is a lipoprotein that is required for gliding motility and chitin utilization. J. Bacteriol. 185, 6648-6657. doi: 10.1128/jb.185.22.6648-6657.2003

McCarthy, U., Steiropoulos, N. A., Thompson, K. D., Adams, A., Ellis, A. E., and Ferguson, H. W. (2005). Confirmation of Piscirickettsia salmonis as a pathogen in European sea bass Dicentrarchus labrax and phylogenetic comparison with salmonid strains. Dis. Aquat. Org. 64, 107-119. doi: 10.3354/dao064107

McCarthy, ÚM., Bron, J. E., Brown, L., Pourahmad, F., Bricknell, I. R., Thompson, K. D., et al. (2008). Survival and replication of Piscirickettsia salmonis in rainbow trout head kidney macrophages. Fish Shellfish Immunol 25, 477-484. doi: 10.1016/j.fsi.2008.07.005

Merino, S., Rubires, X., Aguilar, A., and Tomás. (1996). The O:34-antigen lipopolysaccharide as an adhesin in Aeromonas hydrophila. FEMS Microbiol. Lett 139, 97-101. doi: 10.1111/j.1574-6968.1996.tb08186.x

Merle, C., Faure, D., Urdaci, M. C., and Le Henaff, M. (2003). Purification and characterization of a membrane glycoprotein from the fish pathogen Flavobacterium psychrophilum. J. Appl. Microbiol. 94, 1120-1127.

Merle, N. S., Church, S. E., Fremeaux-Bacchi, V., and Roumenina, L. T. (2015). Complement system part I-molecular mechanisms of activation and regulation. Front. Immunol. 6:262. doi: 10.3389/fimmu.2015.00262

Meuskens, I., Saragliadis, A., Leo, J. C., and Linke, D. (2019). Type V secretion systems: an overview of passenger domain functions. Front. Microbiol. 10:1163. doi: $10.3389 /$ fmicb. 2019.01163

Milton, D. L., Norqvist, A., and Wolf-Watz, H. (1992). Cloning of a metalloprotease gene involved in the virulence mechanism of Vibrio anguillarum. J. Bacteriol. 174, 7235-7244. doi: 10.1128/jb.174.22.7235-7244.1992

Milton, D. L., O’Toole, R., Horstedt, P., and Wolf-Watz, H. (1996). Flagellin A is essential for the virulence of Vibrio anguillarum. J. Bacteriol. 178, 1310-1319. doi: 10.1128/jb.178.5.1310-1319.1996

Miyazaki, T., and Plumb, J. A. (1985). Histopathology of Edwardsiella ictaluri in channel catfish, Ictalurus punctatus (Rafinesque). J. Fish Dis. 8, 389-392. doi: 10.1111/j.1365-2761.1985.tb00961.x

Mo, Z., Guo, D., Mao, Y., Ye, X., Zou, Y., Xiao, P., et al. (2010). Identification and characterization of the Vibrio anguillarum prtV gene encoding a new metalloprotease. Chin. J. Oceanol. Limnol. 28, 55-61. doi: 10.1007/s00343-0109246-4

Mohanty, B. R., and Sahoo, P. K. (2007). Edwardsiellosis in fish: a brief review. J. Biosci. 32, 1331-1344. doi: 10.1007/s12038-007-0143-8

Møller, J. D., Ellis, A. E., Barnes, A. C., and Dalsgaard, I. (2005). Iron acquisition mechanisms of Flavobacterium psychrophilum. J. Fish Dis. 28, 391-398.

Møller, J. D., Larsen, J. L., Madsen, L., and Dalsgaard, I. (2003). Involvement of a sialic acid-binding lectin with hemagglutination and hydrophobicity of Flavobacterium psychrophilum. Appl. Environ. Microbiol. 69, 5275-5280. doi: 10.1128/AEM.69.9.5275-5280.2003

Mouriño, S., Osorio, C. R., and Lemos, M. L. (2004). Characterization of heme uptake cluster genes in the fish pathogen Vibrio anguillarum. J. Bacteriol. 186, 6159-6167. doi: 10.1128/JB.186.18.6159-6167.2004
Mouriño, S., Rodríguez-Ares, I., Osorio, C. R., and Lemos, M. L. (2005). Genetic variability of the heme uptake system among different strains of the fish pathogen Vibrio anguillarum: identification of a new heme receptor. Appl. Environ. Microbiol. 71, 8434-8441. doi: 10.1128/AEM.71.12.8434-8441.2005

Murray, P. R., Holmes, B., and Aucken, H. M. (2010). "Citrobacter, Enterobacter, klebsiella, plesiomonas, serratia, and other members of the Enterobacteriaceae," in Topley \& Wilson's Microbiology and Microbial Infections, eds H. E. Jensen and F. W. Chandler (Hoboken, NJ: John Wiley \& Sons Ltd).

Nag, D., Farr, D. A., Walton, M. G., and Withey, J. H. (2020). Zebrafish models for Pathogenic Vibrios. J. Bacteriol. 202:e00165-20.

Nagamatsu, K., Kuwae, A., Konaka, T., Nagai, S., Yoshida, S., Eguchi, M., et al. (2009). Bordetella evades the host immune system by inducing IL-10 through a type III effector. BopN. J. Exp. Med. 206, 3073-3088. doi: 10.1084/jem.20090494

Najimi, M., Lemos, M. L., and Osorio, C. R. (2008b). Identification of siderophore biosynthesis genes essential for growth of Aeromonas salmonicida under iron limitation conditions. Appl. Environ. Microbiol. 74, 2341-2348. doi: 10.1128/ AEM.02728-07

Najimi, M., Lemos, M. L., and Osorio, C. R. (2008a). Identification of heme uptake genes in the fish pathogen Aeromonas salmonicida subsp. salmonicida. Arch. Microbiol. 190, 439-449. doi: 10.1007/s00203-008-0391-5

Naka, H., Actis, L. A., and Crosa, J. H. (2013). The anguibactin biosynthesis and transport genes are encoded in the chromosome of Vibrio harveyi: a possible evolutionary origin for the pJM1 plasmid-encoded system of Vibrio anguillarum? Microbiologyopen 2, 182-194. doi: 10.1002/mbo3.65

Naka, H., Dias, G. M., Thompson, C. C., Dubay, C., Thompson, F. L., and Crosa, J. H. (2011). Complete genome sequence of the marine fish pathogen Vibrio anguillarum harboring the pJM1 virulence plasmid and genomic comparison with other virulent strains of V. anguillarum and V. ordalii. Infect. Immun. 79, 2889-2900. doi: 10.1128/IAI.05138-11

Naka, H., Reitz, Z. L., Jelowicki, A. M., Butler, A., and Haygood, M. G. (2018). Amphi-enterobactin commonly produced among Vibrio campbellii and Vibrio harveyi strains can be taken up by a novel outer membrane protein FapA that also can transport canonical Fe(III)-enterobactin. J. Biol. Inorg. Chem. 23, 1009-1022. doi: 10.1007/s00775-018-1601-5

Nakai, T. (1985). Resistance of Pseudomonas anguilliseptica [an eel pathogen] to bactericidal action of fish serum. Bull. Jpn. Soc. Sci. Fish. 51, 1431-1436. doi: 10.2331/suisan.51.1431

Nakayama, H., Tanaka, K. H., Teramura, N., and Hattori, S. (2016). Expression of collagenase in Flavobacterium psychrophilum isolated from cold-water diseaseaffected ayu (Plecoglossus altivelis). Biosci. Biotechnol. Biochem. 80, 135-144. doi: 10.1080/09168451.2015.1079477

Namba, A., Mano, N., Takano, H., Beppu, T., Ueda, K., and Hirose, H. (2008). OmpA is an adhesion factor of Aeromonas veronii, an optimistic pathogen that habituates in carp intestinal tract. J. Appl. Microbiol. 105, 1441-1451. doi: 10.1111/j.1365-2672.2008.03883.x

Navais, R., Méndez, J., Pérez-Pascual, D., Cascales, D., and Guijarro, J. A. (2014). The yrpAB operon of Yersinia ruckeri encoding two putative U32 peptidases is involved in virulence and induced under microaerobic conditions. Virulence 5, 619-624. doi: 10.4161/viru.29363

Nematollahi, A., Decostere, A., Pasmans, F., and Haesebrouck, F. (2003b). Flavobacterium psychrophilum infections in salmonid fish. J. Fish Dis. 26, 563-574. doi: 10.1046/j.1365-2761.2003.00488.x

Nematollahi, A., Decostere, A., Pasmans, F., Ducatelle, R., and Haesebrouck, F. (2003a). Adhesion of high and low virulence Flavobacterium psychrophilum strains to isolated gill arches of rainbow trout Oncorhynchus mykiss. Dis. Aquat. Org. 55, 101-107. doi: 10.3354/dao055101

Nikoskelainen, S., Salminen, S., Bylund, G., and Ouwehand, A. C. (2001). Characterization of the properties of human-and dairy-derived probiotics for prevention of infectious diseases in fish. Appl. Environ. Microbiol. 67, 24302435. doi: 10.1128/AEM.67.6.2430-2435.2001

Nivaskumar, M., and Francetic, O. (2014). Type II secretion system: a magic beanstalk or a protein escalator. Biochim. Biophys. Acta Mol. Cell Res. 1843, 1568-1577. doi: 10.1016/j.bbamcr.2013.12.020

Nomura, S., Fujino, M., Yamakawa, M., and Kawahara, E. (1988). Purification and characterization of salmolysin, an extracellular hemolytic toxin from Aeromonas salmonicida. J. Bacteriol. 170, 3694-3702. doi: 10.1128/jb.170.8. 3694-3702.1988 
Noonan, B., and Trust, T. J. (1997). The synthesis, secretion and role in virulence of the paracrystalline surface protein layers of Aeromonas salmonicida and A. hydrophila. FEMS Microbiol. Lett. 154, 1-7. doi: 10.1111/j.1574-6968.1997. tb12616.x

Norqvist, A., Norrman, B., and Wolf-Watz, H. (1990). Identification and characterization of a zinc metalloprotease associated with invasion by the fish pathogen Vibrio anguillarum. Infect. Immun. 58, 3731-3736. doi: 10.1128/iai. 58.11.3731-3736.1990

O’Boyle, N., Houeix, B., Kilcoyne, M., Joshi, L., and Boyd, A. (2013). The MSHA pilus of Vibrio parahaemolyticus has lectin functionality and enables TTSSmediated pathogenicity. Int. J. Med. Microbiol. 303, 563-573. doi: 10.1016/j. ijmm.2013.07.010

Oda, M., Takahashi, M., Matsuno, T., Uoo, K., Nagahama, M., and Sakurai, J. (2010). Hemolysis induced by Bacillus cereus sphingomyelinase. Biochim. Biophys. Acta 1798, 1073-1080. doi: 10.1016/j.bbamem.2010.03.004

Okada, K., Iida, T., Kita-Tsukamoto, K., and Honda, T. (2005). Vibrios commonly possess two chromosomes. J. Bacteriol. 187, 752-757. doi: 10.1128/JB.187.2. $752-757.2005$

Olivares-Fuster, O., and Arias, C. R. (2008). Use of suppressive subtractive hybridization to identify Flavobacterium columnare DNA sequences not shared with Flavobacterium johnsoniae. Lett. Appl. Microbiol. 46, 605-612. doi: 10. 1111/j.1472-765X.2008.02366.x

Oliver, C., Valenzuela, K., Hernández, M., Sandoval, R., Haro, R. E., AvendañoHerrera, R., et al. (2016). Characterization and pathogenic role of outer membrane vesicles produced by the fish pathogen Piscirickettsia salmonis under in vitro conditions. Vet. Microbiol. 184, 94-101. doi: 10.1016/j.vetmic.2015.09. 012

Ormonde, P., Hörstedt, P., O’Toole, R., and Milton, D. L. (2000). Role of motility in adherence to and invasion of a fish cell line by Vibrio anguillarum. J. Bacteriol. 182, 2326-2328. doi: 10.1128/JB.182.8.2326-2328.2000

Ortiz-Severín, J., Travisany, D., Maass, A., Chávez, F. P., and Cambiazo, V. (2019). Piscirickettsia salmonis cryptic plasmids: source of mobile DNA and virulence factors. Pathogens 8:269. doi: 10.3390/pathogens8040269

Osei-Adjei, G., Huang, X., and Zhang, Y. (2018). The extracellular proteases produced by Vibrio parahaemolyticus. World J. Microbiol. Biotechnol. 34:68. doi: 10.1007/s11274-018-2453-4

Osorio, C. R. (2018). T3SS effectors in vibrios: homology in sequence, diversity in biological functions? Virulence 9, 721-723. doi: 10.1080/21505594.2018. 1435965

Osorio, C. R., Rivas, A. J., Balado, M., Fuentes-Monteverde, J. C., Rodríguez, J., Jiménez, C., et al. (2015). A transmissible plasmid-borne pathogenicity island confers piscibactin biosynthesis in the fish pathogen Photobacterium damselae subsp. piscicida. Appl. Environ. Microbiol. 81, 5867-5879. doi: 10.1128/AEM. 01580- 15

Ostland, V. E., Byrne, P. J., Hoover, G., and Ferguson, H. W. (2000). Necrotic myositis of rainbow trout, Oncorhynchus mykiss (Walbaum): proteolytic characteristics of a crude extracellular preparation from Flavobacterium psychrophilum. J. Fish Dis. 23, 329-336. doi: 10.1046/j.1365-2761.2000.00251.x

Ostland, V. E., Lumsden, J. S., MacPhee, D. D., Derksen, J. A., and Ferguson, H. W. (1997). Inhibition of the attachment of Flavobacterium branchiophilum to the gills of rainbow trout Oncorhynchus Mykiss (Walbaum). J. Fish Dis. 20, 109-117. doi: 10.1046/j.1365-2761.1997.d01-113.x

O'Toole, R., Milton, D. L., and Wolf-Watz, H. (1996). Chemotactic motility is required for invasion of the host by the fish pathogen Vibrio anguillarum. Mol. Microbiol. 19, 625-637. doi: 10.1046/j.1365-2958.1996.412927.x

Otsuka, Y. (2016). Prokaryotic toxin-antitoxin systems: novel regulations of the toxins. Curr. Genet. 62, 379-382.

Palleroni, N. J. (2010). The Pseudomonas story. Environ. Microbiol. 12, 1377-1383.

Palmer, T., and Berks, B. C. (2012). The twin-arginine translocation (Tat) protein export pathway. Nat. Rev. Microbiol. 10, 483-496. doi: 10.1038/nrmicro2814

Palmer, T., Finney, A. J., Saha, C. K., Atkinson, G. C., and Sargent, F. (2021). A holin/peptidoglycan hydrolase-dependent protein secretion system. Mol. Microbiol. 115, 345-355. doi: 10.1111/mmi.14599

Pan, L., Yang, Y., Peng, Y., Li, D., Khan, T. A., Chen, P., et al. (2021). The novel pathogenic Citrobacter freundii (CFC202) isolated from diseased crucian carp (Carassius auratus) and its ghost vaccine as a new prophylactic strategy against infection. Aquaculture 533:736190.
Pang, M., Jiang, J., Xie, X., Wu, Y., Dong, Y., Kwok, A. H. Y., et al. (2015). Novel insights into the pathogenicity of epidemic Aeromonas hydrophila ST251 clones from comparative genomics. Sci. Rep. 5, 1-15. doi: 10.1038/srep09833

Park, S. B., Aoki, T., and Jung, T. S. (2012). Pathogenesis of and strategies for preventing Edwardsiella tarda infection in fish. Vet. Res. 43:67.

Pedersen, L. L., Radulic, M., Doric, M., and Kwaik, Y. A. (2001). HtrA homologue of Legionella pneumophila: an indispensable element for intracellular infection of mammalian but not protozoan cells. Infect. Immun. 69, 2569-2579. doi: 10.1128/IAI.69.4.2569-2579.2001

Penttinen, R., Hoikkala, V., and Sundberg, L. R. (2018). Gliding motility and expression of motility-related genes in spreading and non-spreading colonies of Flavobacterium columnare. Front. Microbiol. 9:525. doi: 10.3389/fmicb.2018. 00525

Pérez-Pascual, D., Gómez, E., and Guijarro, J. A. (2015). Lack of a type2 glycosyltransferase in the fish pathogen Flavobacterium psychrophilum determines pleiotropic changes and loss of virulence. Vet. Res. 46:1. doi: 10. 1186/s13567-014-0124-5

Pérez-Pascual, D., Lunazzi, A., Magdelenat, G., Rouy, Z., Roulet, A., LopezRoques, C., et al. (2017). The complete genome sequence of the fish pathogen Tenacibaculum maritimum provides insights into virulence mechanisms. Front. Microbiol. 8:1542. doi: 10.3389/fmicb.2017.01542

Perry, L. B. (1973). Gliding motility in some non-spreading flexibacteria. J. Appl. Bacteriol. 36, 227-232. doi: 10.1111/j.1365-2672.1973.tb04095.x

Pirarat, N., Ooi, E. L., Thompson, K. D., Thinh, N. H., Maita, M., and Katagiri, T. (2016). Examination of entry portal and pathogenesis of Edwardsiella ictaluri infection in striped catfish, Pangasianodon hypophthalmus. Aquaculture 464, 279-285. doi: 10.1016/j.aquaculture.2016.06.043

Rahman, T., Suga, K., Kanai, K., and Sugihara, Y. (2014). Biological and serological characterization of a non-gliding strain of Tenacibaculum maritimum isolated from a diseased puffer fish Takifugu rubripes. Fish Pathol. 49, 121-129. doi: $10.3147 /$ jsfp. 49.121

Reith, M. E., Singh, R. K., Curtis, B., Boyd, J. M., Bouevitch, A., Kimball, J., et al. (2008). The genome of Aeromonas salmonicida subsp. salmonicida A449: insights into the evolution of a fish pathogen. BMC Genomics 9:427. doi: 10.1186/1471-2164-9-427

Rey-Varela, D., Cisneros-Sureda, J., Balado, M., Rodríguez, J., Lemos, M. L., and Jiménez, C. (2019). The outer membrane protein FstC of Aeromonas salmonicida subsp. salmonicida acts as receptor for amonabactin siderophores and displays a wide ligand plasticity. Structure-activity relationships of synthetic amonabactin analogues. ACS Infect. Dis. 5, 1936-1951. doi: 10.1021/ acsinfecdis.9b00274

Rhee, J. E., Rhee, J. H., Ryu, P. Y., and Choi, S. H. (2002). Identification of the cadBA operon from Vibrio vulnificus and its influence on survival to acid stress. FEMS Microbiol. Lett. 208, 245-251. doi: 10.1111/j.1574-6968.2002.tb11089.x

Richard, K. L., Kelley, B. R., and Johnson, J. G. (2019). Heme uptake and utilization by gram-negative bacterial pathogens. Front. Cell. Infect. Microbiol. 9:81. doi: 10.3389/fcimb.2019.00081

Ringø, E., Jutfelt, F., Kanapathippillai, P., Bakken, Y., Sundell, K., Glette, J., et al. (2004). Damaging effect of the fish pathogen Aeromonas salmonicida ssp. salmonicida on intestinal enterocytes of Atlantic salmon (Salmo salar L.). Cell Tissue Res. 318, 305-311. doi: 10.1007/s00441-004-0934-2

Rivas, A. J., Balado, M., Lemos, M. L., and Osorio, C. R. (2011). The Photobacterium damselae subsp. damselae hemolysins damselysin and HlyA are encoded within a new virulence plasmid. Infect. Immun. 79, 4617-4627. doi: 10.1128/IAI. 05436- 11

Rivas, A. J., Hoven, G. V., Neukirch, C., Meyenburg, M., Qin, Q., Füser, S. et al. (2015). Phobalysin, a small beta-pore-forming toxin of Photobacterium damselae subsp. damselae. Infect. Immun. 83, 4335-4348. doi: 10.1128/IAI. 00277- 15

Rivera-Calzada, A., Famelis, N., Llorca, O., and Geibel, S. (2021). Type VII secretion systems: structure, functions and transport models. Nat. Rev. Microbiol. 19, 567-584.

Robien, M. A., Krumm, B. E., Sandkvist, M., and Hol, W. G. J. (2003). Crystal structure of the extracellular protein secretion NTPase EpsE of Vibrio cholerae. J. Mol. Biol. 333, 657-674. doi: 10.1016/j.jmb.2003.07.015

Rochat, T., Pérez-Pascual, D., Nilsen, H., Carpentier, M., Bridel, S., Bernardet, J. F., et al. (2019). Identification of a novel elastin-degrading enzyme from 
the fish pathogen Flavobacterium psychrophilum. Appl. Environ. Microbiol. 85:e02535-18. doi: 10.1128/AEM.02535-18

Rodkhum, C., Hirono, I., Crosa, J. H., and Aoki, T. (2005). Four novel hemolysin genes of Vibrio anguillarum and their virulence to rainbow trout. Microb. Pathog. 39, 109-119. doi: 10.1016/j.micpath.2005.06.004

Rojas, M. E., Galleguillos, M., Diaz, S., Machuca, A., Carbonero, A., and Smith, P. A. (2013). Evidence of exotoxin secretion of Piscirickettsia salmonis, the causative agent of piscirickettsiosis. J. Fish Dis. 36, 703-709. doi: 10.1111/jfd. 12019

Romeo, J. M., Esmon, B., and Zusman, D. R. (1986). Nucleotide sequence of the myxobacterial hemagglutinin gene contains four homologous domains. Proc. Natl. Acad. Sci. U.S.A. 83, 6332-6336. doi: 10.1073/pnas.83.17.6332

Rompikuntal, P. K., Vdovikova, S., Duperthuy, M., Johnson, T. L., Åhlund, M., Lundmark, R., et al. (2015). Outer membrane vesicle-mediated export of processed PrtV protease from Vibrio cholerae. PLoS One 10:e134098. doi: 10.1371/journal.pone.0134098

Røsjø, C., Salte, R., Thomassen, M. S., and Eggset, G. (1993). Glycerophospholipid:cholesterol acyltransferase complexed with lipopolysaccharide (GCAT-LPS) of Aeromonas salmonicida produces lysophospholipids in salmonid red cell membranes: a probable haemolytic mechanism. J. Fish Dis. 16, 87-99. doi: 10.1111/j.1365-2761.1993.tb00852.x

Rowe, H. M., Withey, J. H., and Neely, M. N. (2014). Zebrafish as a model for zoonotic aquatic pathogens. Dev. Comp. Immunol. 46, 96-107.

Rozas, M., and Enríquez, R. (2014). Piscirickettsiosis and Piscirickettsia salmonis in fish: a review. J. Fish Dis. 37, 163-188.

Rucker, R. R. (1959). Vibrio infections among marine and fresh-water fish. Prog. Fish Cult. 21, 22-25.

Ruiz, P., Balado, M., Fuentes-Monteverde, J. C., Toranzo, A. E., Rodríguez, J., Jiménez, C., et al. (2019). The fish pathogen Vibrio ordalii under iron deprivation produces the siderophore piscibactin. Microorganisms 7:313. doi: 10.3390/microorganisms7090313

Russell, A. B., Peterson, S. B., and Mougous, J. D. (2014a). Type VI secretion system effectors: poisons with a purpose. Nat. Rev. Microbiol. 12, 137-148.

Russell, A. B., Wexler, A. G., Harding, B. N., Whitney, J. C., Bohn, A. J., Goo, Y. A., et al. (2014b). A Type VI secretion-related pathway in Bacteroidetes mediates interbacterial antagonism. Cell Host Microbe 16, 227-236.

Sadarangani, V., Datta, S., and Arunachalam, M. (2013). New players in the same old game: a system level in silico study to predict Type III secretion system and effector proteins in bacterial genomes reveals common themes in T3SS mediated pathogenesis. BMC Res. Notes 6:297. doi: 10.1186/1756-05006-297

Sakai, D. K. (1985). Loss of virulence in a protease-deficient mutant of Aeromonas salmonicida. Infect. Immun. 48, 146-152.

Salomon, D., Klimko, J. A., Trudgian, D. C., Kinch, L. N., Grishin, N. V., Mirzaei, H., et al. (2015). Type VI secretion system toxins horizontally shared between marine bacteria. PLoS Pathog. 11:e1005128. doi: 10.1371/journal.ppat.1005128

Sampath, V. P. (2018). Bacterial endotoxin-lipopolysaccharide; structure, function and its role in immunity in vertebrates and invertebrates. Agric. Nat. Resour. 52, $115-120$.

Sandkvist, M. (2001). Type II secretion and pathogenesis. Infect. Immun. 69, 3523-3535.

Santander, J., Golden, G., Wanda, S. Y., and Curtiss, R. R. (2012). Fur-regulated iron uptake system of Edwardsiella ictaluri and its influence on pathogenesis and immunogenicity in the catfish host. Infect. Immun. 80, 2689-2703.

Sarma, J. V., and Ward, P. A. (2011). The complement system. Cell Tissue Res. 343, $227-235$.

Satchell, K. J. F. (2007). MARTX, multifunctional autoprocessing repeats-in-toxin toxins. Infect. Immun. 75, 5079-5084.

Sato, K., Naito, M., Yukitake, H., Hirakawa, H., Shoji, M., McBride, M. J., et al. (2010). A protein secretion system linked to bacteroidete gliding motility and pathogenesis. Proc. Natl. Acad. Sci. U.S.A. 107, 276-281.

Schaechter, M., Medoff, G., and Eisenstein, B. I. (1993). Mechanisms Of Microbial Disease. Philadelphia, PA: Lippincott Williams \& Wilkins.

Schauer, D. B., and Falkow, S. (1993). Attaching and effacing locus of a Citrobacter freundii biotype that causes transmissible murine colonic hyperplasia. Infect. Immun. 61, 2486-2492.

Secades, P., Alvarez, B., and Guijarro, J. A. (2001). Purification and characterization of a psychrophilic, calcium-induced, growth-phase-dependent metalloprotease from the fish pathogen Flavobacterium psychrophilum. Appl. Environ. Microbiol. 67, 2436-2444.

Secades, P., Alvarez, B., and Guijarro, J. A. (2003). Purification and properties of a new psychrophilic metalloprotease (Fpp2) in the fish pathogen Flavobacterium psychrophilum. FEMS Microbiol. Lett. 226, 273-279.

Secombes, C. J. (1996). The nonspecific immune system: cellular defenses. Fish Immune Syst. 15, 63-103.

Sekine, Y., Tanzawa, T., Tanaka, Y., Ishimori, K., and Uchida, T. (2016). Cytoplasmic heme-binding protein (HutX) from Vibrio cholerae is an intracellular heme transport protein for the heme-degrading enzyme, HutZ. Biochemistry 55, 884-893.

Seshadri, R., Joseph, S. W., Chopra, A. K., Sha, J., Shaw, J., Graf, J., et al. (2006). Genome sequence of Aeromonas hydrophila ATCC 7966T: jack of all trades. J. Bacteriol. 188, 8272-8282.

Sharma, A., Sojar, H. T., Glurich, I., Honma, K., Kuramitsu, H. K., and Genco, R. J. (1998). Cloning, expression, and sequencing of a cell surface antigen containing a leucine-rich repeat motif from Bacteroides forsythus ATCC 43037. Infect. Immun. 66, 5703-5710.

Shi, Y. J., Fang, Q. J., Huang, H. Q., Gong, C. G., and Hu, Y. H. (2019). HutZ is required for biofilm formation and contributes to the pathogenicity of Edwardsiella piscicida. Vet. Res. 50:76.

Shotts, E. B. Jr., and Cooper, I. R. K. (1996). Chondroitinase Attenuated Edwardsiella Ictaluri And A Vaccine For Prevention Of Enteric Septicemia (ES) In Fish, United States Patent 5536658.

Silhavy, T. J., Kahne, D., and Walker, S. (2010). The bacterial cell envelope. Cold Spring Harb. Perspect. Biol. 2:a000414.

Silver, A. C., and Graf, J. (2009). Prevalence of genes encoding the type three secretion system and the effectors AexT and AexU in the Aeromonas veronii group. DNA Cell Biol. 28, 383-388.

Sixma, T. K., Pronk, S. E., Kalk, K. H., Wartna, E. S., van Zanten, B. A. M., Witholt, B., et al. (1991). Crystal structure of a cholera toxin-related heat-labile enterotoxin from E. coli. Nature 351, 371-377.

Smith, P. A., Pizarro, P., Ojeda, P., Contreras, J., Oyanedel, S., and Larenas, J. (1999). Routes of entry of Piscirickettsia salmonis in rainbow trout Oncorhynchus mykiss. Dis. Aquat. Org. 37, 165-172.

Soengas, R. G., Anta, C., Espada, A., Paz, V., Ares, I. R., Balado, M., et al. (2006). Structural characterization of vanchrobactin, a new catechol siderophore produced by the fish pathogen Vibrio anguillarum serotype O2. Tetrahedron Lett. 47, 7113-7116.

Soengas, R. G., Larrosa, M., Balado, M., Rodríguez, J., Lemos, M. L., and Jiménez, C. (2008). Synthesis and biological activity of analogues of vanchrobactin, a siderophore from Vibrio anguillarum serotype O2. Org. Biomol. Chem. 6, 1278-1287.

Song, T., Liu, H., Lv, T., Zhao, X., Shao, Y., Han, Q., et al. (2018). Characteristics of the iron uptake-related process of a pathogenic Vibrio splendidus strain associated with massive mortalities of the sea cucumber Apostichopus japonicus. J. Invertebr. Pathol. 155, 25-31.

Souto, A., Montaos, M. A., Rivas, A. J., Balado, M., Osorio, C. R., Rodríguez, J., et al. (2012). Structure and biosynthetic assembly of piscibactin, a siderophore from Photobacterium damselae subsp. piscicida, predicted from genome analysis. Eur. J. Org. Chem. 2012, 5693-5700.

Stackebrandt, E., and Hespell, R. (2006). The family succinivibrionaceae. Prokaryotes 3, 419-429.

Stanley, S. A., Raghavan, S., Hwang, W. W., and Cox, J. S. (2003). Acute infection and macrophage subversion by Mycobacterium tuberculosis require a specialized secretion system. Proc. Natl. Acad. Sci. U.S.A. 100, 13001-13006.

Staroscik, A. M., Denkin, S. M., and Nelson, D. R. (2005). Regulation of the Vibrio anguillarum metalloprotease EmpA by posttranslational modification. J. Bacteriol. 187, 2257-2260.

Stewart, D. J., Woldemariam, K., Dear, G., and Mochaba, F. M. (1983). An outbreak of 'Sekiten-byo' among cultured European eels, Anguilla anguilla L., in Scotland. J. Fish Dis. 6, 75-76.

Stintzi, A., and Raymond, K. N. (2000). Amonabactin-mediated iron acquisition from transferrin and lactoferrin by Aeromonas hydrophila: direct measurement of individual microscopic rate constants. J. Biol. Inorg. Chem. 5, 57-66.

Stork, M., Lorenzo, M. D., Mouriño, S., Osorio, C. R., Lemos, M. L., and Crosa, J. H. (2004). Two tonB systems function in iron transport in Vibrio anguillarum, but only one is essential for virulence. Infect. Immun. 72, 7326-7329. 
Stratev, D., and Odeyemi, O. A. (2017). An overview of motile Aeromonas septicaemia management. Aquac. Int. 25, 1095-1105.

Stringer-Roth, K. M., Yunghans, W., and Caslake, L. F. (2002). Differences in chondroitin AC lyase activity of Flavobacterium columnare isolates. J. Fish Dis. $25,687-691$.

Sudheesh, P. S., Al-Ghabshi, A., Al-Mazrooei, N., and Al-Habsi, S. (2012). Comparative pathogenomics of bacteria causing infectious diseases in fish. Int. J. Evol. Biol. 2012:457264.

Sui, Z. H., Xu, H., Wang, H., Jiang, S., Chi, H., and Sun, L. (2017). Intracellular trafficking pathways of Edwardsiella tarda: from clathrin-and caveolinmediated endocytosis to endosome and lysosome. Front. Cell. Infect. Microbiol. 7:400. doi: $10.3389 /$ fcimb. 2017.00400

Sun, B. G., Zhang, X. H., Tang, X., Wang, S., Zhong, Y., Chen, J., et al. (2007). A single residue change in Vibrio harveyi hemolysin results in the loss of phospholipase and hemolytic activities and pathogenicity for turbot (Scophthalmus maximus). J. Bacteriol. 189, 2575-2579.

Sun, H. Y., Cao, X. H., Jiang, Y. F., Ni, L. Y., Mo, Z. Q., Qin, Q. W., et al. (2018). Outbreak of a novel disease associated with Citrobacter freundii infection in freshwater cultured stingray, Potamotrygon motoro. Aquaculture 492, 35-39.

Sun, J., and Barbieri, J. T. (2003). Pseudomonas aeruginosa ExoT ADP-ribosylates CT10 regulator of kinase (Crk) proteins. J. Biol. Chem. 278, 32794-32800.

Sunagawa, S. (2015). Ocean plankton: structure and function of the global ocean 793 microbiome. Science 348:794.

Svendsen, Y. S., and Bøgwald, J. (1997). Influence of artificial wound and non-intact mucus layer on mortality of Atlantic salmon (Salmo salar) following a bath challenge with Vibrio anguillarum and Aeromonas salmonicida. Fish Shellfish Immun. 7, 317-325.

Szymanski, C. M., Michael, F. S., Jarrell, H. C., Li, J., Gilbert, M., Larocque, S., et al. (2003). Detection of conserved N-linked glycans and phasevariable lipooligosaccharides and capsules from campylobacter cells by mass spectrometry and high resolution magic angle spinning NMR spectroscopy. J. Biol. Chem. 278, 24509-24520.

Tacchi, L., Bron, J. E., Taggart, J. B., Secombes, C. J., Bickerdike, R., Adler, M. A., et al. (2011). Multiple tissue transcriptomic responses to Piscirickettsia salmonis in Atlantic salmon (Salmo salar). Physiol. Genomics 43, 1241-1254.

Takeuchi, H., Shibano, Y., Morihara, K., Fukushima, J., Inami, S., Keil, B., et al. (1992). Structural gene and complete amino acid sequence of Vibrio alginolyticus collagenase. Biochem. J. 281(Pt 3), 703-708.

Tan, Y. P., Zheng, J., Tung, S. L., Rosenshine, I., and Leung, K. Y. (2005). Role of type III secretion in Edwardsiella tarda virulence. Microbiology 151, 2301-2313.

Tanabe, T., Funahashi, T., Nakao, H., Miyoshi, S. I., Shinoda, S., and Yamamoto, S. (2003). Identification and characterization of genes required for biosynthesis and transport of the siderophore vibrioferrin in Vibrio parahaemolyticus. J. Bacteriol. 185, 6938-6949.

Tanaka, K. H., Dallaire-Dufresne, S., Daher, R. K., Frenette, M., and Charette, S. J. (2012). An insertion sequence-dependent plasmid rearrangement in Aeromonas salmonicida causes the loss of the type three secretion system. PLoS One 7:e33725.

Tanaka, K. H., Vincent, A. T., Emond-Rheault, J. G., Adamczuk, M., Frenette, M., and Charette, S. J. (2017). Plasmid composition in Aeromonas salmonicida subsp. salmonicida 01-B526 unravels unsuspected type three secretion system loss patterns. BMC Genom. 18:528. doi: 10.1186/s12864-0173921-1

Tekedar, H. C., Karsi, A., Gillaspy, A. F., Dyer, D. W., Benton, N. R., Zaitshik, J., et al. (2012). Genome sequence of the fish pathogen Flavobacterium columnare ATCC 49512. J. Bacteriol. 194, 2763-2764.

Tekedar, H. C., Kumru, S., Blom, J., Perkins, A. D., Griffin, M. J., Abdelhamed, H., et al. (2019b). Comparative genomics of Aeromonas veronii: identification of a pathotype impacting aquaculture globally. PLoS One 14:e0221018. doi: 10.1371/journal.pone.0221018

Tekedar, H. C., Abdelhamed, H., Kumru, S., Blom, J., Karsi, A., and Lawrence, M. L. (2019a). Comparative genomics of Aeromonas hydrophila secretion systems and mutational analysis of hcp1 and vgrG1 genes from T6SS. Front. Microbiol. 9:3216. doi: $10.3389 /$ fmicb. 2018.03216

Telford, J. R., and Raymond, K. N. (1998). Coordination chemistry of the amonabactins, bis(catecholate) siderophores from Aeromonas hydrophila(1). Inorg. Chem. 37, 4578-4583.
Thanassi, D. G., and Hultgren, S. J. (2000). Multiple pathways allow protein secretion across the bacterial outer membrane. Curr. Opin. Cell Biol. 12, 420-430.

Thode, S. K., Rojek, E., Kozlowski, M., Ahmad, R., and Haugen, P. (2018). Distribution of siderophore gene systems on a Vibrionaceae phylogeny: database searches, phylogenetic analyses and evolutionary perspectives. PLoS One 13:e191860. doi: 10.1371/journal.pone.0191860

Thomas, D. R., Newton, P., Lau, N., and Newton, H. J. (2020). Interfering with autophagy: the opposing strategies deployed by Legionella pneumophila and Coxiella burnetii effector proteins. Front. Cell. Infect. Microbiol. 10:599762. doi: $10.3389 /$ fcimb.2020.599762

Thomas, F., Hehemann, J. H., Rebuffet, E., Czjzek, M., and Michel, G. (2011). Environmental and gut bacteroidetes: the food connection. Front. Microbiol. 2:93. doi: $10.3389 /$ fmicb.2011.00093

Thomas, S., Holland, B. I., and Schmitt, L. (2014). The type 1 secretion pathway the hemolysin system and beyond. Biochim. Biophys. Acta Mol. Cell Res. 1843, 1629-1641.

Thornley, J. P., Shaw, J. G., Gryllos, A. I., and Eley, A. (1997). Virulence properties of clinically significant Aeromonas species: evidence for pathogenicity. Rev. Med. Microbiol. 8, 61-72.

Thune, R. L., Fernandez, D. H., Benoit, J. L., Kelly-Smith, M., Rogge, M. L., Booth, N. J., et al. (2007). Signature-tagged mutagenesis of Edwardsiella ictaluri identifies virulence-related genes, including a Salmonella pathogenicity island 2 class of Type III secretion systems. Appl. Environ. Microbiol. 73, 7934-7946.

Thune, R. L., Stanley, L. A., and Cooper, R. K. (1993). Pathogenesis of gramnegative bacterial infections in warmwater fish. Annu. Rev. Fish Dis. 3, 37-68.

Titball, R. W., and Munn, C. B. (1985). The purification and some properties of H-lysin from Aeromonas salmonicida. J. Gen. Microbiol. 131, 1603-1609.

Titball, R., and Munn, C. (1981). Evidence for two haemolytic activities from Aeromonas salmonicida. FEMS Microbiol. Lett. 12, 27-30.

Tobback, E., Decostere, A., Hermans, K., Haesebrouck, F., and Chiers, K. (2007). Yersinia ruckeri infections in salmonid fish. J. Fish Dis. 30, 257-268.

Toranzo, A. E., and Barja, J. L. (1993). Virulence factors of bacteria pathogenic for coldwater fish. Annu. Rev. Fish Dis. 3, 5-36.

Toranzo, A. E., Magariños, B., and Romalde, J. L. (2005). A review of the main bacterial fish diseases in mariculture systems. Aquaculture 246, 37-61.

Tort, L., Padros, F., Rotllant, J., and Crespo, S. (1998). Winter syndrome in the gilthead sea bream Sparus aurata. Immunological and histopathological features. Fish Shellfish Immunol. 8, 37-47.

Touchon, M., Barbier, P., Bernardet, J. F., Loux, V., Vacherie, B., Barbe, V., et al. (2011). Complete genome sequence of the fish pathogen Flavobacterium branchiophilum. Appl. Environ. Microbiol. 77, 7656-7662.

Trosky, J. E., Li, Y., Mukherjee, S., Keitany, G., Ball, H., and Orth, K. (2007). VopA inhibits ATP binding by acetylating the catalytic loop of MAPK kinases. J. Biol. Chem. 282, 34299-34305.

Tsirigotaki, A., De Geyter, J., Šoštaric', N., Economou, A., and Karamanou, S. (2017). Protein export through the bacterial Sec pathway. Nat. Rev. Microbiol $15,21-36$.

Tunsjø, H. S., Paulsen, S. M., Berg, K., Sørum, H., and L'Abée-Lund, T. M. (2009). The winter ulcer bacterium Moritella viscosa demonstrates adhesion and cytotoxicity in a fish cell model. Microb. Pathog. 47, 134-142.

Valderrama, K., Balado, M., Rey-Varela, D., Rodríguez, J., Vila-Sanjurjo, A., Jiménez, C., et al. (2019). Outer membrane protein FrpA, the siderophore piscibactin receptor of Photobacterium damselae subsp. piscicida, as a subunit vaccine against photobacteriosis in sole (Solea senegalensis). Fish Shellfish Immunol. 94, 723-729.

Valiente, E., Lee, C. T., Lamas, J., Hor, L., and Amaro, C. (2008). Role of the virulence plasmid pR99 and the metalloprotease Vvp in resistance of Vibrio vulnificus serovar E to eel innate immunity. Fish Shellfish Immunol. 24, 134141.

Varina, M., Denkin, S. M., Staroscik, A. M., and Nelson, D. R. (2008). Identification and characterization of Epp, the secreted processing protease for the Vibrio anguillarum EmpA metalloprotease. J. Bacteriol. 190, 6589-6597.

Veith, P. D., Glew, M. D., Gorasia, D. G., and Reynolds, E. C. (2017). Type IX secretion: the generation of bacterial cell surface coatings involved in virulence, gliding motility and the degradation of complex biopolymers. Mol. Microbiol. $106,35-53$. 
Vilches, S., Urgell, C., Merino, S., Chacón, M. R., Soler, L., Castro-Escarpulli, G., et al. (2004). Complete Type III secretion system of a mesophilic Aeromonas hydrophila Strain. Appl. Environ. Microbiol. 70, 6914-6919.

Villarreal, L. P. (2008). Origin of Group Identity: Viruses, Addiction And Cooperation. Berlin: Springer Science \& Business Media.

Vipond, R., Bricknell, R. I., Durant, E., Bowden, T. J., Ellis, A. E., Smith, M., et al. (1998). Defined deletion mutants demonstrate that the major secreted toxins are not essential for the virulence of Aeromonas salmonicida. Infect. Immun. 66, 1990-1998.

Virji, M. (1997). Post-translational modifications of meningococcal pili. Identification of common substituents: glycans and $\alpha$-glycerophosphate-a review. Gene 192, 141-147.

von Hoven, G., Neukirch, C., Meyenburg, M., Schmidt, S., Vences, A., Osorio, C. R., et al. (2018). Cytotoxin- and chemotaxis-genes cooperate to promote adhesion of Photobacterium damselae subsp. damselae. Front. Microbiol. 9:2996. doi: 10.3389/fmicb.2018.02996

Wakabayashi, H., and Egusa, S. (1972). Characteristics of a Pseudomonas sp. from an epizootic of pond-cultured eels (Anguilla japonica). Bull. Jpn. Soc. Sci. Fish. $38,577-587$.

Wakabayashi, H., Hikida, M., and Masumura, K. (1986). Flexibacter maritimus sp. nov., a pathogen of marine fishes. Int. J. Syst. Evol. Microbiol. 36, 396-398.

Walport, M. J. (2001). Complement. First of two parts. N. Engl. J. Med. 344, 1058-1066.

Waltman, W. D., Shotts, E. B., and Hsu, T. C. (1986). Biochemical characteristics of Edwardsiella ictaluri. Appl. Environ. Microbiol. 51, 101-104.

Wandersman, C., and Delepelaire, P. (2004). Bacterial iron sources: from siderophores to hemophores. Annu. Rev. Microbiol. 58, 611-647.

Wang, H., Zeng, X., Mo, Y., He, B., Lin, H., and Lin, J. (2019). Enterobactin-specific antibodies induced by a novel enterobactin conjugate vaccine. Appl. Environ. Microbiol. 85:e00358-19.

Wang, Q., Liu, Q., Ma, Y., Zhou, L., and Zhang, Y. (2007). Isolation, sequencing and characterization of cluster genes involved in the biosynthesis and utilization of the siderophore of marine fish pathogen Vibrio alginolyticus. Arch. Microbiol. 188, 433-439.

Wang, Q., Yang, M., Xiao, J., Wu, H., Wang, X., Lv, Y., et al. (2009). Genome sequence of the versatile fish pathogen Edwardsiella tarda provides insights into its adaptation to broad host ranges and intracellular niches. PLoS One 4:e7646. doi: 10.1371/journal.pone.0007646

Wang, X., Wang, Q., Xiao, J., Liu, Q., Wu, H., and Zhang, Y. (2010). Hemolysin EthA in Edwardsiella tarda is essential for fish invasion in vivo and in vitro and regulated by two-component system EsrA-EsrB and nucleoid protein HhaEt. Fish Shellfish Immunol. 29, 1082-1091.

Wang, X., Wang, Q., Xiao, J., Liu, Q., Wu, H., Xu, L., et al. (2009). Edwardsiella tarda T6SS component evpP is regulated by esrB and iron, and plays essential roles in the invasion of fish. Fish. Shellfish Immunol. 27, 469-477.

Weber, B., Chen, C., and Milton, D. L. (2010). Colonization of fish skin is vital for Vibrio anguillarum to cause disease. Environ. Microbiol. Rep. 2, 133-139.

Webster, A. C., and Litwin, C. M. (2000). Cloning and characterization of vuuA, a gene encoding the Vibrio vulnificus ferric vulnibactin receptor. Infect. Immun. $68,526-534$.

Wheeler, R. W., Davies, R. L., Dalsgaard, I., Garcia, J., Welch, T. J., Wagley, S., et al. (2009). Yersinia ruckeri biotype 2 isolates from mainland Europe and the UK likely represent different clonal groups. Dis. Aquat. Organ. 84, 25-33.

Whitby, P., Landon, M., and Coleman, G. (1992). The cloning and nucleotide sequence of the serine protease gene (aspA) of Aeromonas salmonicida ssp. salmonicida. FEMS Microbiol. Lett. 78, 65-71.

Wiklund, T., and Bylund, G. (1990). Pseudomonas anguilliseptica as a pathogen of salmonid fish in Finland. Dis. Aqu. Org. 8, 13-19.

Wilkie, M. P. (2002). Ammonia excretion and urea handling by fish gills: present understanding and future research challenges. J. Exp. Zool. 293, 284-301.

Wilmsen, H. U., Pattus, F., and Buckley, J. T. (1990). Aerolysin, a hemolysin from Aeromonas hydrophila, forms voltage-gated channels in planar lipid bilayers. J. Membr. Biol. 115, 71-81.

Wilson, R. L., Brown, L. L., Kirkwood-Watts, D., Warren, T. K., Lund, S. A., King, D. S., et al. (2006). Listeria monocytogenes 10403 S HtrA is necessary for resistance to cellular stress and virulence. Infect. Immun. 74, 765-768.

Winkelmann, G., Schmid, D. G., Nicholson, G., Jung, G., and Colquhoun, D. J. (2002). Bisucaberin-a dihydroxamate siderophore isolated from Vibrio salmonicida, an important pathogen of farmed Atlantic salmon (Salmo salar). Biometals 15, 153-160.

Wong, A. R. C., Pearson, J. S., Bright, M. D., Munera, D., Robinson, K. S., Lee, S. F., et al. (2011). Enteropathogenic and enterohaemorrhagic Escherichia coli: even more subversive elements. Mol. Microbiol. 80, 1420-1438.

Wrobel, A., Leo, J. C., and Linke, D. (2019). Overcoming fish defences: the virulence factors of Yersinia ruckeri. Genes (Basel) 10:700.

Wrobel, A., Ottoni, C., Leo, J. C., and Linke, D. (2018). pYR4 from a Norwegian isolate of Yersinia ruckeri is a putative virulence plasmid encoding both a Type IV pilus and a Type IV secretion system. Front. Cell. Infect. Microbiol. 8:373. doi: 10.3389/fcimb.2018.00373

Xie, H. X., Lu, J. F., Zhou, Y., Yi, J., Yu, X. J., Leung, K. Y., et al. (2015). Identification and functional characterization of the novel Edwardsiella tarda effector EseJ. Infect. Immun. 83, 1650-1660.

Xu, X., Li, H., Qi, X., Chen, Y., Qin, Y., Zheng, J., et al. (2021). cheA, cheB, cheR, cheV, and cheY are involved in regulating the adhesion of Vibrio harveyi. Front. Cell. Infect. Microbiol. 10:591751. doi: 10.3389/fcimb.2020.591751

Yahr, T. L., Barbieri, J. T., and Frank, D. W. (1996a). Genetic relationship between the 53- and 49-kilodalton forms of exoenzyme S from Pseudomonas aeruginosa. J. Bacteriol. 178, 1412-1419.

Yahr, T. L., Goranson, J., and Frank, D. W. (1996b). Exoenzyme S of Pseudomonas aeruginosa is secreted by a type III pathway. Mol. Microbiol. 22, 991-1003.

Yan, Z., Yin, M., Chen, J., and Li, X. (2020). Assembly and substrate recognition of curli biogenesis system. Nat. Commun. 11:241.

Yarbrough, M. L., Li, Y., Kinch, L. N., Grishin, N. V., Ball, H. L., and Orth, K. (2009). AMPylation of Rho GTPases by Vibrio VopS disrupts effector binding and downstream signaling. Science 323, 269-272.

Young, N. M., Brisson, J. R., Kelly, J., Watson, D. C., Tessier, L., Lanthier, P. H., et al. (2002). Structure of the N-linked glycan present on multiple glycoproteins in the Gram-negative bacterium, Campylobacter jejuni. J. Biol. Chem. 277, 42530-42539.

Yu, H. B., Rao, P. S. S., Lee, H. C., Vilches, S., Merino, S., Tomas, J. M., et al. (2004). A type III secretion system is required for Aeromonas hydrophila AH-1 pathogenesis. Infect. Immun. 72, 1248-1256.

Yu, Y., Yang, H., Li, J., Zhang, P., Wu, B., Zhu, B., et al. (2012). Putative Type VI secretion systems of Vibrio parahaemolyticus contribute to adhesion to cultured cell monolayers. Arch. Microbiol. 194, 827-835.

Zane, H. K., Naka, H., Rosconi, F., Sandy, M., Haygood, M. G., and Butler, A. (2014). Biosynthesis of amphi-enterobactin siderophores by Vibrio harveyi BAA-1116: identification of a bifunctional nonribosomal peptide synthetase condensation domain. J. Am. Chem. Soc. 136, 5615-5618.

Zhang, F., Chen, J., Chi, Z., and Wu, L. F. (2006). Expression and processing of Vibrio anguillarum zinc-metalloprotease in Escherichia coli. Arch. Microbiol. 186, 11-20.

Zhang, L., Krachler, A. M., Broberg, C. A., Li, Y., Mirzaei, H., Gilpin, C. J., et al. (2012). Type III effector VopC mediates invasion for Vibrio species. Cell Rep. 1, $453-460$.

Zhang, X. H., and Austin, B. (2005). Haemolysins in Vibrio species. J. Appl. Microbiol. 98, 1011-1019.

Zhang, Y., Deng, Y., Feng, J., Guo, Z., Chen, H., Wang, B., et al. (2021). Functional characterization of VscCD, an important component of the Type III secretion system of Vibrio harveyi. Microb. Pathog. 157:104965.

Zhang, Y., Zhao, L., Chen, W., Huang, Y., Yang, L., Sarathbabu, V., et al. (2017). Complete genome sequence analysis of the fish pathogen Flavobacterium columnare provides insights into antibiotic resistance and pathogenicity related genes. Microb. Pathog. 111, 203-211.

Zhao, Z., Chen, C., Hu, C. Q., Ren, C. H., Zhao, J. J., Zhang, L. P., et al. (2010). The Type III secretion system of Vibrio alginolyticus induces rapid apoptosis, cell rounding and osmotic lysis of fish cells. Microbiology 156, 2864-2872.

Zhao-lan, M., Shi-yong, C., and Pei-jun, Z. (2002). Properties of proteolytic toxin of Vibrio anguilolarum from diseased flounder. Chin. J. Oceanol. Limnol. 20, 316-322.

Zhong, Y., Zhang, X. H., Chen, J., Chi, Z., Sun, B., Li, Y., et al. (2006). Overexpression, purification, characterization, and pathogenicity of Vibrio harveyi hemolysin VHH. Infect. Immun. 74, 6001-6005.

Zhou, Z.-J., Sun, B. G., and Sun, L. (2015). Edwardsiella tarda Sip1: A seruminduced zinc metalloprotease that is essential to serum resistance and host infection. Vet. Microbiol. 177, 332-340. 
Zhu, Z., Dong, C., Weng, S., and He, J. (2019). Identification of outer membrane protein TolC as the major adhesin and potential vaccine candidate for Vibrio harveyi in hybrid grouper, Epinephelus fuscoguttatus $(+9) \times$ E. lanceolatus $\left(\sigma^{7}\right)$. Fish Shellfish Immunol. 86, 143-151.

Zhuang, Q., Dai, F., Shao, Y., Li, C., and Zhang, W. (2021). vscN encodes a Type III secretion system ATPase in Vibrio splendidus AJ01 that contributes to pathogenicity and Hop secretion. Aquaculture 533: 736228.

Zhuang, Q., Dai, F., Zhao, X., Shao, Y., Guo, M., Lv, Z., et al. (2020). Cloning and characterization of the virulence factor Hop from Vibrio splendidus. Microb. Pathog. 139:103900.

Zúñiga, A., Aravena, P., Pulgar, R., Travisany, D., Ortiz-Severín, J., Chávez, F. P., et al. (2020). Transcriptomic changes of Piscirickettsia salmonis during intracellular growth in a salmon macrophage-like cell line. Front. Cell. Infect. Microbiol. 9:426. doi: 10.3389/fcimb.2019. 00426
Conflict of Interest: The authors declare that the research was conducted in the absence of any commercial or financial relationships that could be construed as a potential conflict of interest.

Publisher's Note: All claims expressed in this article are solely those of the authors and do not necessarily represent those of their affiliated organizations, or those of the publisher, the editors and the reviewers. Any product that may be evaluated in this article, or claim that may be made by its manufacturer, is not guaranteed or endorsed by the publisher.

Copyright (c) 2021 Mekasha and Linke. This is an open-access article distributed under the terms of the Creative Commons Attribution License (CC BY). The use, distribution or reproduction in other forums is permitted, provided the original author(s) and the copyright owner(s) are credited and that the original publication in this journal is cited, in accordance with accepted academic practice. No use, distribution or reproduction is permitted which does not comply with these terms. 